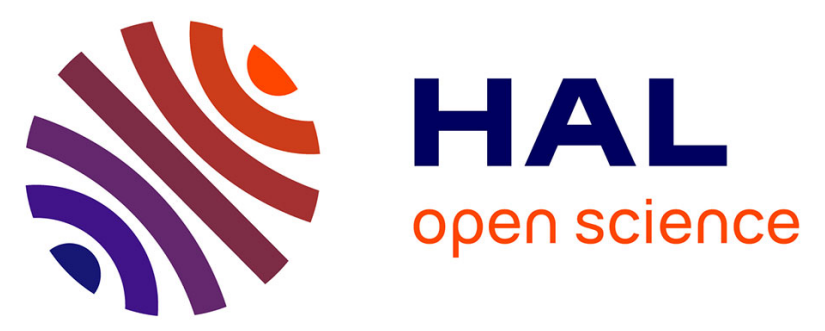

\title{
Endothelial dysfunction in individuals born after fetal growth restriction: cardiovascular and renal consequences and preventive approaches
}

\author{
C. Yzydorczyk, B. Armengaud, C. Peyter, Hassib Chehade, F. Cachat, C.
} Juvet, B. Siddeek, Stephanie Simoncini, F. Sabatier, Francoise Dignat-George, et al.

\section{To cite this version:}

C. Yzydorczyk, B. Armengaud, C. Peyter, Hassib Chehade, F. Cachat, et al.. Endothelial dysfunction in individuals born after fetal growth restriction: cardiovascular and renal consequences and preventive approaches. 2017, pp.448 - 464. 10.1017/S2040174417000265 . hal-01770227

\section{HAL Id: hal-01770227 \\ https://hal-amu.archives-ouvertes.fr/hal-01770227}

Submitted on 26 Apr 2018

HAL is a multi-disciplinary open access archive for the deposit and dissemination of scientific research documents, whether they are published or not. The documents may come from teaching and research institutions in France or abroad, or from public or private research centers.
L'archive ouverte pluridisciplinaire HAL, est destinée au dépôt et à la diffusion de documents scientifiques de niveau recherche, publiés ou non, émanant des établissements d'enseignement et de recherche français ou étrangers, des laboratoires publics ou privés. 


\section{Endothelial dysfunction in individuals born after fetal growth restriction: cardiovascular and renal consequences, and preventive approaches}

\begin{tabular}{|c|c|}
\hline Journal: & Journal of Developmental Origins of Health and Disease \\
\hline Manuscript ID & DOHaD-10-16-RE-0723.R2 \\
\hline Manuscript Type: & Review \\
\hline Date Submitted by the Author: & $\mathrm{n} / \mathrm{a}$ \\
\hline Complete List of Authors: & $\begin{array}{l}\text { YZYDORCZYK, Catherine; Centre Hospitalier Universitaire Vaudois, } \\
\text { Department Woman-Mother-Child, DOHaD laboratory } \\
\text { Armengaud, Jean Baptiste; Centre Hospitalier Universitaire Vaudois, } \\
\text { Department Woman-Mother-Child, DOHaD laboratory } \\
\text { Peyter, Anne Christine; Centre Hospitalier Universitaire Vaudois, } \\
\text { Department Woman-Mother-Child, Neonatal research laboratory } \\
\text { Chehade, Hassib; Centre Hospitalier Universitaire Vaudois, Department } \\
\text { Woman-Mother-Child, DOHaD laboratory } \\
\text { Cachat, François; Centre Hospitalier Universitaire Vaudois, Department } \\
\text { Woman-Mother-Child } \\
\text { Juvet, Christian; Centre Hospitalier Universitaire Vaudois, Department } \\
\text { Woman-Mother-Child, DOHaD laboratory } \\
\text { Siddeek, benazir; Centre Hospitalier Universitaire Vaudois, Department } \\
\text { Woman-Mother-Child, DOHaD laboratory } \\
\text { Simoncini, Stephanie; VRCM, Aix Marseille University,UMR S INSERM } 1076 \\
\text { Sabatier, Florence; VRCM, Aix Marseille University, UMR S INSERM } 1076 \\
\text { Dignat-George, Françoise; VRCM, Aix Marseille University, UMR S INSERM } \\
\text { 1076 } \\
\text { Mitanchez, Delphine; Division of Neonatology, Department of Perinatology, } \\
\text { APHP, Armand Trousseau Hospital } \\
\text { Simeoni, Umberto; Centre Hospitalier Universitaire Vaudois, Department } \\
\text { Woman-Mother-Child, DOHaD laboratory }\end{array}$ \\
\hline Model or Method: & Newborn/Children $<$ Human, Non-human primates $<$ Animal \\
\hline Topic: & $\begin{array}{l}\text { Child growth and health < Developmental Stage, Newborn/Infant < } \\
\text { Developmental Stage }\end{array}$ \\
\hline Abstract: & $\begin{array}{l}\text { Individuals born after intrauterine growth restriction (IUGR) have an } \\
\text { increased risk of perinatal morbidity/mortality, and those who survive face } \\
\text { long-term consequences such as cardiovascular-related diseases, including } \\
\text { systemic hypertension, atherosclerosis, coronary heart disease, and } \\
\text { chronic kidney disease. } \\
\text { In addition to the demonstrated long-term effects of decreased nephron } \\
\text { endowment and hyperactivity of the hypothalamic-pituitary-adrenal axis, } \\
\text { individuals born after IUGR also exhibit early alterations in vascular } \\
\text { structure and function, which have been identified as key factors of the } \\
\text { development of cardiovascular-related diseases. The endothelium plays a }\end{array}$ \\
\hline
\end{tabular}




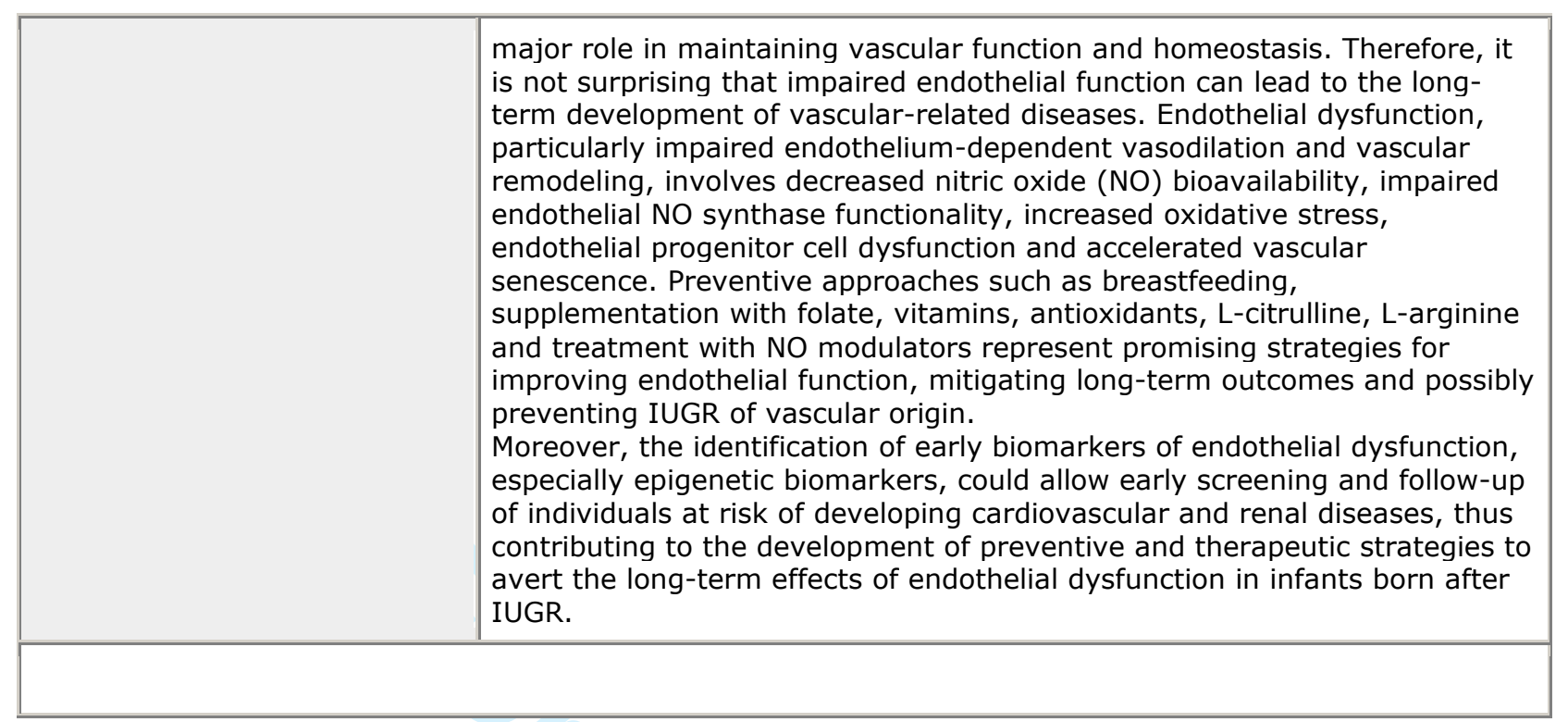

\section{SCHOLARONE ${ }^{m}$}

Manuscripts 
Endothelial dysfunction in individuals born after fetal growth restriction: cardiovascular and renal consequences and preventive approaches

\section{Yzydorczyk ${ }^{1 \bullet}$, JB Armengaud ${ }^{1 *}$, AC Peyter $^{2 *}$, H Chehade $^{1,3}$, F Cachat $^{3}$, C Juvet $^{1,3}$, B Siddeek $^{1}$, S Simoncini $^{4}$, F Sabatier ${ }^{4}$, F Dignat-George ${ }^{4}$, D Mitanchez $^{5}$, U Simeoni $^{1}$}

1 Department Woman-Mother-Child, Clinic of Pediatrics, DOHaD Laboratory, Centre Hospitalier Universitaire Vaudois and University of Lausanne, Switzerland;

${ }^{2}$ Department Woman-Mother-Child, Clinic of Neonatology, Neonatal Research Laboratory, Centre Hospitalier Universitaire Vaudois and University of Lausanne, Switzerland;

${ }^{3}$ Department Woman-Mother-Child, Clinic of Pediatrics, Division of Pediatric Nephrology, Centre Hospitalier Universitaire Vaudois and University of Lausanne, Switzerland;

${ }^{4}$ VRCM, Aix Marseille University, UMR S INSERM 1076, Faculté de Pharmacie, Marseille, France;

${ }^{5}$ Division of Neonatology, Department of Perinatology, APHP, Armand Trousseau Hospital, 75012 Paris \& Sorbonne Universities UPMC University Paris 06, Paris, France.

* These authors contributed equally to this work

- Corresponding author: Catherine.yzydorczyk@chuv.ch

Short title: Endothelial dysfunction following IUGR 
Individuals born after intrauterine growth restriction (IUGR) have an increased risk of perinatal morbidity/mortality, and those who survive face long-term consequences such as cardiovascular-related diseases, including systemic hypertension, atherosclerosis, coronary heart disease, and chronic kidney disease.

In addition to the demonstrated long-term effects of decreased nephron endowment and hyperactivity of the hypothalamic-pituitary-adrenal axis, individuals born after IUGR also exhibit early alterations in vascular structure and function, which have been identified as key factors of the development of cardiovascular-related diseases. The endothelium plays a major role in maintaining vascular function and homeostasis. Therefore, it is not surprising that impaired endothelial function can lead to the long-term development of vascular-related diseases. Endothelial dysfunction, particularly impaired endothelium-dependent vasodilation and vascular remodeling, involves decreased nitric oxide (NO) bioavailability, impaired endothelial NO synthase functionality, increased oxidative stress, endothelial progenitor cell dysfunction and accelerated vascular senescence. Preventive approaches such as breastfeeding, supplementation with folate, vitamins, antioxidants, L-citrulline, L-arginine and treatment with NO modulators represent promising strategies for improving endothelial function, mitigating long-term outcomes and possibly preventing IUGR of vascular origin. Moreover, the identification of early biomarkers of endothelial dysfunction, especially epigenetic biomarkers, could allow early screening and follow-up of individuals at risk of developing cardiovascular and renal diseases, thus contributing to the development of preventive and therapeutic strategies to avert the long-term effects of endothelial dysfunction in infants born after IUGR.

Key words: intrauterine growth restriction, endothelial dysfunction, developmental programming, $\mathrm{DOHaD}$, hypertension, cardiovascular disease, chronic renal disease. 
We performed an extensive and critical review of the literature in order to explore the manifestations of endothelial dysfunction in individuals born after intrauterine growth restriction (IUGR) and examined which mechanisms may be incriminated and which preventive strategies could represent promising approaches. We used the following terms in the Pubmed library (MESH terms and free text, without time or language limits: (Prenatal Exposure Delayed Effects OR Late Effect, Prenatal Exposure OR Nutrition Disorders/Physiopathology OR Fetal Growth restriction) AND (Cardiovascular Diseases/Etiology OR Hypertension/Etiology) AND (Impaired Endothelial Function OR Oxidative Stress/Senescence). We included the most significant human and animal studies. From the references of the retrieved papers, additional articles were selected for this review. One author (CY) read the titles and abstracts and selected the articles to be included.

\section{I- Intrauterine growth restriction: definition and risk factors}

\section{I-a-Definition}

Intrauterine growth restriction (IUGR) is defined as the inability of the fetus to reach its genetically determined potential size. ${ }^{1,2}$ IUGR affects approximately $5-15 \%$ of all pregnancies in the United States and Europe, but its incidence varies widely and appears to be higher in low income countries (it affects $30-55 \%$ of infants born in South Central Asia, 15$25 \%$ in Africa, and $10-20 \%$ in Latin America). ${ }^{3}$ Using the ReCoDe classification system, IUGR has been considered the most commonly identified factor in stillborn infants. ${ }^{4}$ Therefore, the management of growth-restricted fetuses in terms of choosing the optimal delivery time is important to decrease perinatal mortality/morbidity. Fetal growth restriction is difficult to detect because of the lack of international consensus on the definition and diagnostic criteria for IUGR. In clinical practice, growth-restricted fetuses are usually identified based on birth weight $\left(<10^{\text {th }}\right.$ percentile $)$. However, some propose that using $<3^{\text {rd }}$ or 
$<5^{\text {th }}$ percentile as the criterion would better identify individuals at a higher risk of adverse perinatal outcomes. ${ }^{5}$ Moreover, low estimated fetal weight $\left(<10^{\text {th }}\right.$ percentile $)$, certain ultrasound findings of fetal growth (abdominal circumference $<2.5^{\text {th }}$ percentile) and altered Doppler velocimetry indices, such as abnormal umbilical artery waveforms or decreased pulsatility of the middle cerebral artery, that suggest abnormalities in fetal circulation are also indicative of IUGR. ${ }^{6}$ To better understand abnormal fetal growth and to detect IUGR, specific computerized fetal growth charts that consider fetal gender and maternal characteristics such as height, weight, parity and ethnic origin were developed by Gardosi et al. ${ }^{7}$ Pathological factors, including maternal systemic hypertension (HTN), diabetes, tobacco use and preterm delivery, were excluded from the model to predict the optimum weight that a baby can reach at term during a normal pregnancy. Because it is necessary to distinguish between growthrestricted and constitutive "small for gestational age" fetuses, longitudinal assessments of fetal growth trajectories are required to identify pathological fetal growth restriction, even if the altered growth trajectory is above the $10^{\text {th }}$ centile limit. ${ }^{8}$ More recently, universal standards of fetal growth have been proposed by the Intergrowth project. ${ }^{9,10}$

\section{I-b-Risk factors for intrauterine growth restriction}

IUGR can result from a multitude of risk factors, including maternal and fetal causes. Several maternal factors have been identified, such as undernutrition, which notably affects the activity and/or expression of placental nutrient and ion transporters; $;{ }^{11-13}$ chronic diseases, such as preeclampsia; ${ }^{14}$ bacterial infection during pregnancy, particularly with Escherichia coli, group B Streptococcus, Listeria monocytogenes, Treponema pallidum, or Trichomonas vaginalis; parasitic diseases, such as malaria; viral infection (for example, human cytomegalovirus or rubella virus); ${ }^{15,16}$ young age (adolescent pregnancy); and alcohol and/or tobacco consumption. ${ }^{17}$ Additionally, pregnancy-induced HTN, preeclampsia and placental insufficiency are known causes of asymmetrical IUGR (defined as restriction of weight 
followed by length). ${ }^{18}$ Among the fetal causes, chromosomal anomalies (including trisomy of chromosome 13, 18, or 21; tri- and polyploidies; Mulibrey nanism; 3-M, Bloom, and Turner syndromes; and Majewski osteodysplastic primordial dwarfism (MOPD) type II) ${ }^{19}$ and fetal structural defects, such as congenital heart disease, ${ }^{20}$ result in symmetrical IUGR (defined as global growth restriction), which is usually more severe than asymmetrical IUGR. ${ }^{18}$

Along with maternal causes, paternal health has also been identified as a possible contributor to IUGR. Insulin resistance, smoking habits, elevated blood pressure, endothelial dysfunction, upper body fat distribution and an atherogenic lipid profile have all been suggested as potential paternally determined factors that correlate with IUGR. ${ }^{21}$ These factors presumably impact fetal growth through epigenetic processes. ${ }^{22}$

IUGR is now considered a critical public health issue because of its high perinatal mortality rate and long-term consequences. As numerous epidemiological studies have reported, infants born with fetal growth restriction have an increased risk of developing non-communicable chronic diseases, notably cardiovascular (e.g., systemic HTN and coronary artery disease) and renal (chronic kidney disease, CKD) diseases, later in life. These observations are consistent with the concept of Developmental Origins of Health and Disease, which suggests that conditions affecting specific sensitive developmental periods, from conception throughout pregnancy to early infancy, "program" tissue/organ structure and function throughout life in a process known as developmental plasticity that is adapted to short-term, prevailing environmental conditions but possibly not to the further life course. The underlying mechanisms are not clearly defined. In parallel with the long-term effects of decreased nephron numbers and hyperactivity of the hypothalamic-pituitary-adrenal axis in these infants, endothelial dysfunction may also contribute to the development of certain chronic diseases in adulthood. 


\section{II- Endothelium dysfunction in individuals born with intrauterine growth restriction}

\section{II-a The endothelium: a major role in vascular homeostasis}

The endothelium plays a major role in maintaining vascular homeostasis and is one of the largest organs in the human body, consisting of more than $10^{14}$ cells lining the vascular network. It is intimately involved in the balance between vasodilation and vasoconstriction and between thrombogenesis and fibrinolysis, the inhibition and promotion of smooth muscle cell proliferation and migration, and the prevention and stimulation of platelet adhesion and aggregation. ${ }^{23}$ All these functions are mediated by the release of numerous vasoactive factors, such as nitric oxide (NO) and endothelin. In this respect, the maintenance of endothelial structural and functional integrity is essential for vascular homeostasis; therefore, impaired endothelial function can lead to the development of vascular-related diseases.

Convincing evidence suggests that endothelial dysfunction during early childhood and persisting to adulthood in individuals born with IUGR is a key event in the development of HTN, atherosclerosis, coronary heart disease, and CKD later in life. In these individuals, endothelial dysfunction primarily manifests as impaired endothelium-dependent vasodilation and vascular remodeling.

\section{II-b-Impaired endothelium-dependent vasodilation in individuals born with fetal growth} restriction

Endothelium-dependent vasodilation can be clinically evaluated using flow-mediated brachial artery tests, plethysmography, or skin perfusion in response to acetylcholine using the laser

Doppler technique. ${ }^{24-26}$ Impaired endothelium-dependent vasodilation has been described in children (9-11 years) $)^{27-29}$ and young adults (20-28 years) born with fetal growth restriction ${ }^{30}$ and in umbilical and placental vessels derived from growth-restricted fetuses. ${ }^{31}$

An association between fetal growth restriction and impaired NO-dependent vasorelaxation 
has also been observed in several animal models, mainly in rats, mice and sheep. IUGR can be induced in rats by exposure to a maternal low-protein diet (LPD, containing $9 \%$ casein) ${ }^{32}$ or restricted diet (50\% of normal intake) and in sheep by single in utero umbilical artery ligation (at 105-110 days gestation); these diets and procedures result in low birth weight (LBW) offspring and lead to impaired endothelium-dependent vasodilation in small arteries, ${ }^{33,34}$ the aorta $^{35}$ and coronary arteries $^{36}$ in adulthood.

The effects on endothelium-dependent vasodilation are more pronounced in males, while females seem to be protected by the NO-dependent vasoprotective role of estrogens. However, impaired endothelium-dependent vasodilation has been observed in female Wistar rats born with IUGR stemming from maternal undernutrition. ${ }^{35}$ As suggested by Borwick et al., fetal undernutrition may decrease estrogen synthesis, ultimately leading to ovarian damage. ${ }^{37}$ Interestingly, estrogen-mediated vasoprotective activity has been reported in humans; specifically, postmenopausal women taking conjugated equine estrogens $(0.625 \mathrm{mg}$ for 28 days) showed improved vascular NO-dependent relaxation of the brachial artery. ${ }^{38}$

\section{II-c-Vascular remodeling in individuals born with fetal growth restriction}

\section{Endothelial activation}

Endothelial dysfunction is associated with leukocyte infiltration and the adhesion of monocytes, macrophages and low-density lipoprotein (LDL), which is oxidized to OxLDL in the arterial wall. This leads to foam cell formation and initiates atherogenesis. In addition, monocytes and macrophages secrete higher levels of cytokines and pro-inflammatory proteins such as interleukin-6 (IL-6), tumor necrosis factor-alpha and C-reactive protein (CRP). ${ }^{39}$ These events create a vicious cycle: neutrophils and macrophages produce higher levels of IL6 in response to inflammation, which in turn increases CRP production in the liver. CRP decreases NO availability and increases endothelin-1 production, thereby contributing to 
impaired endothelium-dependent vasodilation and leading to irreversible vascular damage. $^{39,40}$ Elevated levels of pro-inflammatory markers and endothelial activators are characteristic of middle-aged adults (45-64 years) born with LBW, indicating that endothelial dysfunction is patent in these individuals. ${ }^{41}$

\section{Vascular structural changes}

Histopathological analyses showed that the first atherosclerotic lesions begin to develop in the abdominal aorta. ${ }^{42}$ Increased arterial wall thickness, measured using non-invasive assessments of the intima-media or carotid intima-media thickness, has been observed in newborns ${ }^{43-46}$ and young children ${ }^{47,48}$ and persists in adults (27-30 years) born after IUGR, and it is particularly apparent in those with exaggerated postnatal growth. ${ }^{49}$

\section{Hypoxia and oxidative stress in vascular remodeling}

Hypoxia and oxidative stress have been implicated in vascular remodeling.

Placental insufficiency is related to reduced nutrient and oxygen delivery to the fetus, contributing to the development of fetal growth restriction. Several maternal factors, such as living at a high altitude, HTN, anemia, pulmonary disease, preeclampsia, drugs and/or tobacco consumption can contribute to fetal hypoxia ${ }^{50}$ which can induce IUGR, LBW ${ }^{51}$ and increase the risk of CVD later in life. ${ }^{52,53}$ During fetal development, hypoxia plays a crucial role by driving vasculogenesis/angiogenesis, hematopoeisis, and chondrogenesis. ${ }^{54}$ However, prolonged in utero hypoxia can lead to detrimental effects. In growth-restricted fetuses, circulating levels of angiopoietin-2, an angiogenic factor up-regulated by hypoxia, were increased at postnatal day 4 compared with appropriate-for-gestational age infants, thus contributing to postnatal vascular remodeling. ${ }^{55}$

Oxidative stress can be defined by decreased antioxidant defenses and increased reactive oxygen species (ROS) production. Under physiological conditions, ROS play an important 
role as a regulator of vascular functions such as migration, growth, smooth muscle and endothelial cell survival and the secretion of extracellular matrix proteins. However, uncontrolled ROS production can contribute to vascular diseases. ${ }^{56,57}$ ROS have been implicated in the hypertrophy and hyperplasia of vascular smooth muscle cells. In vascular cells (endothelial cells and vascular smooth muscle cells, adventitial fibroblasts), the main enzyme responsible for ROS production is NADPH oxidase. ${ }^{58}$

Angiotensin II (AngII), via Angiotensin type 1 receptor (AT1R), has been implicated in increasing superoxide anion levels followed by increased hydrogen peroxide production, which induces long-term outcomes of AngII, such as hypertrophy and hyperplasia of vascular smooth muscle cells. ${ }^{59,60}$ The flavoprotein inhibitor DPI $^{60}$ and catalase overexpression ${ }^{61}$ inhibits these vascular defects. In a rat model of IUGR induced by maternal LPD associated with adult HTN, we observed increased ex vivo vasoreactivity of the carotid rings to AngII, mediated by AT1R, which was normalized by diphenyleneiodonium (DPI) and apocynin (NADPH oxidase inhibitor) pre-incubation. ${ }^{32}$

The regulation of extracellular matrix proteins such as collagen and elastin can be modulated by ROS. Elastinolysis and collagenolysis play crucial roles in arterial remodeling and vascular diseases. ${ }^{62}$ Metalloproteinases (MMPs) and their related TIMPs are enzymes secreted by macrophages and vascular smooth muscle cells. MMP-2 and MMP-9 cleave gelatin, collagen and elastin and have been associated with vascular diseases. ${ }^{63}$ ROS have been demonstrated to activate MMPs. ${ }^{64}$ Increased circulating levels of MMP-2 and MMP-9 and increased MMP-2/TIMP-2 and MMP-9/TIMP-2 ratios have been observed in children who were small for gestational age and are positively correlated with systolic blood pressure and vascular function. ${ }^{65}$ In a developmental programing animal model of HTA induced by neonatal oxygen exposure, we observed increased aortic MMP-2 and TIMP-1 and reduced TIMP-2 staining as early as 4 weeks of age, indicating a shift in the balance towards 
degradation of the extracellular matrix and increased collagen deposition. ${ }^{66}$ These data suggest that early changes could contribute to the onset of the elevated blood pressure and arterial stiffness observed at adulthood in this animal model. ${ }^{67,68}$

\section{III- Mechanisms involved in endothelial dysfunction in individuals born with fetal growth restriction}

\section{III-a- Impaired NO bioavailability}

The endothelium-mediated release of NO is widely accepted as the key determinant of endothelial function, and reduced NO bioavailability has been linked to most serious vascular pathologies. ${ }^{69}$ In particular, the loss of NO production contributes to impaired endotheliumdependent vasodilation and to endothelium activation by improving the recruitment of proinflammatory cytokines, such as VCAM-1 and ICAM-1, and the infiltration of leukocytes into the vessel wall. ${ }^{70-72}$ In normal pregnancies, NO synthesis is up-regulated, as reflected by increased nitrite/nitrate concentrations in maternal and fetal circulation, thus mediating maternal cardiovascular adaptations and the low systemic and umbilical vascular resistance in the fetus. In pregnancies complicated by IUGR, research findings are inconsistent. Some have displayed a decrease in NO metabolite concentrations in maternal and/or fetal serum, reflecting reduced NO synthesis compared with controls. ${ }^{73,74}$ Other have found higher nitrite/nitrate concentrations in umbilical venous plasma $^{55}$ or an increase in eNOS protein staining in placental vessels compared with normal pregnancies, suggesting that increased NO production could be a compensatory response to improve blood flow in the placenta. ${ }^{75,76}$

Decreased NO synthesis, evaluated in terms of nitrate/nitrite production, was observed in animal models of IUGR induced by a reduction in utero-placental perfusion pressure ${ }^{77}$ or maternal $\operatorname{LPD}^{78,79}$ and in a rat model of developmental programming of HTN induced by exposing pregnant rats to androgens. ${ }^{80}$ 
Reduced NO bioavailability may result either from altered NO synthesis or from NO scavenging by other molecules, such as ROS.

\section{III-b-Impaired eNOS functionality}

Under physiological conditions, NO is synthetized in the vasculature by endothelial nitric oxide synthase (eNOS), using L-arginine (L-Arg) as a substrate and tetrahydrobiopterin (BH4) as a cofactor. There are contradictory data on eNOS expression in individuals born after IUGR. In humans, independent studies have indicated that eNOS expression is increased in the umbilical arteries of babies born after fetal growth restriction, suggesting that activated NO synthesis may be a compensatory mechanism to improve placental blood flow. ${ }^{31,81}$ However, these results are controversial because they could not be replicated. ${ }^{82}$ Moreover, differences in eNOS expression have been observed in human endothelial cells isolated from the umbilical arteries (HUAEC) or veins (HUVEC) of IUGR newborns. eNOS expression is increased in IUGR-HUAEC but decreased in IUGR-HUVEC. These differences may be explained by the type of vessel (artery $v s$. vein) or could be the consequence of altered blood flow and oxygen levels in pregnancies complicated by IUGR. ${ }^{18}$

In animal studies, eNOS expression varies depending on the animal model of IUGR used. In Dahl-S rats fed a high-salt diet to induce fetal growth restriction, the placental eNOS mRNA expression level was significantly increased compared with controls. ${ }^{83}$ In an animal model of IUGR induced by placental insufficiency using hyperthermic exposure, placental and umbilical artery eNOS protein in the placenta was decreased at mid-gestation but increased near term. ${ }^{84}$

However, eNOS expression and activity and the gender effect seem particularly sensitive to undernutrition. In fact, decreased eNOS expression and/or activity have been reported in animal models of IUGR induced by intrauterine undernourishment. ${ }^{35}$ In a rat IUGR model 
induced by intrauterine undernourishment, ${ }^{35}$ eNOS expression was decreased only in males, whereas eNOS activity was decreased in both males and females. This reduction in eNOS activity in females, which is probably the consequence of decreased estrogen levels, could explain the impaired endothelium-dependent vasodilation observed in this animal model. ${ }^{35}$ The modulation of eNOS activity by estrogens has been confirmed in vitro. Long-term estrogen treatment of cultured human and bovine endothelial cells up-regulates eNOS activity. $^{85}$

\section{III-c-Upregulation of the arginase pathway}

Arginases produce urea and ornithine, using L-Arg as a substrate. By competing with eNOS for the bioavailability of L-Arg, arginases can indirectly contribute the reduction of NO synthesis by eNOS. Accordingly, arginase up-regulation is an important factor that drives endothelial dysfunction. Increased arginase-2 expression was observed in human umbilical endothelium from IUGR fetuses. ${ }^{86}$ Pre-incubation with S-(2-boronoethyl)-L-cysteine (BEC), an arginase inhibitor, improved ex vivo endothelium-dependent relaxation in umbilical and placental vessels from babies born after fetal growth restriction ${ }^{31}$ and in aortic rings from a rat IUGR model induced by maternal LPD (personal unpublished data). These data suggest that arginase activity was increased in these vessels.

\section{III-d- Increased ADMA levels}

Asymmetric dimethylarginine (ADMA), an endogenous NO synthase inhibitor, is also considered an early marker and mediator of endothelial dysfunction. ADMA acts as a competitor of L-Arg, thereby inhibiting NO synthesis by eNOS. However, the observations in human studies are controversial. In pregnancies complicated by IUGR, ADMA levels in maternal serum were found to be either increased ${ }^{87,88}$ or decreased compared with those in 
normal gestations during the first (11-14 weeks), second (20-24 weeks) and third trimesters (28-35 weeks) ${ }^{89}$ Estrogen therapy could improve endothelial function by reducing ADMA levels. Clinical data revealed that estrogen therapy, chiefly the oral form, decreased plasma ADMA concentrations and therefore improved NO production in healthy postmenopausal women. $^{90,91}$

In animal models of atherosclerosis (rabbits and monkeys), endothelial dysfunction was associated with increased ADMA levels. ${ }^{92,93}$ To the best of our knowledge, ADMA levels have not been assessed in animal models of IUGR.

\section{III-e-Oxidative stress}

Oxidative stress plays an important role in endothelial dysfunction. ROS, particularly the superoxide anion $\left(\mathrm{O}_{2}^{-}\right)$, play a central role in vascular physiology, and their overproduction is especially relevant to vascular pathologies. ${ }^{94}$ In IUGR placentae, markers of oxidative stress, such as 8-hydroxy-2'-deoxyguanosine, redox factor-1, ${ }^{95,96}$ malondialdehyde and oxidized LDL, are increased in venous cord blood..$^{97}$ Therefore, it has been suggested that oxidative stress is involved in both the short- and long-term modulation of endothelial function in individuals born after IUGR. ${ }^{98}$ Oxidative stress affects the NO pathway by influencing NO synthesis and bioavailability. NO rapidly reacts with $\mathrm{O}_{2}^{-\cdot}$ to form peroxynitrite, a highly reactive and toxic species, which reduces endothelium-dependent relaxation ${ }^{99}$ and accelerates the development of pre-atherosclerotic lesions. ${ }^{100}$

As mentioned above, L-Arg and $\mathrm{BH}_{4}$ are crucial for $\mathrm{NO}$ production. A deficit in substrate and/or cofactor leads to enzymatic uncoupling, which causes eNOS to produce $\mathrm{O}_{2}^{-}{ }^{-}$rather than $\mathrm{NO},{ }^{101}$ thus contributing to endothelial dysfunction and impaired endothelium-dependent vasodilation. ${ }^{102,103}$ Decreased BH4 bioavailability can contribute to eNOS uncoupling. Regardless of whether the BH4 level is sufficient, the oxidation of L-Arg is coupled with the 
reduction of oxygen molecules to form L-citrulline and NO. However, BH4 bioavailability can be decreased through reduced production, ${ }^{104}$ increased oxidation ${ }^{105}$ or impaired recycling of the oxidized form (BH2) ${ }^{106}$ therefore leading to eNOS uncoupling.

Increased $\mathrm{O}_{2}^{-}$production up-regulates ADMA levels, thus worsening endothelial dysfunction. ${ }^{107}$ In humans, impaired NO-dependent vasodilation in placental vessels from IUGR pregnancies is coupled with a higher sensitivity to oxidative stress. ${ }^{108}$

Increased $\mathrm{O}_{2}^{-}$production mediated by NADPH oxidase and eNOS uncoupling was associated with defective endothelial function in a rat model of HTN induced by deoxycorticosterone and saline treatment ${ }^{109}$ and in a rat model of IUGR induced by maternal diet restriction $(50 \%$ of ad libitum intake throughout gestation) or LPD (9\% casein). ${ }^{32,110}$

\section{III-f-Endothelial progenitor cell dysfunction}

Endothelial dysfunction is characterized by impaired vasculogenesis and decreased repair capacity, functions that are mediated by circulating endothelial progenitor cells (EPCs). These cells are bone marrow-derived stem cells that can differentiate into mature endothelial cells, thus contributing to postnatal vasculogenesis and endothelial repair at damage sites. ${ }^{111}$ EPC subsets are differentiated by their phenotype and functional properties. The myeloid subset represents early EPCs, called colony-forming unit-endothelial cells, that appear early in cultures and display endothelial markers but do not form vessels in vivo. ${ }^{12,113}$ Endothelial colony-forming cells (ECFCs), the true angioblasts, appear later and display properties such as proliferation, auto-renewal, migration, and differentiation; additionally, they can support vascular growth and neovascularization. Both loss and impaired function of EPCs have been identified as markers of endothelial dysfunction, as described by Hill et al. ${ }^{114}$ In adult men with different degrees of cardiovascular risk but without a history of cardiovascular disease, levels of circulating EPCs have been identified as a surrogate biological marker of vascular 
function and cumulative cardiovascular risk. ${ }^{114}$ In pregnancy-related complications, most notably IUGR, aberrant vasculature and abnormal endothelial function were found on both the maternal and fetal sides of the placenta, and it is believed that altered fetal circulating EPCs contribute to these complications. ${ }^{115} \mathrm{We}$ and others have evaluated ECFCs isolated from LBW newborns and observed altered angiogenic properties in vitro, as evidenced by decreased numbers of colonies and sprouts, ${ }^{116}$ and in vivo, as shown by a reduction in the number of perfused vessels. ${ }^{117}$ Moreover, an imbalance between angiogenic and antiangiogenic factors was noted. ${ }^{117,118}$ These data suggest that the impairment of early angiogenic properties (structural and functional) could predispose LBW infants to endothelial dysfunction later in life.

\section{III-g-Vascular senescence}

Vascular senescence can contribute to endothelial dysfunction. ${ }^{119}$ It is characterized by a state of irreversible (replicative senescence) or reversible (stress-induced senescence) growth arrest, the expression of negative cell cycle regulators (such as p53 and p16) and increased senescence-related $\beta$-galactosidase staining. ${ }^{120}$ Senescent endothelial cells have a decreased ability to form new vascular structures; therefore, they contribute to impaired endothelial function. Sirtuins (SIRTs), particularly SIRT1, belong to a family of proteins involved in the regulation of many cellular processes, including senescence. SIRT1 is highly expressed in endothelial cells, wherein it regulates numerous functions, such as NOS expression and cellular senescence. ${ }^{121}$ The depletion of SIRT1 expression in endothelial cells led to endothelial dysfunction and premature senescence in several models of cardiovascular diseases, whereas overexpression of SIRT1 protected endothelial cells from senescenceassociated morphological and molecular changes. ${ }^{122}$ ECFCs from LBW newborns exhibit stress-induced vascular senescence characterized by growth arrest, increased $\beta$-galactosidase 
activity, and $\mathrm{p} 16^{\mathrm{INK} 4 \mathrm{a}}$ expression, all of which are mediated by decreased SIRT1 levels. ${ }^{123}$ Therefore, stress-induced vascular senescence is coincident with impaired angiogenic properties and could participate in the endothelial dysfunction observed later in life in individuals born after IUGR.

\section{IV- Relationship between intrauterine growth restriction and cardiovascular and renal outcomes later in life}

Early endothelial dysfunction observed in individuals born after IUGR could persist for the long term and lead to the onset of cardiovascular-related diseases.

\section{IV-a- Systemic hypertension}

Epidemiological studies have highlighted an inverse correlation between LBW and increased blood pressure in infancy, ${ }^{124}$ adolescence, ${ }^{125,126}$ young adulthood ${ }^{127,128}$ and adulthood. ${ }^{129-132}$ Some authors have questioned these results, suggesting that the data were inappropriately adjusted for confounding factors ${ }^{133}$ that could potentially damage kidneys and/or vascular endothelial cells early in life (e.g., nephrotoxic drugs or umbilical catheter placement). Recent data have indicated that the risk of HTN is not only linked to birth weight but is also amplified by postnatal overfeeding, leading to exaggerated catch-up growth. ${ }^{134}$

Several animal models have shown that IUGR induced by ligation of the bilateral uterine vessels, prenatal exposure to hypoxia $\left(11.5 \%\right.$ vs. $\left.21 \% \mathrm{O}_{2}\right)$ or glucocorticoids, maternal global undernutrition, caloric restriction or LPD during gestation induces HTN in adulthood ${ }^{32,135-141}$ and is often associated with vascular dysfunction. ${ }^{32,142,143}$ However, it is not well established whether HTN precedes endothelial dysfunction. Some clinical investigations have suggested that endothelial dysfunction is a primary defect in essential HTN that appears before the increase in blood pressure, ${ }^{144}$ but other observations have hinted that endothelial dysfunction is a consequence of elevated blood pressure. Different animal models of HTN induced by 
aortic coarctation (rabbits), ${ }^{145}$ a high-salt diet (rats) ${ }^{146}$ or neonatal hyperoxia (rats) ${ }^{67}$ showed selective impairment of endothelium-dependent vasodilation secondary to increased blood pressure. However, in an animal model of IUGR caused by maternal LPD during gestation, impaired endothelium-dependent relaxation preceded the onset of increased blood pressure (personal unpublished data).

\section{IV-b-Coronary heart disease}

Impaired endothelial function plays a major role in the development and progression of atherosclerosis, ${ }^{147,148}$ which ultimately leads to coronary heart disease. Many studies have proposed a relationship between birth weight and coronary heart disease: some showed an inverse relationship between LBW and increased risk of coronary heart disease, ${ }^{149-151}$ while others found no significant correlation $^{152}$ or a positive correlation only in males. ${ }^{153}$ Interestingly, the risk of coronary heart disease decreases with increasing birth weight. In fact, a $1-\mathrm{kg}$ increase in birth weight was associated with a 10-20\% decreased risk of coronary heart disease later in life. ${ }^{151}$

\section{IV-c-Chronic kidney disease}

The role of vascular components in the renal system is of particular significance because the kidneys receive approximately $20-25 \%$ of the total cardiac output. However, the contribution of the endothelial compartment to kidney development has been the subject of many hypotheses. Previous experiments showed that a significant proportion of the renal endothelium is derived from a resident precursor, the metanephric mesenchyme. ${ }^{154}$ Sprouting angiogenesis from the major renal vessels plays a significant role in forming the kidney endothelium, thus giving rise to most of the renal vessels and glomerular capillaries. ${ }^{155}$ Endothelial dysfunction is involved in the development and progression of CKD. ${ }^{156}$ Patients with CKD display microalbuminuria, which is thought to reflect endothelial damage in the 
capillary system of the renal medulla and increased endothelial permeability. ${ }^{156-159}$ Capillary damage is characterized by increased plasma concentrations of endothelium-derived proteins, such as von Willebrand factor, tissue-type plasminogen activator and urokinase-type plasminogen activator, and increased concentrations of markers of endothelial cell injury, such as soluble thrombomodulin. Decreased endothelium-dependent vasodilation occurs in end-stage kidney disease. ${ }^{160}$ Several epidemiological and experimental studies have shown that intrauterine insults are associated with the development of CKD. In humans, birth weight is positively correlated with glomerular number and inversely correlated with glomerular volume. ${ }^{161}$ In a meta-analysis of 18 studies, infants born after fetal growth restriction appeared to have a significantly higher risk of albuminuria (OR, 1.81; 95\% CI, 1.19 to 2.77), end-stage renal disease (OR, 1.58; $95 \% \mathrm{CI}, 1.33$ to 1.88$)$, or a low estimated glomerular filtration rate $(\mathrm{OR}, 1.79 ; 95 \% \mathrm{CI}, 1.31$ to 2.45$) .{ }^{162}$ Similar to HTN, the impairment of glomerular and tubular function secondary to IUGR is further amplified by environmental insults, such as drug exposure during the neonatal period ${ }^{163}$ or overweight in adulthood. ${ }^{164}$

Several animal models have enabled the identification of mechanisms involved in the development of renal dysfunction later in life. Rat models of IUGR induced by exposure to maternal LPD followed by early postnatal overnutrition during the lactation period or not according litter size reduction or increased protein intake to induce accelerated postnatal growth displayed alterations in renal structural development and a risk of chronic renal failure later in life. ${ }^{165-169}$ Decreased glomerular number potentially leads to reduced filtration capacity, reduced salt and water retention and the subsequent development of HTN. Furthermore, early loss of nephron numbers/mass may result in a state of hyperfiltration in the remaining nephrons, which will lead to focal segmental glomerulosclerosis and further loss of glomeruli, thus initiating a vicious circle. ${ }^{170}$ However, it is not clear whether endothelial dysfunction precedes or is a consequence of CKD. Regarding the impact of postnatal nutrition 
on renal maturation, rodent models could likely be more affected than humans because nephrogenesis is completed at approximately 36 weeks of gestation in humans, whereas in rats, this process is completed during postnatal life (between 7 to 10 days of life).

\section{V-Potential preventive approaches}

Several interventions have been identified to potentially prevent IUGR, improve endothelial function and thus antagonize the development of detrimental cardiovascular issues.

\section{V-a-Breastfeeding}

Breast milk could represent a promising approach, and the easiest one, for improving endothelial function in offspring. In fact, breastfeeding, as opposed to feeding with commercial infant formulas, is one of the best approaches for fighting neonatal oxidative stress because of breast milk's ability to "trap" free radicals. Breast milk contains enzymatic and non-enzymatic components such as superoxide dismutase, glutathione peroxidase, vitamins (A, C, and E), alpha-carotene, lactoferrin, and trace amounts of iron. Breastfeeding could improve endothelial function, primarily due to the presence of lactoferrin, an ironbinding glycoprotein with antioxidant, anti-inflammatory, pro-angiogenic and NO-dependent vasodilator properties. Daily treatment with lactoferrin after unilateral hind limb surgeryinduced ischemia in $\mathrm{C} 57 \mathrm{BL} / 6 \mathrm{~J}$ mice promoted angiogenesis, activated endothelial function via an NO-dependent mechanism ${ }^{171}$ and protected HUVECs against hydrogen peroxideinduced oxidative stress. ${ }^{172}$

\section{V-b-Folate supplementation}

Epidemiological studies have shown that folate deficiency is associated with increased 
cardiovascular risk. ${ }^{173,174}$ Because of the homocysteine-lowering and antioxidant effects of folate and its ability to modulate eNOS activity and cofactor availability, folic acid supplementation could improve vascular endothelial structure and function.

In a study including patients with coronary heart disease, the circulating form of folic acid, 5methyltetrahydrofolate, increased NO-dependent vasodilation, reduced vascular superoxide production, and improved enzymatic coupling of eNOS by increasing the availability of tetrahydrobiopterin. ${ }^{175}$ Folate supplementation in patients with acute ischemic stroke ${ }^{176}$ or $\mathrm{HTN}^{177}$ decreased plasma ADMA levels, suggesting that folate intake may also be beneficial in these contexts. Moreover, folic acid supplementation during pregnancy increased the birth weight of newborns. ${ }^{178}$

Folate deficiency in $\mathrm{ApoE}^{-/-}$mice was associated with the development of atherosclerotic lesions, which can be prevented by folate supplementation. ${ }^{179}$ Moreover, folate supplementation of a maternal LPD diet prevented the development of increased blood pressure and restored endothelium-dependent vasodilation and eNOS mRNA expression ${ }^{180}$ and enzyme activity. ${ }^{181}$

\section{V-c-Vitamin supplementation}

Studies of animal models of IUGR and developmental programming of CVD have demonstrated that maternal diet supplementation with vitamins $\mathrm{C}$ and $\mathrm{E}$ can prevent adverse perinatal and long-term outcomes. In an animal model of IUGR induced by high maternal cholesterol levels during the early stages of gestation, maternal dietary supplementation with vitamin $\mathrm{E}$ was found to prevent growth restriction in fetuses. Vitamin $\mathrm{E}$ has been shown to regulate molecular pathways controlling cell proliferation and viability ${ }^{182}$ and to increase the release of vasodilator prostanoids from human aortic endothelial cells ${ }^{183}$ and human umbilical vein endothelial cells, ${ }^{184}$ thus improving placenta-fetal blood flow and thereby increasing 
nutrient delivery to the fetus.

Vitamin C was found to protect chick embryos against the developmental toxicity of ethanol. Indeed, concomitant injection of vitamin $\mathrm{C}$ and ethanol in chick embryos prevented the decreased survival, growth retardation and malformations induced by ethanol alone. ${ }^{185}$

However, in human studies, these treatments have failed to show clear benefits in terms of birth weight and associated long-term diseases. ${ }^{186-189}$ A possible explanation is the potential confounding effects of maternal endogenous antioxidant defenses and redox status and maternal vitamin intake resulting from diversified nutrition. Differences in vitamin metabolism between humans and animals could also be involved in the discrepancy between human and animal studies.

\section{V-d-Antioxidant therapy}

Supplementation with resveratrol, a polyphenolic molecule found at high concentrations in red grapes, berries and peanuts, has been identified as a potential therapeutic strategy for the treatment of cardiovascular diseases, primarily due to its antioxidant properties and ability to modulate the NO signaling pathway. In spontaneously hypertensive rats, maternal dietary supplementation with resveratrol during the perinatal period prevented the onset of HTN in adult offspring. ${ }^{190}$ Resveratrol also modulates SIRT1 expression. Pre-incubation with resveratrol restored angiogenic capacity and reversed the accelerated senescence of ECFCs from LBW newborns. ${ }^{123}$

Lazaroid is a potent inhibitor of free radical formation, notably $\mathrm{O}_{2}^{-}$-mediated lipid peroxidation. Treatment with Lazaroid reversed HTN in several rat models, ${ }^{191,192}$ and the addition of Lazaroid to a maternal LPD diet throughout gestation increased birth weight and reversed later vascular dysfunction in offspring by decreasing oxidative stress. ${ }^{143}$ 
In a guinea pig model of IUGR induced by progressive uterine artery occlusion starting at mid-gestation, maternal $\mathrm{N}$-acetylcysteine treatment during the second half of gestation restored ex vivo eNOS-dependent relaxation in the fetal aorta and umbilical artery and normalized eNOS expression in fetal and umbilical endothelial cells. ${ }^{193}$

Melatonin, a hormone with antioxidant and anti-inflammatory properties, is involved in regulating circadian and circannual rhythms ${ }^{194}$ and could improve endothelial function. Melatonin exhibits direct scavenging activity on $\mathrm{O}_{2}{ }^{-36,195,196}$ up-regulates antioxidant enzymes such as superoxide dismutase and glutathione peroxidase, and down-regulates pro-oxidant enzymes such as lipoxygenase, ${ }^{197}$ thereby increasing NO production and improving its availability to induce vasodilation ${ }^{198}$ in different vascular beds. ${ }^{199-202}$

\section{V-e- L-citrulline supplementation}

L-citrulline is a precursor of L-arginine. L-citrulline is a non-protein amino acid, which is absent from the regular diet, escapes liver metabolism, has high bioavailability, and is quantitatively converted to arginine in vivo. ${ }^{203}$ Data have suggested that L-citrulline supplementation improves fetal growth an in animal model of IUGR induced by in utero exposure to maternal $\mathrm{LPD},{ }^{79}$ probably by improving maternal nutritional status and fetal growth through increased NO synthesis as a result of enhanced L-arginine availability in fetal circulation. L-citrulline can also exert a protective role on vascular endothelium. In fact, it has been proposed that L-citrulline supplementation could represent an alternative to L-arginine supplementation to improve vascular function, ${ }^{204,205}$ and it attenuated blood pressure in young normotensive men. ${ }^{206}$ In animal models, ex vivo pre-incubation with L-citrulline prevented endothelial dysfunction induced by ADMA in porcine coronary artery; indeed, such incubation favors L-citrulline to L-arginine recycling and the restoration of NO production, as a consequence of eNOS expression and activity up-regulation, the inhibition of superoxide 
anion production, and activation of the cGMP pathway. ${ }^{207}$ Such direct beneficial effects of Lcitrulline on endothelium-dependent relaxation suggest that L-citrulline supplementation could be an efficient way to improve endothelial function in individuals born after fetal growth restriction.

\section{V-f-Supplementation with L-arginine and NO mediators}

It was reported that L-Arg could be administered to increase maternal NO levels to enhance birth weight and decrease neonatal morbidity. ${ }^{74}$ More recently, the combined results of ten small trials showed that L-Arg supplementation can increase the body weight and gestational age at birth of IUGR fetuses. ${ }^{208}$ However, this study contrasts with others that reported no benefit of L-Arg therapy. ${ }^{209,210}$ Such differences could be explained by the different route of administration (oral or intravenous). In fact, with oral administration, $40 \%$ of L-Arg is degraded by the small intestine and metabolized by arginase in the liver. Therefore, poor LArg availability in the blood could decrease its efficacy. ${ }^{203,211}$

Among NO modulators, phosphodiesterase inhibitors are promising agents for improving uterine perfusion in pregnancies complicated by IUGR. Type 5 phosphodiesterase (PDE5) is one of the enzymes responsible for the degradation of cGMP to GMP in smooth muscle. Therefore, inhibiting PDE5 delays the breakdown of cGMP and increases vasorelaxation. Sildenafil citrate (Viagra $\left.{ }^{\circledR}\right)$ is probably the most famous PDE5 inhibitor. In women whose pregnancies were complicated by IUGR, sildenafil citrate improved fetoplacental perfusion ${ }^{212}$ and decreased the ex vivo vasoconstriction (in response to the thromboxane analogue U46619)

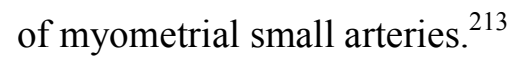

In animal models, parenteral administration of L-Arg (from day 60 of pregnancy to parturition) to underfed ewes prevented fetal growth restriction, ${ }^{214}$ and in a rat model of IUGR induced by maternal LPD, pre-incubating the aortic rings with L-Arg restored impaired 
endothelium-dependent vasodilation (personal unpublished data). Sildenafil citrate supplementation reversed the maternal effects of preeclampsia by improving uteroplacental and fetal perfusion ${ }^{215}$ in a Wistar rat model and increased fetal size in pregnant rats exposed to hypoxia at the end of gestation (18-20 days). ${ }^{216}$

\section{VI- Epigenetic markers of endothelial dysfunction}

Epigenetics plays a major role in the developmental origins of health and diseases. ${ }^{217}$ Epigenetics can be defined as a phenomenon of altered phenotypic expression of heritable genetic information without changes in the DNA sequence. Three main pathways can silence, activate, or regulate the level and time of expression of many genes: DNA methylation, histone modifications (acetylation, methylation, ubiquitination, phosphorylation, or ADPribosylation), and small non-coding RNAs, such as microRNAs (miRNAs). ${ }^{218,219}$ In general, these three epigenetic mechanisms appear to work together to regulate gene expression. DNA methylation or histone modifications can alter the expression of miRNAs, which can in turn regulate the epigenetic processes of DNA methylation and histone modifications.

\section{VI-a-DNA methylation}

DNA methylation has been known to be particularly sensitive to an adverse early environment. DNA methylation occurs through the binding of a methyl group in position 5 of the cytosine ring dinucleotide $\mathrm{CpG}$ sequences present in the DNA by DNA-methyltransferase, which can methylate and demethylate the DNA, thus making the modification reversible. ${ }^{220}$ In general, low levels of DNA methylation (hypomethylation) are associated with increased gene activity, whereas high levels of methylation (hypermethylation) are associated with gene repression. $^{221}$ Moreover, hydroxymethylated cytosine (5-hydroxymethylcytosine $(5 \mathrm{hmeC})$ ) has been identified as another functional DNA modification, representing an intermediate state of active DNA demethylation and also influencing gene expression. ${ }^{222,223}$ 
eNOS expression in human endothelial cells isolated from umbilical arteries (HUAECs) and veins (HUVECs) of IUGR pregnancies can be controlled by DNA methylation levels. eNOS protein and mRNA levels were increased in HUAECs but decreased in HUVECs from IUGR pregnancies ${ }^{86}$ and were associated in the eNOS promoter with decreased DNA methylation at CpG -352 in IUGR-HUAECs and an increased in IUGR-HUVECs. Additionally, in human umbilical artery endothelial cells from patients with placental insufficiency, levels of $5 \mathrm{hmeC}$ at the eNOS transcription start site directly correlated with elevated eNOS levels. ${ }^{224}$ In a guinea pig model of IUGR, increased eNOS expression was associated with decreased DNA methylation levels in eNOS promoter of endothelial cells derived from aorta, femoral and umbilical arteries; such modifications were prevented by maternal administration of $\mathrm{N}$ acetylcysteine. ${ }^{193}$

\section{VI-b-histone modifications}

In the nucleus, DNA is packaged into chromatin as repeating units of nucleosomes, which form a "beads-on-a-string" structure that can compact into higher order structures to affect gene expression. Nucleosomes are composed of 146-bp DNA wrapped in histone octamers (composed of two H2A, H2B, H3, and H4) and are connected by a linker DNA, which can associate with histone $\mathrm{H} 1$ to form heterochromatin. Histone proteins contain a globular domain and an amino-terminal tail, which can be post-translationally modified. The posttranslational modification of lysine (acetylation, methylation, ubiquitination, sumoylation), arginine (methylation) and serine and threonine (phosphorylation) are the most commonly described modifications. ${ }^{218,225}$ In general, the acetylation of histone H3 and H4 is associated with increased gene expression and has been shown to regulate the angiogenic function of endothelial cells.

Levels of $\mathrm{H} 3 \mathrm{~K} 9 \mathrm{ac}$ and $\mathrm{H} 2 \mathrm{~A} . \mathrm{Zac}$ were significantly higher at the eNOS transcription start site 
and were directly correlated with elevated eNOS levels observed in the human umbilical artery endothelial cells from patients with placental insufficiency. ${ }^{224}$ Additionally, increased histone $\mathrm{H} 3$ acetylation in the endothelin-1 promoter of pulmonary vascular endothelial cells and in the peripheral leucocytes in a IUGR rat model induced by maternal undernutrition has been correlated with higher endothelin-1 expression, which could increase the risk of pulmonary disorders (pulmonary hypertension or asthma) later in life. ${ }^{226}$ Recently, we observed that SIRT1 repression in ECFCs from LBW newborns, associated with premature senescence, could be modulated by changes in "active" or "repressive" epigenetic marks. The "active" marks trimethyl-H3K4 (H3K4me3) associated with the SIRT1 promoter were significantly decreased in LBW newborns compared to controls, whereas the "repressive" marks trimethyl- $\mathrm{H} 3 \mathrm{~K} 9$, associated with heterochromatin formation, were increased. ${ }^{123}$

\section{VI-c-Non-coding RNAs}

MiRNAs are small single-strand RNAs that do not encode proteins. Each miRNA binds to specific messenger RNAs (mRNAs), resulting in the degradation of target mRNA or the inhibition of its translation into protein. miRNAs regulate the post-transcriptional expression level of many genes and processes such as apoptosis, cell growth, and differentiation in a large range of tissues, ${ }^{227,228}$ and notably in the regulation of endothelial functions. MiR-21 expression is increased in cases of shear stress, which helps to protect endothelial cells by decreasing apoptosis and increasing eNOS expression and NO production. ${ }^{229}$ However, in atherosclerotic plaques, an up-regulation of miR-21 decreases the function of superoxide dismutase, which leads to increased ROS production and decreased migration of the progenitor cells. ${ }^{230}$ MiR-221 and miR-222 are highly expressed in endothelial cells ${ }^{231}$ and exert antiangiogenic, antiproliferative, antimigration and proapoptotic effects on endothelial cells, ${ }^{231}$ which can be partly caused by reduced eNOS expression. ${ }^{232}$ Additionally, miRNAs can modulate SIRT1 expression. Increased expression of miR-217 and miR-34a have been 
observed in endothelial senescence, which leads to loss of SIRT1 function, notably by reducing eNOS expression. $^{233}$

\section{VI-Conclusions}

In individuals born after fetal growth restriction, early endothelial dysfunction plays an important role in the subsequent development of HTN, coronary heart disease and CKD. Decreased NO synthesis and bioavailability caused by defective eNOS function and oxidative stress, decreased EPC number and function, and vascular senescence have all been shown to be involved in endothelial dysfunction (Figure 1). Preventive approaches, including breastfeeding and supplementation with folate, vitamins, antioxidants, L-citrulline, L-Arg and NO modulators, represent promising and simple ways to prevent fetal growth restriction, improve endothelial function and vasodilation responses early in life and delay/prevent detrimental cardiovascular issues.

Epigenetic modulation of gene expression appears to be one of the main contributors to the long-term effects of an adverse perinatal environment. The identification of early biomarkers of endothelial dysfunction, especially epigenetic biomarkers, could allow early screening and follow-up of individuals at risk of developing CVD, thus contributing to the development of preventive and therapeutic strategies to avert the long-term effects of endothelial dysfunction in infants born after IUGR. 


\section{VII-Acknowledgements}

The authors thank Dolorès Mosig, Katya Nardou and Dr. Fabienne Maurer for their invaluable contributions. 


\section{VIII-Financial Support}

This research received no specific grant from any funding agency in the commercial or notfor-profit sectors. 


\section{IX-Conflicts of interest}

None. 


\section{X-References}

1. Brodsky D, Christou H. Current concepts in intrauterine growth restriction. J Intensive Care Med. 2004; 19, 307-319.

2. Jang DG, Jo YS, Lee SJ, Kim N, Lee GS. Perinatal outcomes and maternal clinical characteristics in IUGR with absent or reversed end-diastolic flow velocity in the umbilical artery. Arch Gynecol Obstet. 2011; 284, 73-78.

3. Saleem T, Sajjad N, Fatima S, et al. Intrauterine growth retardation--small events, big consequences. Ital J Pediatr. 2011; 37, 41.

4. Mongelli M, Gardosi J. Symphysis-fundus height and pregnancy characteristics in ultrasound-dated pregnancies. Obstet Gynecol. 1999; 94, 591-594.

5. Committee on Practice Bulletins--Gynecology ACoO, Gynecologists WDCUSA. Intrauterine growth restriction. Clinical management guidelines for obstetriciangynecologists. American College of Obstetricians and Gynecologists. Int J Gynaecol Obstet. 2001; 72, 85-96.

6. Alberry M, Soothill P. Management of fetal growth restriction. Arch Dis Child Fetal Neonatal Ed. 2007; 92, F62-67.

7. Figueras F, Gardosi J. Intrauterine growth restriction: new concepts in antenatal surveillance, diagnosis, and management. Am J Obstet Gynecol. 2011; 204, 288-300.

8. Barker ED, McAuliffe FM, Alderdice F, et al. The role of growth trajectories in classifying fetal growth restriction. Obstet Gynecol. 2013; 122, 248-254.

9. Villar J, Cheikh Ismail L, Victora CG, et al. International standards for newborn weight, length, and head circumference by gestational age and sex: the Newborn Cross-Sectional Study of the INTERGROWTH-21st Project. Lancet. 2014; 384, 857 868. 
10. Villar J, Giuliani F, Fenton TR, et al. INTERGROWTH-21st very preterm size at birth reference charts. Lancet. 2016; 387, 844-845.

11. Rosario FJ, Jansson N, Kanai Y, et al. Maternal protein restriction in the rat inhibits placental insulin, mTOR, and STAT3 signaling and down-regulates placental amino acid transporters. Endocrinology. 2011; 152, 1119-1129.

12. Johansson M, Karlsson L, Wennergren M, Jansson T, Powell TL. Activity and protein expression of $\mathrm{Na}+/ \mathrm{K}+$ ATPase are reduced in microvillous syncytiotrophoblast plasma membranes isolated from pregnancies complicated by intrauterine growth restriction. $J$ Clin Endocrinol Metab. 2003; 88, 2831-2837.

13. Settle P, Sibley CP, Doughty IM, et al. Placental lactate transporter activity and expression in intrauterine growth restriction. J Soc Gynecol Investig. 2006; 13, 357363.

14. Chaiworapongsa T, Chaemsaithong P, Yeo L, Romero R. Pre-eclampsia part 1: current understanding of its pathophysiology. Nat Rev Nephrol. 2014; 10, 466-480.

15. Adams Waldorf KM, McAdams RM. Influence of infection during pregnancy on fetal development. Reproduction. 2013; 146, R151-162.

16. Derricott H, Jones RL, Heazell AE. Investigating the association of villitis of unknown etiology with stillbirth and fetal growth restriction - a systematic review. Placenta. 2013; 34, 856-862.

17. Baba S, Wikstrom AK, Stephansson O, Cnattingius S. Changes in snuff and smoking habits in Swedish pregnant women and risk for small for gestational age births. BJOG. $2013 ; 120,456-462$.

18. Maruyama H, Shinozuka M, Kondoh Y, et al. Thrombocytopenia in preterm infants with intrauterine growth restriction. Acta Med Okayama. 2008; 62, 313-317. 
19. Hall JG. Review and hypothesis: syndromes with severe intrauterine growth restriction and very short stature--are they related to the epigenetic mechanism(s) of fetal survival involved in the developmental origins of adult health and disease? Am J Med Genet A. 2010; 152A, 512-527.

20. Malik S, Cleves MA, Zhao W, et al. Association between congenital heart defects and small for gestational age. Pediatrics. 2007; 119, e976-982.

21. Hillman S, Peebles DM, Williams DJ. Paternal metabolic and cardiovascular risk factors for fetal growth restriction: a case-control study. Diabetes Care. 2013; 36, 1675-1680.

22. Li J, Tsuprykov O, Yang X, Hocher B. Paternal programming of offspring cardiometabolic diseases in later life. J Hypertens. 2016; 34, 2111-2126.

23. Minshall RD, Tiruppathi C, Vogel SM, Malik AB. Vesicle formation and trafficking in endothelial cells and regulation of endothelial barrier function. Histochem Cell Biol. $2002 ; 117,105-112$.

24. Purnomowati A, Kariadi SH, Achmad TH, Mose JC, Setianto B. Endothelial dysfunction in the young adult: a retrospective cohort study on the effect of low birth weight. Acta Med Indones. 2014; 46, 111-116.

25. Bassareo PP, Fanos V, Puddu M, et al. Reduced brachial flow-mediated vasodilation in young adult ex extremely low birth weight preterm: a condition predictive of increased cardiovascular risk? J Matern Fetal Neonatal Med. 2010; 23 Suppl 3, 121 124.

26. Martin H, Lindblad B, Norman M. Endothelial function in newborn infants is related to folate levels and birth weight. Pediatrics. 2007; 119, 1152-1158. 
27. Leeson P, Thorne S, Donald A, et al. Non-invasive measurement of endothelial function: effect on brachial artery dilatation of graded endothelial dependent and independent stimuli. Heart. 1997; 78, 22-27.

28. Leeson C, Whincup P, Cook D, et al. Flow-mediated dilation in 9- to 11-year-old children: the influence of intrauterine and childhood factors. Circulation. 1997; 96, $2233-2238$.

29. Goodfellow J, Bellamy MF, Gorman ST, et al. Endothelial function is impaired in fit young adults of low birth weight. Cardiovasc Res. 1998; 40, 600-606.

30. Leeson C, Kattenhorn M, Morley R, Lucas A, Deanfield J. Impact of low birth weight and cardiovascular risk factors on endothelial function in early adult life. Circulation. $2001 ; 103,1264-1268$.

31. Krause BJ, Carrasco-Wong I, Caniuguir A, et al. Endothelial eNOS/arginase imbalance contributes to vascular dysfunction in IUGR umbilical and placental vessels. Placenta. 2013; 34, 20-28.

32. Yzydorczyk C, Gobeil F, Jr., Cambonie G, et al. Exaggerated vasomotor response to ANG II in rats with fetal programming of hypertension associated with exposure to a low-protein diet during gestation. Am J Physiol Regul Integr Comp Physiol. 2006; 291, R1060-1068.

33. Pladys P, Sennlaub F, Brault S, et al. Microvascular rarefaction and decreased angiogenesis in rats with fetal programming of hypertension associated with exposure to a low-protein diet in utero. Am J Physiol Regul Integr Comp Physiol. 2005; 289, R1580-1588.

34. Brawley L, Itoh S, Torrens $\mathrm{C}$, et al. Dietary protein restriction in pregnancy induces hypertension and vascular defects in rat male offspring. Pediatr Res. 2003; 54, 83-90. 
35. Franco MC, Arruda R, Dantas A, et al. Intrauterine undernutrition: expression and activity of the endothelial nitric oxide synthase in male and female adult offspring. Cardiovasc Res. 2002; 56, 145-153.

36. Tare M, Parkington HC, Wallace EM, et al. Maternal melatonin administration mitigates coronary stiffness and endothelial dysfunction, and improves heart resilience to insult in growth restricted lambs. $J$ Physiol. 2014; 592, 2695-2709.

37. Borwick SC, Rhind SM, McMillen SR, Racey PA. Effect of undernutrition of ewes from the time of mating on fetal ovarian development in mid gestation. Reprod Fertil Dev. 1997; 9, 711-715.

38. Hurtado R, Celani M, Geber S. Effect of short-term estrogen therapy on endothelial function: a double-blinded, randomized, controlled trial. Climacteric. 2016; 19, 448451.

39. Gleeson M, Bishop NC, Stensel DJ, et al. The anti-inflammatory effects of exercise: mechanisms and implications for the prevention and treatment of disease. Nat Rev Immunol. 2011; 11, 607-615.

40. Leinonen E, Hurt-Camejo E, Wiklund O, et al. Insulin resistance and adiposity correlate with acute-phase reaction and soluble cell adhesion molecules in type 2 diabetes. Atherosclerosis. 2003; 166, 387-394.

41. Pellanda LC, Duncan BB, Vigo A, et al. Low birth weight and markers of inflammation and endothelial activation in adulthood: the ARIC study. Int J Cardiol. $2009 ; 134,371-377$.

42. Teeninga N, Schreuder MF, Bokenkamp A, Delemarre-van de Waal HA, van Wijk JA. Influence of low birth weight on minimal change nephrotic syndrome in children, including a meta-analysis. Nephrol Dial Transplant. 2008; 23, 1615-1620. 
43. Skilton MR, Evans N, Griffiths KA, Harmer JA, Celermajer DS. Aortic wall thickness in newborns with intrauterine growth restriction. Lancet. 2005; 365, 1484-1486.

44. Koklu E, Ozturk MA, Gunes T, Akcakus M, Kurtoglu S. Is increased intima-media thickness associated with preatherosclerotic changes in intrauterine growth restricted newborns? Acta Paediatr. 2007; 96, 1858; author reply 1859.

45. Litwin M, Niemirska A. Intima-media thickness measurements in children with cardiovascular risk factors. Pediatr Nephrol. 2009; 24, 707-719.

46. Cosmi E, Visentin S, Fanelli T, Mautone AJ, Zanardo V. Aortic intima media thickness in fetuses and children with intrauterine growth restriction. Obstet Gynecol. $2009 ; 114,1109-1114$.

47. Crispi F, Figueras F, Cruz-Lemini M, et al. Cardiovascular programming in children born small for gestational age and relationship with prenatal signs of severity. Am J Obstet Gynecol. 2012; 207, 121 e121-129.

48. Crispi F, Bijnens B, Figueras F, et al. Fetal growth restriction results in remodeled and less efficient hearts in children. Circulation. 2010; 121, 2427-2436.

49. Oren A, Vos LE, Uiterwaal CS, et al. Birth weight and carotid intima-media thickness: new perspectives from the atherosclerosis risk in young adults (ARYA) study. Ann Epidemiol. 2004; 14, 8-16.

50. Jensen GM, Moore LG. The effect of high altitude and other risk factors on birthweight: independent or interactive effects? Am J Public Health. 1997; 87, $1003-$ 1007.

51. Lueder FL, Kim SB, Buroker CA, Bangalore SA, Ogata ES. Chronic maternal hypoxia retards fetal growth and increases glucose utilization of select fetal tissues in the rat. Metabolism. 1995; 44, 532-537. 
52. Barker DJ. The fetal origins of coronary heart disease. Acta Paediatr Suppl. 1997; $422,78-82$.

53. Barker DJ, Osmond C, Golding J, Kuh D, Wadsworth ME. Growth in utero, blood pressure in childhood and adult life, and mortality from cardiovascular disease. BMJ. $1989 ; 298,564-567$.

54. Giaccia AJ, Simon MC, Johnson R. The biology of hypoxia: the role of oxygen sensing in development, normal function, and disease. Genes Dev. 2004; 18, 2183 2194.

55. Malamitsi-Puchner A, Boutsikou T, Economou E, et al. Angiopoietin-2 in the perinatal period and the role of intrauterine growth restriction. Acta Obstet Gynecol Scand. 2006; 85, 45-48.

56. Griendling KK, Harrison DG. Dual role of reactive oxygen species in vascular growth. Circ Res. 1999; 85, 562-563.

57. Irani K. Oxidant signaling in vascular cell growth, death, and survival : a review of the roles of reactive oxygen species in smooth muscle and endothelial cell mitogenic and apoptotic signaling. Circ Res. 2000; 87, 179-183.

58. Touyz RM, Schiffrin EL. Reactive oxygen species in vascular biology: implications in hypertension. Histochem Cell Biol. 2004; 122, 339-352.

59. Ushio-Fukai M, Zafari AM, Fukui T, Ishizaka N, Griendling KK. p22phox is a critical component of the superoxide-generating NADH/NADPH oxidase system and regulates angiotensin II-induced hypertrophy in vascular smooth muscle cells. J Biol Chem. 1996; 271, 23317-23321.

60. Griendling KK, Minieri CA, Ollerenshaw JD, Alexander RW. Angiotensin II stimulates NADH and NADPH oxidase activity in cultured vascular smooth muscle cells. Circ Res. 1994; 74, 1141-1148. 
61. Zafari AM, Ushio-Fukai M, Akers M, et al. Role of NADH/NADPH oxidase-derived H2O2 in angiotensin II-induced vascular hypertrophy. Hypertension. 1998; 32, 488495.

62. Tyagi SC, Simon SR. Regulation of neutrophil elastase activity by elastin-derived peptide. J Biol Chem. 1993; 268, 16513-16518.

63. Chow AK, Cena J, Schulz R. Acute actions and novel targets of matrix metalloproteinases in the heart and vasculature. Br J Pharmacol. 2007; 152, 189-205.

64. Rajagopalan S, Meng XP, Ramasamy S, Harrison DG, Galis ZS. Reactive oxygen species produced by macrophage-derived foam cells regulate the activity of vascular matrix metalloproteinases in vitro. Implications for atherosclerotic plaque stability. $J$ Clin Invest. 1996; 98, 2572-2579.

65. Sesso R, Franco MC. Abnormalities in metalloproteinase pathways and IGF-I axis: a link between birth weight, hypertension, and vascular damage in childhood. Am J Hypertens. 2010; 23, 6-11.

66. Huyard F, Yzydorczyk C, Castro MM, et al. Remodeling of aorta extracellular matrix as a result of transient high oxygen exposure in newborn rats: implication for arterial rigidity and hypertension risk. PLoS One. 2014; 9, e92287.

67. Yzydorczyk C, Comte B, Cambonie G, et al. Neonatal oxygen exposure in rats leads to cardiovascular and renal alterations in adulthood. Hypertension. 2008; 52, 889-895.

68. Mivelaz Y YC, Barbier A, Cloutier A, Fouron JC, Nuyt AM. Neonatal oxygen exposure leads to increased aortic wall stiffness in adult rats: a doppler ultrasound study. J Dev Orig Health Dis. 2011; 2, 6.

69. Chatterjee A, Black SM, Catravas JD. Endothelial nitric oxide (NO) and its pathophysiologic regulation. Vascul Pharmacol. 2008; 49, 134-140. 
70. Förstermann U, Münzel T. Endothelial nitric oxide synthase in vascular disease: from marvel to menace. Circulation. 2006; 113, 1708-1714.

71. Searles CD. Transcriptional and posttranscriptional regulation of endothelial nitric oxide synthase expression. Am J Physiol Cell Physiol. 2006; 291, C803-816.

72. De Caterina R, Libby P, Peng HB, et al. Nitric oxide decreases cytokine-induced endothelial activation. Nitric oxide selectively reduces endothelial expression of adhesion molecules and proinflammatory cytokines. J Clin Invest. 1995; 96, 60-68.

73. Hata T, Hashimoto M, Manabe A, et al. Maternal and fetal nitric oxide synthesis is decreased in pregnancies with small for gestational age infants. Hum Reprod. 1998; 13, 1070-1073.

74. Singh S, Singh A, Sharma D, et al. Effect of 1-Arginine on Nitric Oxide Levels in Intrauterine Growth Restriction and its Correlation with Fetal Outcome. Indian J Clin Biochem. 2015; 30, 298-304.

75. Lyall F, Greer IA, Young A, Myatt L. Nitric oxide concentrations are increased in the feto-placental circulation in intrauterine growth restriction. Placenta. 1996; 17, 165 168.

76. Myatt L, Eis AL, Brockman DE, Greer IA, Lyall F. Endothelial nitric oxide synthase in placental villous tissue from normal, pre-eclamptic and intrauterine growth restricted pregnancies. Hum Reprod. 1997; 12, 167-172.

77. Payne JA, Alexander BT, Khalil RA. Reduced endothelial vascular relaxation in growth-restricted offspring of pregnant rats with reduced uterine perfusion. Hypertension. 2003; 42, 768-774.

78. Sathishkumar K, Elkins R, Yallampalli U, Yallampalli C. Protein restriction during pregnancy induces hypertension and impairs endothelium-dependent vascular function in adult female offspring. J Vasc Res. 2009; 46, 229-239. 
79. Bourdon A, Parnet P, Nowak C, et al. 1-Citrulline Supplementation Enhances Fetal Growth and Protein Synthesis in Rats with Intrauterine Growth Restriction. J Nutr. $2016 ; 146,532-541$.

80. Sathishkumar K, Elkins R, Yallampalli U, Balakrishnan M, Yallampalli C. Fetal programming of adult hypertension in female rat offspring exposed to androgens in utero. Early Hum Dev. 2011; 87, 407-414.

81. Hracsko Z, Hermesz E, Ferencz A, et al. Endothelial nitric oxide synthase is upregulated in the umbilical cord in pregnancies complicated with intrauterine growth retardation. In Vivo. 2009; 23, 727-732.

82. Dellee U, Tobias S, Li H, Mildenberger E. Expression of NO synthases and redox enzymes in umbilical arteries from newborns born small, appropriate, and large for gestational age. Pediatr Res. 2013; 73, 142-146.

83. Takushima S, Nishi Y, Nonoshita A, et al. Changes in the nitric oxide-soluble guanylate cyclase system and natriuretic peptide receptor system in placentas of pregnant Dahl salt-sensitive rats. J Obstet Gynaecol Res. 2015; 41, 540-550.

84. Arroyo JA, Anthony RV, Parker TA, Galan HL. eNOS, NO, and the activation of ERK and AKT signaling at mid-gestation and near-term in an ovine model of intrauterine growth restriction. Syst Biol Reprod Med. 2010; 56, 62-73.

85. Tolbert T, Thompson JA, Bouchard P, Oparil S. Estrogen-induced vasoprotection is independent of inducible nitric oxide synthase expression: evidence from the mouse carotid artery ligation model. Circulation. 2001; 104, 2740-2745.

86. Krause BJ, Costello PM, Munoz-Urrutia E, et al. Role of DNA methyltransferase 1 on the altered eNOS expression in human umbilical endothelium from intrauterine growth restricted fetuses. Epigenetics. 2013; 8, 944-952. 
87. Laskowska M, Laskowska K, Oleszczuk J. Differences in the association between maternal serum homocysteine and ADMA levels in women with pregnancies complicated by preeclampsia and/or intrauterine growth restriction. Hypertens Pregnancy. 2013; 32, 83-93.

88. Gumus E, Atalay MA, Cetinkaya Demir B, Sahin Gunes E. Possible role of asymmetric dimethylarginine (ADMA) in prediction of perinatal outcome in preeclampsia and fetal growth retardation related to preeclampsia. J Matern Fetal Neonatal Med. 2016; 29, 3806-3811.

89. Rizos D, Eleftheriades M, Batakis E, et al. Levels of asymmetric dimethylarginine throughout normal pregnancy and in pregnancies complicated with preeclampsia or had a small for gestational age baby. J Matern Fetal Neonatal Med. 2012; 25, 1311 1315.

90. Post MS, Verhoeven MO, van der Mooren MJ, et al. Effect of hormone replacement therapy on plasma levels of the cardiovascular risk factor asymmetric dimethylarginine: a randomized, placebo-controlled 12-week study in healthy early postmenopausal women. J Clin Endocrinol Metab. 2003; 88, 4221-4226.

91. Karkanaki A, Vavilis D, Traianos A, Kalogiannidis I, Panidis D. Hormone therapy and asymmetrical dimethylarginine in postmenopausal women. Hormones (Athens). $2010 ; 9,127-135$.

92. Yu XJ, Li YJ, Xiong Y. Increase of an endogenous inhibitor of nitric oxide synthesis in serum of high cholesterol fed rabbits. Life Sci. 1994; 54, 753-758.

93. Boger RH, Bode-Boger SM, Sydow K, Heistad DD, Lentz SR. Plasma concentration of asymmetric dimethylarginine, an endogenous inhibitor of nitric oxide synthase, is elevated in monkeys with hyperhomocyst(e)inemia or hypercholesterolemia. Arterioscler Thromb Vasc Biol. 2000; 20, 1557-1564. 
94. Griendling KK, FitzGerald GA. Oxidative stress and cardiovascular injury: Part I: basic mechanisms and in vivo monitoring of ROS. Circulation. 2003; 108, 1912-1916.

95. Burton GJ, Jauniaux E. Oxidative stress. Best Pract Res Clin Obstet Gynaecol. 2011; $25,287-299$.

96. Takagi Y, Nikaido T, Toki T, et al. Levels of oxidative stress and redox-related molecules in the placenta in preeclampsia and fetal growth restriction. Virchows Arch. 2004; 444, 49-55.

97. Maisonneuve E, Delvin E, Edgard A, et al. Oxidative conditions prevail in severe IUGR with vascular disease and Doppler anomalies. J Matern Fetal Neonatal Med. $2015 ; 28,1471-1475$.

98. Webster RP, Roberts VH, Myatt L. Protein nitration in placenta - functional significance. Placenta. 2008; 29, 985-994.

99. Kossenjans W, Eis A, Sahay R, Brockman D, Myatt L. Role of peroxynitrite in altered fetal-placental vascular reactivity in diabetes or preeclampsia. Am J Physiol Heart Circ Physiol. 2000; 278, H1311-1319.

100. Santilli F, D'Ardes D, Davi G. Oxidative stress in chronic vascular disease: From prediction to prevention. Vascul Pharmacol. 2015; 74, 23-37.

101. Yzydorczyk C, Comte B, Huyard F, et al. Developmental programming of eNOS uncoupling and enhanced vascular oxidative stress in adult rats after transient neonatal oxygen exposure J Cardiovasc Pharmacol. 2013; 61, 8-16.

102. Vasquez-Vivar J, Kalyanaraman B, Martasek P, et al. Superoxide generation by endothelial nitric oxide synthase: the influence of cofactors. Proc Natl Acad Sci USA. 1998; 95, 9220-9225. 
103. d'Uscio LV, Santhanam AV, Katusic ZS. Erythropoietin prevents endothelial dysfunction in GTP-cyclohydrolase I-deficient hph1 mice. J Cardiovasc Pharmacol. 2014; 64, 514-521.

104. Yang YM, Huang A, Kaley G, Sun D. eNOS uncoupling and endothelial dysfunction in aged vessels. Am J Physiol Heart Circ Physiol. 2009; 297, H1829-1836.

105. Landmesser U, Dikalov S, Price SR, et al. Oxidation of tetrahydrobiopterin leads to uncoupling of endothelial cell nitric oxide synthase in hypertension. J Clin Invest. $2003 ; 111,1201-1209$.

106. Chalupsky K, Cai H. Endothelial dihydrofolate reductase: critical for nitric oxide bioavailability and role in angiotensin II uncoupling of endothelial nitric oxide synthase. Proc Natl Acad Sci USA. 2005; 102, 9056-9061.

107. Sydow K, Munzel T. ADMA and oxidative stress. Atheroscler Suppl. 2003; 4, 41-51.

108. Schneider D, Hernandez C, Farias M, et al. Oxidative stress as common trait of endothelial dysfunction in chorionic arteries from fetuses with IUGR and LGA. Placenta. 2015; 36, 552-558.

109. Mitchell BM, Cook LG, Danchuk S, Puschett JB. Uncoupled endothelial nitric oxide synthase and oxidative stress in a rat model of pregnancy-induced hypertension. Am J Hypertens. 2007; 20, 1297-1304.

110. Oliveira V, Akamine EH, Carvalho $\mathrm{MH}$, et al. Influence of aerobic training on the reduced vasoconstriction to angiotensin II in rats exposed to intrauterine growth restriction: possible role of oxidative stress and AT2 receptor of angiotensin II. PLoS One. 2014; 9, e113035.

111. Asahara T, Murohara T, Sullivan A, et al. Isolation of putative progenitor endothelial cells for angiogenesis. Science. 1997; 275, 964-967. 
112. Yoder MC, Mead LE, Prater D, et al. Redefining endothelial progenitor cells via clonal analysis and hematopoietic stem/progenitor cell principals. Blood. 2007; 109, 1801-1809.

113. Purhonen S, Palm J, Rossi D, et al. Bone marrow-derived circulating endothelial precursors do not contribute to vascular endothelium and are not needed for tumor growth. Proc Natl Acad Sci USA. 2008; 105, 6620-6625.

114. Hill JM, Zalos G, Halcox JP, et al. Circulating endothelial progenitor cells, vascular function, and cardiovascular risk. N Engl J Med. 2003; 348, 593-600.

115. Sipos PI, Crocker IP, Hubel CA, Baker PN. Endothelial progenitor cells: their potential in the placental vasculature and related complications. Placenta. 2010; 31, 110.

116. Hwang HS, Kwon YG, Kwon JY, et al. Senescence of fetal endothelial progenitor cell in pregnancy with idiopathic fetal growth restriction. J Matern Fetal Neonatal Med. $2012 ; 25,1769-1773$.

117. Ligi I, Simoncini S, Tellier E, et al. A switch toward angiostatic gene expression impairs the angiogenic properties of endothelial progenitor cells in low birth weight preterm infants. Blood. 2011; 118, 1699-1709.

118. Ligi I, Simoncini S, Tellier E, et al. Altered angiogenesis in low birth weight individuals: a role for anti-angiogenic circulating factors. J Matern Fetal Neonatal Med. 2014; 27, 233-238.

119. Minamino T, Komuro I. Vascular cell senescence: contribution to atherosclerosis. Circ Res. 2007; 100, 15-26.

120. Erusalimsky JD, Fenton M. Further in vivo evidence that cellular senescence is implicated in vascular pathophysiology. Circulation. 2002; 106, e144; author reply e144. 
121. Borradaile NM, Pickering JG. NAD $(+)$, sirtuins, and cardiovascular disease. Curr Pharm Des. 2009; 15, 110-117.

122. Ota H, Akishita M, Eto M, et al. Sirt1 modulates premature senescence-like phenotype in human endothelial cells. J Mol Cell Cardiol. 2007; 43, 571-579.

123. Vassallo PF, Simoncini S, Ligi I, et al. Accelerated senescence of cord blood endothelial progenitor cells in premature neonates is driven by SIRT1 decreased expression. Blood. 2014; 123, 2116-2126.

124. Fattal-Valevski A, Bernheim J, Leitner Y, et al. Blood pressure values in children with intrauterine growth retardation. Isr Med Assoc J. 2001; 3, 805-808.

125. Rossi P, Tauzin L, Marchand E, et al. Respective roles of preterm birth and fetal growth restriction in blood pressure and arterial stiffness in adolescence. $J$ Adolesc Health. 2011; 48, 520-522.

126. Chiolero A, Cachat F, Burnier M, Paccaud F, Bovet P. Prevalence of hypertension in schoolchildren based on repeated measurements and association with overweight. $J$ Hypertens. 2007; 25, 2209-2217.

127. Leon DA, Johansson M, and Rasmussen F. Gestational age and growth rate of fetal mass are inversely associated with systolic blood pressure in young adults: an epidemiologic study of 165,136 Swedish men aged 18 years. Am J Epidemiol. $2000 ; 152,8$.

128. Nilsson PM, Ostergren PO, Nyberg P, Soderstrom M, Allebeck P. Low birth weight is associated with elevated systolic blood pressure in adolescence: a prospective study of a birth cohort of 149378 Swedish boys. J Hypertens. 1997; 15, 1627-1631.

129. Gennser G, Rymark P, Isberg PE. Low birth weight and risk of high blood pressure in adulthood. Br Med J (Clin Res Ed). 1988; 296, 1498-1500. 
130. Martyn CN, Barker DJ, Jespersen S, Greenwald S, Osmond C, Berry C. Growth in utero, adult blood pressure, and arterial compliance. Br Heart J 1995; 73, 6.

131. Curhan GC, Willett WC, Rimm EB, et al. Birth weight and adult hypertension, diabetes mellitus, and obesity in US men. Circulation. 1996; 94, 3246-3250.

132. Law CM, Shiell AW. Is blood pressure inversely related to birth weight? The strength of evidence from a systematic review of the literature. J Hypertens. 1996; 14, 935941.

133. Huxley R, Neil A, Collins R. Unravelling the fetal origins hypothesis: is there really an inverse association between birthweight and subsequent blood pressure? Lancet. $2002 ; 360,659-665$.

134. Tauzin L, Rossi P, Grosse C, et al. Increased systemic blood pressure and arterial stiffness in young adults born prematurely. J Dev Orig Health Dis. 2014; 5, 448-452.

135. Wlodek ME, Westcott K, Siebel AL, Owens JA, Moritz KM. Growth restriction before or after birth reduces nephron number and increases blood pressure in male rats. Kidney Int. 2008; 74, 187-195.

136. Alexander BT. Placental insufficiency leads to development of hypertension in growth-restricted offspring. Hypertension. 2003; 41, 457-462.

137. Bourque SL, Gragasin FS, Quon AL, et al. Prenatal hypoxia causes long-term alterations in vascular endothelin-1 function in aged male, but not female, offspring. Hypertension. 2013; 62, 753-758.

138. Ortiz LA, Quan A, Zarzar F, Weinberg A, Baum M. Prenatal dexamethasone programs hypertension and renal injury in the rat. Hypertension. 2003; 41, 328-334.

139. Mossa F, Carter F, Walsh SW, et al. Maternal undernutrition in cows impairs ovarian and cardiovascular systems in their offspring. Biol Reprod. 2013; 88, 92. 
140. Goyal R, Van-Wickle J, Goyal D, Longo LD. Antenatal maternal low protein diet: ACE-2 in the mouse lung and sexually dimorphic programming of hypertension. $B M C$ Physiol. 2015; 15, 2.

141. Gilbert JS, Lang AL, Grant AR, Nijland MJ. Maternal nutrient restriction in sheep: hypertension and decreased nephron number in offspring at 9 months of age. $J$ Physiol. 2005; 565, 137-147.

142. Ozaki T, Nishina H, Hanson M, Poston L. Dietary restriction in pregnant rats causes gender-related hypertension and vascular dysfunction in offspring. J Physiol. 2001; $530,141-152$

143. Cambonie G, Comte B, Yzydorczyk C, et al. Antenatal antioxidant prevents adult hypertension, vascular dysfunction, and microvascular rarefaction associated with in utero exposure to a low-protein diet. Am J Physiol Regul Integr Comp Physiol. 2007; 292, R1236-1245.

144. Taddei S, Virdis A, Mattei P, Arzilli F, Salvetti A. Endothelium-dependent forearm vasodilation is reduced in normotensive subjects with familial history of hypertension. J Cardiovasc Pharmacol. 1992; 20 Suppl 12, S193-195.

145. Miller MJ, Pinto A, Mullane KM. Impaired endothelium-dependent relaxations in rabbits subjected to aortic coarctation hypertension. Hypertension. 1987; 10, 164-170.

146. d'Uscio LV, Barton M, Shaw S, Moreau P, Luscher TF. Structure and function of small arteries in salt-induced hypertension: effects of chronic endothelin-subtype-Areceptor blockade. Hypertension. 1997; 30, 905-911.

147. Verma S, Anderson TJ. Fundamentals of endothelial function for the clinical cardiologist. Circulation. 2002; 105, 546-549. 
148. Ludmer PL, Selwyn AP, Shook TL, et al. Paradoxical vasoconstriction induced by acetylcholine in atherosclerotic coronary arteries. N Engl J Med. 1986; 315, 10461051.

149. Barker DJ, Gluckman PD, Godfrey KM, et al. Fetal nutrition and cardiovascular disease in adult life. Lancet. 1993; 341, 938-941.

150. Leon DA, Lithell HO, Vagero D, et al. Reduced fetal growth rate and increased risk of death from ischaemic heart disease: cohort study of 15000 Swedish men and women born 1915-29. BMJ. 1998; 317, 241-245.

151. Wang SF, Shu L, Sheng J, et al. Birth weight and risk of coronary heart disease in adults: a meta-analysis of prospective cohort studies. J Dev Orig Health Dis. 2014; 5, 408-419.

152. Eriksson M, Tibblin G, Cnattingius S. Low birthweight and ischaemic heart disease. Lancet. 1994; 343, 731.

153. Banci M, Saccucci P, Dofcaci A, et al. Birth weight and coronary artery disease. The effect of gender and diabetes. Int J Biol Sci. 2009; 5, 244-248.

154. Abrahamson DR, Robert B, Hyink DP, St John PL, Daniel TO. Origins and formation of microvasculature in the developing kidney. Kidney Int Suppl. 1998; 67, S7-11.

155. Hyink DP, Tucker DC, St John PL, et al. Endogenous origin of glomerular endothelial and mesangial cells in grafts of embryonic kidneys. Am J Physiol. 1996; 270, F886899.

156. Stehouwer CD, Henry RM, Dekker JM, et al. Microalbuminuria is associated with impaired brachial artery, flow-mediated vasodilation in elderly individuals without and with diabetes: further evidence for a link between microalbuminuria and endothelial dysfunction--the Hoorn Study. Kidney Int Suppl. 2004; 66, S42-44. 
157. Pedrinelli R, Giampietro O, Carmassi F, et al. Microalbuminuria and endothelial dysfunction in essential hypertension. Lancet. 1994; 344, 14-18.

158. Mancuso P, Antoniotti P, Quarna J, et al. Validation of a standardized method for enumerating circulating endothelial cells and progenitors: flow cytometry and molecular and ultrastructural analyses. Clin Cancer Res. 2009; 15, 267-273.

159. Perticone F, Maio R, Perticone M, et al. Endothelial dysfunction and subsequent decline in glomerular filtration rate in hypertensive patients. Circulation. 2010; 122, $379-384$.

160. Gris JC, Branger B, Vecina F, et al. Increased cardiovascular risk factors and features of endothelial activation and dysfunction in dialyzed uremic patients. Kidney Int. $1994 ; 46,807-813$.

161. Manalich R, Reyes L, Herrera M, Melendi C, Fundora I. Relationship between weight at birth and the number and size of renal glomeruli in humans: a histomorphometric study. Kidney Int. 2000; 58, 770-773.

162. White SL, Perkovic V, Cass A, et al. Is low birth weight an antecedent of CKD in later life? A systematic review of observational studies. Am J Kidney Dis. 2009; 54, 248261.

163. Giapros V, Papadimitriou P, Challa A, Andronikou S. The effect of intrauterine growth retardation on renal function in the first two months of life. Nephrol Dial Transplant. 2007; 22, 96-103.

164. Silverwood RJ, Pierce M, Hardy R, et al. Low birth weight, later renal function, and the roles of adulthood blood pressure, diabetes, and obesity in a British birth cohort. Kidney Int. 2013; 84, 1262-1270.

165. Vehaskari VM, Aviles DH, Manning J. Prenatal programming of adult hypertension in the rat. Kidney Int. 2001; 59, 238-245. 
166. Woods LL, Ingelfinger JR, Nyengaard JR, Rasch R. Maternal protein restriction suppresses the newborn renin-angiotensin system and programs adult hypertension in rats. Pediatr Res. 2001; 49, 460-467.

167. Boubred F, Delamaire E, Buffat C, et al. High protein intake in neonatal period induces glomerular hypertrophy and sclerosis in adulthood in rats born with IUGR. Pediatr Res. 2016; 79, 22-26.

168. Boubred F, Buffat C, Feuerstein JM, et al. Effects of early postnatal hypernutrition on nephron number and long-term renal function and structure in rats. Am J Physiol Renal Physiol. 2007; 293, F1944-1949.

169. Boubred F, Daniel L, Buffat C, et al. Early postnatal overfeeding induces early chronic renal dysfunction in adult male rats. Am J Physiol Renal Physiol. 2009; 297, F943-951.

170. Anderson S, King AJ, Brenner BM. Hyperlipidemia and glomerular sclerosis: an alternative viewpoint. Am J Med. 1989; 87, 34N-38N.

171. Ikeda Y, Tajima S, Izawa-Ishizawa Y, et al. Bovine milk-derived lactoferrin exerts proangiogenic effects in an Src-Akt-eNOS-dependent manner in response to ischemia. J Cardiovasc Pharmacol. 2013; 61, 423-429.

172. Safaeian L, Javanmard SH, Mollanoori Y, Dana N. Cytoprotective and antioxidant effects of human lactoferrin against $\mathrm{H} 2 \mathrm{O} 2$-induced oxidative stress in human umbilical vein endothelial cells. Adv Biomed Res. 2015; 4, 188.

173. Verhaar MC, Stroes E, Rabelink TJ. Folates and cardiovascular disease. Arterioscler Thromb Vasc Biol. 2002; 22, 6-13.

174. Robinson K, Arheart K, Refsum H, et al. Low circulating folate and vitamin B6 concentrations: risk factors for stroke, peripheral vascular disease, and coronary artery disease. European COMAC Group. Circulation. 1998; 97, 437-443. 
175. Antoniades C, Shirodaria C, Warrick N, et al. 5-methyltetrahydrofolate rapidly improves endothelial function and decreases superoxide production in human vessels: effects on vascular tetrahydrobiopterin availability and endothelial nitric oxide synthase coupling. Circulation. 2006; 114, 1193-1201.

176. Xia XS, Li X, Wang L, et al. Supplementation of folic acid and vitamin $B(1)(2)$ reduces plasma levels of asymmetric dimethylarginine in patients with acute ischemic stroke. J Clin Neurosci. 2014; 21, 1586-1590.

177. Wu CJ, Wang L, Li X, et al. [Impact of adding folic acid, vitamin B(12) and probucol to standard antihypertensive medication on plasma homocysteine and asymmetric dimethylarginine levels of essential hypertension patients]. Zhonghua Xin Xue Guan Bing Za Zhi. 2012; 40, 1003-1008.

178. Li JM, Qu PF, Dang SN, et al. [Effect of folic acid supplementation in childbearing aged women during pregnancy on neonate birth weight in Shaanxi province]. Zhonghua Liu Xing Bing Xue Za Zhi. 2016; 37, 1017-1020.

179. Alessio AC, Santos CX, Debbas V, et al. Evaluation of mild hyperhomocysteinemia during the development of atherosclerosis in apolipoprotein E-deficient and normal mice. Exp Mol Pathol. 2011; 90, 45-50.

180. Torrens C, Brawley L, Anthony FW, et al. Folate supplementation during pregnancy improves offspring cardiovascular dysfunction induced by protein restriction. Hypertension. 2006; 47, 982-987.

181. Stroes ES, van Faassen EE, Yo M, et al. Folic acid reverts dysfunction of endothelial nitric oxide synthase. Circ Res. 2000; 86, 1129-1134.

182. Zingg JM, Azzi A. Non-antioxidant activities of vitamin E. Curr Med Chem. 2004; 11, 1113-1133. 
183. Wu D, Liu L, Meydani M, Meydani SN. Vitamin E increases production of vasodilator prostanoids in human aortic endothelial cells through opposing effects on cyclooxygenase-2 and phospholipase A2. J Nutr. 2005; 135, 1847-1853.

184. Tran K, Chan AC. R,R,R-alpha-tocopherol potentiates prostacyclin release in human endothelial cells. Evidence for structural specificity of the tocopherol molecule. Biochim Biophys Acta. 1990; 1043, 189-197.

185. Memon S, Pratten MK. Developmental toxicity of ethanol in chick heart in ovo and in micromass culture can be prevented by addition of vitamin $\mathrm{C}$ and folic acid. Reprod Toxicol. 2009; 28, 262-269.

186. Hovdenak N, Haram K. Influence of mineral and vitamin supplements on pregnancy outcome. Eur J Obstet Gynecol Reprod Biol. 2012; 164, 127-132.

187. Sesso HD, Buring JE, Christen WG, et al. Vitamins E and C in the prevention of cardiovascular disease in men: the Physicians' Health Study II randomized controlled trial. JAMA. 2008; 300, 2123-2133.

188. Rumbold A, Ota E, Nagata C, Shahrook S, Crowther CA. Vitamin C supplementation in pregnancy. Cochrane Database Syst Rev. 2015, CD004072.

189. Rumbold AR, Crowther CA, Haslam RR, et al. Vitamins C and E and the risks of preeclampsia and perinatal complications. N Engl J Med. 2006; 354, 1796-1806.

190. Care AS, Sung MM, Panahi S, et al. Perinatal resveratrol supplementation to spontaneously hypertensive rat dams mitigates the development of hypertension in adult offspring. Hypertension. 2016; 67, 1038-1044.

191. Vaziri ND, Ding Y, Ni Z, Gonick HC. Altered nitric oxide metabolism and increased oxygen free radical activity in lead-induced hypertension: effect of lazaroid therapy. Kidney Int. 1997; 52, 1042-1046. 
192. Vaziri ND, Ni Z, Oveisi F, Trnavsky-Hobbs DL. Effect of antioxidant therapy on blood pressure and NO synthase expression in hypertensive rats. Hypertension. 2000; $36,957-964$.

193. Herrera EA, Cifuentes-Zuniga F, Figueroa E, et al. N-Acetylcysteine, a glutathione precursor, reverts vascular dysfunction and endothelial epigenetic programming in intrauterine growth restricted guinea pigs. J Physiol. 2016.

194. Hardeland R, Cardinali DP, Srinivasan V, et al. Melatonin--a pleiotropic, orchestrating regulator molecule. Prog Neurobiol. 2011; 93, 350-384.

195. Reiter RJ, Tan DX, Terron MP, Flores LJ, Czarnocki Z. Melatonin and its metabolites: new findings regarding their production and their radical scavenging actions. Acta Biochim Pol. 2007; 54, 1-9.

196. Franco Mdo C, Akamine EH, Aparecida de Oliveira M, et al. Vitamins C and E improve endothelial dysfunction in intrauterine-undernourished rats by decreasing vascular superoxide anion concentration. J Cardiovasc Pharmacol. 2003; 42, 211-217.

197. Galano A, Tan DX, Reiter RJ. On the free radical scavenging activities of melatonin's metabolites, AFMK and AMK. J Pineal Res. 2013; 54, 245-257.

198. Lopez A, Garcia JA, Escames G, et al. Melatonin protects the mitochondria from oxidative damage reducing oxygen consumption, membrane potential, and superoxide anion production. J Pineal Res. 2009; 46, 188-198.

199. Herrera EA, Macchiavello R, Montt C, et al. Melatonin improves cerebrovascular function and decreases oxidative stress in chronically hypoxic lambs. J Pineal Res. $2014 ; 57,33-42$.

200. Weekley LB. Effects of melatonin on isolated pulmonary artery and vein: role of the vascular endothelium. Pulm Pharmacol. 1993; 6, 149-154. 
201. Girouard H, Chulak C, Lejossec M, Lamontagne D, de Champlain J. Vasorelaxant effects of the chronic treatment with melatonin on mesenteric artery and aorta of spontaneously hypertensive rats. J Hypertens. 2001; 19, 1369-1377.

202. Das R, Balonan L, Ballard HJ, Ho S. Chronic hypoxia inhibits the antihypertensive effect of melatonin on pulmonary artery. Int J Cardiol. 2008; 126, 340-345.

203. Curis E, Nicolis I, Moinard C, et al. Almost all about citrulline in mammals. Amino Acids. 2005; 29, 177-205.

204. Romero MJ, Platt DH, Caldwell RB, Caldwell RW. Therapeutic use of citrulline in cardiovascular disease. Cardiovasc Drug Rev. 2006; 24, 275-290.

205. Chien SJ, Lin KM, Kuo HC, et al. Two different approaches to restore renal nitric oxide and prevent hypertension in young spontaneously hypertensive rats: 1-citrulline and nitrate. Transl Res. 2014; 163, 43-52.

206. Figueroa A, Trivino JA, Sanchez-Gonzalez MA, Vicil F. Oral L-citrulline supplementation attenuates blood pressure response to cold pressor test in young men. Am J Hypertens. 2010; 23, 12-16.

207. Xuan C, Lun LM, Zhao JX, et al. L-citrulline for protection of endothelial function from ADMA-induced injury in porcine coronary artery. Sci Rep. 2015; 5, 10987.

208. Chen J, Gong X, Chen P, Luo K, Zhang X. Effect of L-arginine and sildenafil citrate on intrauterine growth restriction fetuses: a meta-analysis. BMC Pregnancy Childbirth. 2016; 16, 225.

209. Gui S, Jia J, Niu X, et al. Arginine supplementation for improving maternal and neonatal outcomes in hypertensive disorder of pregnancy: a systematic review. $J$ Renin Angiotensin Aldosterone Syst. 2014; 15, 88-96.

210. Vadillo-Ortega F, Perichart-Perera O, Espino S, et al. Effect of supplementation during pregnancy with L-arginine and antioxidant vitamins in medical food on pre- 
eclampsia in high risk population: randomised controlled trial. BMJ. 2011; 342, d2901.

211. Wu G, Bazer FW, Cudd TA, et al. Pharmacokinetics and safety of arginine supplementation in animals. $J$ Nutr. 2007; 137, 1673S-1680S.

212. Dastjerdi MV, Hosseini S, Bayani L. Sildenafil citrate and uteroplacental perfusion in fetal growth restriction. J Res Med Sci. 2012; 17, 632-636.

213. Wareing M, Myers JE, O'Hara M, Baker PN. Sildenafil citrate (Viagra) enhances vasodilatation in fetal growth restriction. J Clin Endocrinol Metab. 2005; 90, 25502555.

214. Lassala A, Bazer FW, Cudd TA, et al. Parenteral administration of L-arginine prevents fetal growth restriction in undernourished ewes. $J$ Nutr. 2010; 140, 1242-1248.

215. Herraiz S, Pellicer B, Serra V, et al. Sildenafil citrate improves perinatal outcome in fetuses from pre-eclamptic rats. BJOG. 2012; 119, 1394-1402.

216. Refuerzo JS, Sokol RJ, Aranda JV, et al. Sildenafil citrate and fetal outcome in pregnant rats. Fetal Diagn Ther. 2006; 21, 259-263.

217. Cutfield WS, Hofman PL, Mitchell M, Morison IM. Could epigenetics play a role in the developmental origins of health and disease? Pediatr Res. 2007; 61, 68R-75R.

218. Chen M, Zhang L. Epigenetic mechanisms in developmental programming of adult disease. Drug Discov Today. 2011; 16, 1007-1018.

219. McKay JA, Mathers JC. Diet induced epigenetic changes and their implications for health. Acta Physiol (Oxf). 2011; 202, 103-118.

220. Kangaspeska S, Stride B, Metivier R, et al. Transient cyclical methylation of promoter DNA. Nature. 2008; 452, 112-115.

221. Lorenzen JM, Martino F, Thum T. Epigenetic modifications in cardiovascular disease. Basic Res Cardiol. 2012; 107, 245. 
222. Ito S, D'Alessio AC, Taranova OV, et al. Role of Tet proteins in $5 \mathrm{mC}$ to $5 \mathrm{hmC}$ conversion, ES-cell self-renewal and inner cell mass specification. Nature. 2010; 466, 1129-1133.

223. Kriaucionis S, Heintz N. The nuclear DNA base 5-hydroxymethylcytosine is present in Purkinje neurons and the brain. Science. 2009; 324, 929-930.

224. Postberg J, Kanders M, Forcob S, et al. CpG signalling, H2A.Z/H3 acetylation and microRNA-mediated deferred self-attenuation orchestrate foetal NOS3 expression. Clin Epigenetics. 2015; 7, 9.

225. Canani RB, Costanzo MD, Leone L, et al. Epigenetic mechanisms elicited by nutrition in early life. Nutr Res Rev. 2011; 24, 198-205.

226. Xu XF, Xu SS, Fu LC, et al. Epigenetic changes in peripheral leucocytes as biomarkers in intrauterine growth retardation rat. Biomed Rep. 2016; 5, 548-552.

227. Shruti K, Shrey K, Vibha R. Micro RNAs: tiny sequences with enormous potential. Biochem Biophys Res Commun. 2011; 407, 445-449.

228. Sayed D, Abdellatif M. MicroRNAs in development and disease. Physiol Rev. 2011; $91,827-887$.

229. Weber M, Baker MB, Moore JP, Searles CD. MiR-21 is induced in endothelial cells by shear stress and modulates apoptosis and eNOS activity. Biochem Biophys Res Commun. 2010; 393, 643-648.

230. Fleissner F, Jazbutyte V, Fiedler J, et al. Short communication: asymmetric dimethylarginine impairs angiogenic progenitor cell function in patients with coronary artery disease through a microRNA-21-dependent mechanism. Circ Res. 2010; 107, 138-143. 
231. Liu X, Cheng Y, Yang J, Xu L, Zhang C. Cell-specific effects of miR-221/222 in vessels: molecular mechanism and therapeutic application. J Mol Cell Cardiol. 2012;

$52,245-255$.

232. Suarez Y, Fernandez-Hernando C, Pober JS, Sessa WC. Dicer dependent microRNAs regulate gene expression and functions in human endothelial cells. Circ Res. 2007; $100,1164-1173$.

233. Xu Q, Seeger FH, Castillo J, et al. Micro-RNA-34a contributes to the impaired function of bone marrow-derived mononuclear cells from patients with cardiovascular disease. J Am Coll Cardiol. 2012; 59, 2107-2117. 


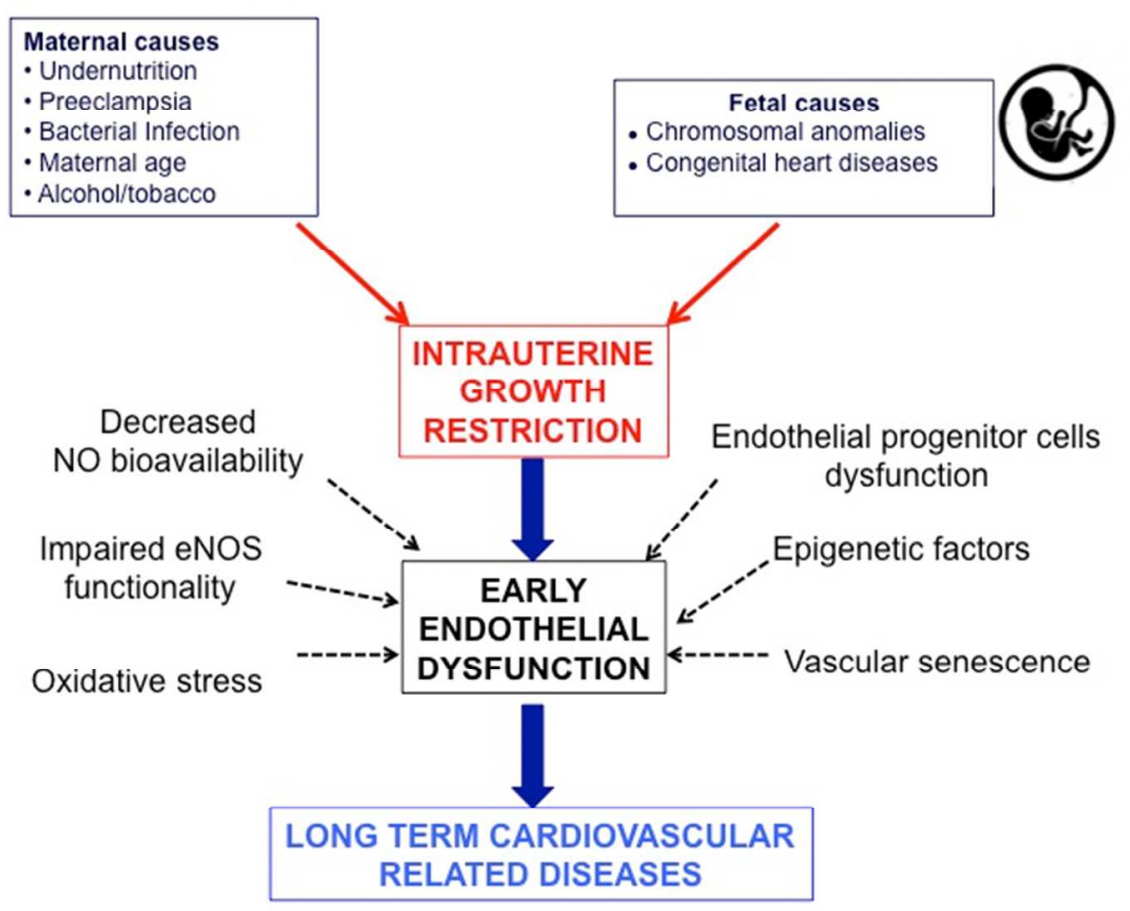

Association between intrauterine growth restriction, early endothelial dysfunction and long-term cardiovascular related diseases

Decreased NO synthesis and bio $254 \times 190 \mathrm{~mm}(72 \times 72 \mathrm{DPI})$ 
-Endothelial dysfunction in individuals born after fetal growth restriction: cardiovascular and renal consequences and preventive approaches

\section{Yzydorczyk ${ }^{1 \bullet}$, JB Armengaud ${ }^{1^{*}}$, AC Peyter $^{2 *}$, H Chehade $^{1,3}$, F Cachat $^{3}$, C Juvet $^{1,3}$, B Siddeek $^{1}$, S Simoncini $^{4}$, F Sabatier ${ }^{4}$, F Dignat-George ${ }^{4}$, D Mitanchez $^{5}$, U Simeoni $^{1}$}

1 Department Woman-Mother-Child, Clinic of Pediatrics, DOHaD Laboratory, Centre Hospitalier Universitaire Vaudois and University of Lausanne, Switzerland;

${ }^{2}$ Department Woman-Mother-Child, Clinic of Neonatology, Neonatal Research Laboratory, Centre Hospitalier Universitaire Vaudois and University of Lausanne, Switzerland;

${ }^{3}$ Department Woman-Mother-Child, Clinic of Pediatrics, Division of Pediatric Nephrology, Centre Hospitalier Universitaire Vaudois and University of Lausanne, Switzerland;

${ }^{4}$ VRCM, Aix Marseille University, UMR S INSERM 1076, Faculté de Pharmacie, Marseille, France;

${ }^{5}$ Division of Neonatology, Department of Perinatology, APHP, Armand Trousseau Hospital, 75012 Paris \& Sorbonne Universities UPMC University Paris 06, Paris, France.

* These authors contributed equally to this work

- Corresponding author: Catherine.yzydorczyk@chuv.ch

Short title: Endothelial dysfunction following IUGR 
Individuals born after intrauterine growth restriction (IUGR) have an increased risk of perinatal morbidity/mortality, and those who survive face long-term consequences such as cardiovascular-related diseases, including systemic hypertension, atherosclerosis, coronary heart disease, and chronic kidney disease.

In addition to the demonstrated long-term effects of decreased nephron endowment and hyperactivity of the hypothalamic-pituitary-adrenal axis, individuals born after IUGR also exhibit early alterations in vascular structure and function, which have been identified as key factors of the development of cardiovascular-related diseases. The endothelium plays a major role in maintaining vascular function and homeostasis. Therefore, it is not surprising that impaired endothelial function can lead to the long-term development of vascular-related diseases. Endothelial dysfunction, particularly impaired endothelium-dependent vasodilation and vascular remodeling, involves decreased nitric oxide (NO) bioavailability, impaired endothelial NO synthase functionality, increased oxidative stress, endothelial progenitor cell dysfunction and accelerated vascular senescence. Preventive approaches such as breastfeeding, supplementation with folate, vitamins, antioxidants, L-citrulline, L-arginine and treatment with NO modulators represent promising strategies for improving endothelial function, mitigating long-term outcomes and possibly preventing IUGR of vascular origin. Moreover, the identification of early biomarkers of endothelial dysfunction, especially epigenetic biomarkers, could allow early screening and follow-up of individuals at risk of developing cardiovascular and renal diseases, thus contributing to the development of preventive and therapeutic strategies to avert the long-term effects of endothelial dysfunction in infants born after IUGR.

$\underline{\text { Key words: }}$ intrauterine growth restriction, endothelial dysfunction, developmental programming, $\mathrm{DOHaD}$, hypertension, cardiovascular disease, chronic renal disease. 
In this systematic review, we have exploredWe performed an extensive and critical review of the literature in order to explore the manifestations of endothelial dysfunction in individuals born after intrauterine growth restriction (IUGR) and examined which mechanisms may be incriminated and which preventive strategies could represent promising approaches. We used the following terms in the Pubmed library (MESH terms and free text, without time or language limits: (Prenatal Exposure Delayed Effects OR Late Effect, Prenatal Exposure OR Nutrition Disorders/Physiopathology OR Fetal Growth restriction) AND (Cardiovascular Diseases/Etiology OR Hypertension/Etiology) AND (Impaired Endothelial Function OR Oxidative Stress/Senescence). We included the most significant human and animal studies. From the references of the retrieved papers, additional articles were selected for this review. One author (CY) read the titles and abstracts and selected the articles to be included.

\section{I- Intrauterine growth restriction: definition and risk factors}

\section{I-a-Definition}

Intrauterine growth restriction (IUGR) is defined as the inability of the fetus to reach its genetically determined potential size. ${ }^{1,2}$ IUGR affects approximately $5-15 \%$ of all pregnancies in the United States and Europe, but its incidence varies widely and appears to be higher in low income countries (it affects 30-55\% of infants born in South Central Asia, 15$25 \%$ in Africa, and $10-20 \%$ in Latin America). ${ }^{3}$ Using the ReCoDe classification system, IUGR has been considered the most commonly identified factor in stillborn infants. ${ }^{4}$ Therefore, the management of growth-restricted fetuses in terms of choosing the optimal delivery time is important to decrease perinatal mortality/morbidity. Fetal growth restriction is difficult to detect because of the lack of international consensus on the definition and diagnostic criteria for IUGR. In clinical practice, growth-restricted fetuses are usually identified based on birth weight $\left(<10^{\text {th }}\right.$ percentile $)$. However, some propose that using $<3^{\text {rd }}$ or 
$<5^{\text {th }}$ percentile as the criterion would better identify individuals at a higher risk of adverse perinatal outcomes. ${ }^{5}$ Moreover, low estimated fetal weight $\left(<10^{\text {th }}\right.$ percentile), certain ultrasound findings of fetal growth (abdominal circumference $<2.5^{\text {th }}$ percentile) and altered Doppler velocimetry indices, such as abnormal umbilical artery waveforms or decreased pulsatility of the middle cerebral artery, that suggest abnormalities in fetal circulation are also indicative of IUGR. ${ }^{6}$ To better understand abnormal fetal growth and to detect IUGR, specific computerized fetal growth charts that consider fetal gender and maternal characteristics such as height, weight, parity and ethnic origin were developed by Gardosi et al. ${ }^{7}$ Pathological factors, including maternal systemic hypertension (HTN), diabetes, tobacco use and preterm delivery, were excluded from the model to predict the optimum weight that a baby can reach at term during a normal pregnancy. Because it is necessary to distinguish between growthrestricted and constitutive "small for gestational age" fetuses, longitudinal assessments of fetal growth trajectories are required to identify pathological fetal growth restriction, even if the altered growth trajectory is above the $10^{\text {th }}$ centile limit. ${ }^{8}$ More recently, universal standards of fetal growth have been proposed by the Intergrowth project. ${ }^{9,10}$

\section{I-b-Risk factors for intrauterine growth restriction}

IUGR can result from a multitude of risk factors, including maternal and fetal causes. Several maternal factors have been identified, such as undernutrition, which notably affects the activity and/or expression of placental nutrient and ion transporters; $;{ }^{11-13}$ chronic diseases, such as preeclampsia; ${ }^{14}$ bacterial infection during pregnancy, particularly with Escherichia coli, group B Streptococcus, Listeria monocytogenes, Treponema pallidum, or Trichomonas vaginalis; parasitic diseases, such as malaria; viral infection (for example, human cytomegalovirus or rubella virus); ${ }^{15,16}$ young age (adolescent pregnancy); and alcohol and/or tobacco consumption. ${ }^{17}$ Additionally, pregnancy-induced HTN, preeclampsia and placental insufficiency are known causes of asymmetrical IUGR (defined as restriction of weight 
followed by length). ${ }^{18}$ Among the fetal causes, chromosomal anomalies (including trisomy of chromosome 13, 18, or 21; tri- and polyploidies; Mulibrey nanism; 3-M, Bloom, and Turner syndromes; and Majewski osteodysplastic primordial dwarfism (MOPD) type II) ${ }^{19}$ and fetal structural defects, such as congenital heart disease, ${ }^{20}$ result in symmetrical IUGR (defined as global growth restriction), which is usually more severe than asymmetrical IUGR. ${ }^{18}$

Along with maternal causes, paternal health has also been identified as a possible contributor to IUGR. Insulin resistance, smoking habits, elevated blood pressure, endothelial dysfunction, upper body fat distribution and an atherogenic lipid profile have all been suggested as potential paternally determined factors that correlate with IUGR. ${ }^{21}$ These factors presumably impact fetal growth through epigenetic processes. $^{22}$

IUGR is now considered a critical public health issue because of its high perinatal mortality rate and long-term consequences. As numerous epidemiological studies have reported, infants born with fetal growth restriction have an increased risk of developing non-communicable chronic diseases, notably cardiovascular (e.g., systemic HTN and coronary artery disease) and renal (chronic kidney disease, CKD) diseases, later in life. These observations are consistent with the concept of Developmental Origins of Health and Disease, which suggests that conditions affecting specific sensitive developmental periods, from conception throughout pregnancy to early infancy, "program" tissue/organ structure and function throughout life in a process known as developmental plasticity that is adapted to short-term, prevailing environmental conditions but possibly not to the further life course. The underlying mechanisms are not clearly defined. In parallel with the long-term effects of decreased nephron numbers and hyperactivity of the hypothalamic-pituitary-adrenal axis in these infants, endothelial dysfunction may also contribute to the development of certain chronic diseases in adulthood. 


\section{II- Endothelium dysfunction in individuals born with intrauterine growth restriction}

\section{II-a The endothelium: a major role in vascular homeostasis}

The endothelium plays a major role in maintaining vascular homeostasis and is one of the largest organs in the human body, consisting of more than $10^{14}$ cells lining the vascular network. It is intimately involved in the balance between vasodilation and vasoconstriction and between thrombogenesis and fibrinolysis, the inhibition and promotion of smooth muscle cell proliferation and migration, and the prevention and stimulation of platelet adhesion and aggregation. ${ }^{23}$ All these functions are mediated by the release of numerous vasoactive factors, such as nitric oxide (NO) and endothelin. In this respect, the maintenance of endothelial structural and functional integrity is essential for vascular homeostasis; therefore, impaired endothelial function can lead to the development of vascular-related diseases.

Convincing evidence suggests that endothelial dysfunction during early childhood and persisting to adulthood in individuals born with IUGR is a key event in the development of HTN, atherosclerosis, coronary heart disease, and CKD later in life. In these individuals, endothelial dysfunction primarily manifests as impaired endothelium-dependent vasodilation and vascular remodeling.

\section{II-b-Impaired endothelium-dependent vasodilation in individuals born with fetal growth} restriction

Endothelium-dependent vasodilation can be clinically evaluated using flow-mediated brachial artery tests, plethysmography, or skin perfusion in response to acetylcholine using the laser

Doppler technique. ${ }^{24-26}$ Impaired endothelium-dependent vasodilation has been described in children (9-11 years) $)^{27-29}$ and young adults (20-28 years) born with fetal growth restriction ${ }^{30}$ and in umbilical and placental vessels derived from growth-restricted fetuses. ${ }^{31}$

An association between fetal growth restriction and impaired NO-dependent vasorelaxation 
has also been observed in several animal models, mainly in rats, mice and sheep. IUGR can be induced in rats by exposure to a maternal low-protein diet (LPD, containing $9 \%$ casein) ${ }^{32}$ or restricted diet (50\% of normal intake) and in sheep by single in utero umbilical artery ligation (at 105-110 days gestation); these diets and procedures result in low birth weight (LBW) offspring and lead to impaired endothelium-dependent vasodilation in small arteries, ${ }^{33,34}$ the aorta $^{35}$ and coronary arteries $^{36}$ in adulthood.

The effects on endothelium-dependent vasodilation are more pronounced in males, while females seem to be protected by the NO-dependent vasoprotective role of estrogens. However, impaired endothelium-dependent vasodilation has been observed in female Wistar rats born with IUGR stemming from maternal undernutrition. ${ }^{35}$ As suggested by Borwick et al., fetal undernutrition may decrease estrogen synthesis, ultimately leading to ovarian damage. ${ }^{37}$ Interestingly, estrogen-mediated vasoprotective activity has been reported in humans; specifically, postmenopausal women taking conjugated equine estrogens $(0.625 \mathrm{mg}$ for 28 days) showed improved vascular NO-dependent relaxation of the brachial artery. ${ }^{38}$

\section{II-c-Vascular remodeling in individuals born with fetal growth restriction}

\section{Endothelial activation}

Endothelial dysfunction is associated with leukocyte infiltration and the adhesion of monocytes, macrophages and low-density lipoprotein (LDL), which is oxidized to OxLDL in the arterial wall. This leads to foam cell formation and initiates atherogenesis. In addition, monocytes and macrophages secrete higher levels of cytokines and pro-inflammatory proteins such as interleukin-6 (IL-6), tumor necrosis factor-alpha and C-reactive protein (CRP). ${ }^{39}$ These events create a vicious cycle: neutrophils and macrophages produce higher levels of IL6 in response to inflammation, which in turn increases CRP production in the liver. CRP decreases NO availability and increases endothelin-1 production, thereby contributing to 
impaired endothelium-dependent vasodilation and leading to irreversible vascular damage. $^{39,40}$ Elevated levels of pro-inflammatory markers and endothelial activators are characteristic of middle-aged adults (45-64 years) born with LBW, indicating that endothelial dysfunction is patent in these individuals. ${ }^{41}$

\section{Vascular structural changes}

Histopathological analyses showed that the first atherosclerotic lesions begin to develop in the abdominal aorta. ${ }^{42}$ Increased arterial wall thickness, measured using non-invasive assessments of the intima-media or carotid intima-media thickness, has been observed in newborns ${ }^{43-46}$ and young children ${ }^{47,48}$ and persists in adults (27-30 years) born after IUGR, and it is particularly apparent in those with exaggerated postnatal growth. ${ }^{49}$

\section{Hypoxia and oxidative stress in vascular remodeling}

Hypoxia and oxidative stress have been implicated in vascular remodeling.

Placental insufficiency is related to reduced nutrient and oxygen delivery to the fetus, contributing to the development of fetal growth restriction. Several maternal factors, such as living at a high altitude, HTN, anemia, pulmonary disease, preeclampsia, drugs and/or tobacco consumption can contribute to fetal hypoxia ${ }^{50}$ which can induce IUGR, LBW ${ }^{51}$ and increase the risk of CVD later in life. ${ }^{52,53}$ During fetal development, hypoxia plays a crucial role by driving vasculogenesis/angiogenesis, hematopoeisis, and chondrogenesis. ${ }^{54}$ However, prolonged in utero hypoxia can lead to detrimental effects. In growth-restricted fetuses, circulating levels of angiopoietin-2, an angiogenic factor up-regulated by hypoxia, were increased at postnatal day 4 compared with appropriate-for-gestational age infants, thus contributing to postnatal vascular remodeling. ${ }^{55}$

Oxidative stress can be defined by decreased antioxidant defenses and increased reactive oxygen species (ROS) production. Under physiological conditions, ROS play an important 
role as a regulator of vascular functions such as migration, growth, smooth muscle and endothelial cell survival and the secretion of extracellular matrix proteins. However, uncontrolled ROS production can contribute to vascular diseases. ${ }^{56,57}$ ROS have been implicated in the hypertrophy and hyperplasia of vascular smooth muscle cells. In vascular cells (endothelial cells and vascular smooth muscle cells, adventitial fibroblasts), the main enzyme responsible for ROS production is NADPH oxidase. ${ }^{58}$

Angiotensin II (AngII), via Angiotensin type 1 receptor (AT1R), has been implicated in increasing superoxide anion levels followed by increased hydrogen peroxide production, which induces long-term outcomes of AngII, such as hypertrophy and hyperplasia of vascular smooth muscle cells. ${ }^{59,60}$ The flavoprotein inhibitor DPI $^{60}$ and catalase overexpression ${ }^{61}$ inhibits these vascular defects. In a rat model of IUGR induced by maternal LPD associated with adult HTN, we observed increased ex vivo vasoreactivity of the carotid rings to AngII, mediated by AT1R, which was normalized by diphenyleneiodonium (DPI) and apocynin (NADPH oxidase inhibitor) pre-incubation. ${ }^{32}$

The regulation of extracellular matrix proteins such as collagen and elastin can be modulated by ROS. Elastinolysis and collagenolysis play crucial roles in arterial remodeling and vascular diseases. ${ }^{62}$ Metalloproteinases (MMPs) and their related TIMPs are enzymes secreted by macrophages and vascular smooth muscle cells. MMP-2 and MMP-9 cleave gelatin, collagen and elastin and have been associated with vascular diseases. ${ }^{63}$ ROS have been demonstrated to activate MMPs. ${ }^{64}$ Increased circulating levels of MMP-2 and MMP-9 and increased MMP-2/TIMP-2 and MMP-9/TIMP-2 ratios have been observed in children who were small for gestational age and are positively correlated with systolic blood pressure and vascular function. ${ }^{65}$ In a developmental programing animal model of HTA induced by neonatal oxygen exposure, we observed increased aortic MMP-2 and TIMP-1 and reduced TIMP-2 staining as early as 4 weeks of age, indicating a shift in the balance towards 
degradation of the extracellular matrix and increased collagen deposition. ${ }^{66}$ These data suggest that early changes could contribute to the onset of the elevated blood pressure and arterial stiffness observed at adulthood in this animal model. ${ }^{67,68}$

\section{III- Mechanisms involved in endothelial dysfunction in individuals born with fetal growth restriction}

\section{III-a- Impaired NO bioavailability}

The endothelium-mediated release of NO is widely accepted as the key determinant of endothelial function, and reduced NO bioavailability has been linked to most serious vascular pathologies. ${ }^{69}$ In particular, the loss of NO production contributes to impaired endotheliumdependent vasodilation and to endothelium activation by improving the recruitment of proinflammatory cytokines, such as VCAM-1 and ICAM-1, and the infiltration of leukocytes into the vessel wall. ${ }^{70-72}$ In normal pregnancies, NO synthesis is up-regulated, as reflected by increased nitrite/nitrate concentrations in maternal and fetal circulation, thus mediating maternal cardiovascular adaptations and the low systemic and umbilical vascular resistance in the fetus. In pregnancies complicated by IUGR, research findings are inconsistent. Some have displayed a decrease in NO metabolite concentrations in maternal and/or fetal serum, reflecting reduced NO synthesis compared with controls. ${ }^{73,74}$ Other have found higher nitrite/nitrate concentrations in umbilical venous plasma $^{55}$ or an increase in eNOS protein staining in placental vessels compared with normal pregnancies, suggesting that increased NO production could be a compensatory response to improve blood flow in the placenta. ${ }^{75,76}$

Decreased NO synthesis, evaluated in terms of nitrate/nitrite production, was observed in animal models of IUGR induced by a reduction in utero-placental perfusion pressure ${ }^{77}$ or maternal $\operatorname{LPD}^{78,79}$ and in a rat model of developmental programming of HTN induced by exposing pregnant rats to androgens. ${ }^{80}$ 
Reduced NO bioavailability may result either from altered NO synthesis or from NO scavenging by other molecules, such as ROS.

\section{III-b-Impaired eNOS functionality}

Under physiological conditions, NO is synthetized in the vasculature by endothelial nitric oxide synthase (eNOS), using L-arginine (L-Arg) as a substrate and tetrahydrobiopterin (BH4) as a cofactor. There are contradictory data on eNOS expression in individuals born after IUGR. In humans, independent studies have indicated that eNOS expression is increased in the umbilical arteries of babies born after fetal growth restriction, suggesting that activated NO synthesis may be a compensatory mechanism to improve placental blood flow. ${ }^{31,81}$ However, these results are controversial because they could not be replicated. ${ }^{82}$ Moreover, differences in eNOS expression have been observed in human endothelial cells isolated from the umbilical arteries (HUAEC) or veins (HUVEC) of IUGR newborns. eNOS expression is increased in IUGR-HUAEC but decreased in IUGR-HUVEC. These differences may be explained by the type of vessel (artery $v s$. vein) or could be the consequence of altered blood flow and oxygen levels in pregnancies complicated by IUGR. ${ }^{18}$

In animal studies, eNOS expression varies depending on the animal model of IUGR used. In Dahl-S rats fed a high-salt diet to induce fetal growth restriction, the placental eNOS mRNA expression level was significantly increased compared with controls. ${ }^{83}$ In an animal model of IUGR induced by placental insufficiency using hyperthermic exposure, placental and umbilical artery eNOS protein in the placenta was decreased at mid-gestation but increased near term. ${ }^{84}$

However, eNOS expression and activity and the gender effect seem particularly sensitive to undernutrition. In fact, decreased eNOS expression and/or activity have been reported in animal models of IUGR induced by intrauterine undernourishment. ${ }^{35}$ In a rat IUGR model 
induced by intrauterine undernourishment, ${ }^{35}$ eNOS expression was decreased only in males, whereas eNOS activity was decreased in both males and females. This reduction in eNOS activity in females, which is probably the consequence of decreased estrogen levels, could explain the impaired endothelium-dependent vasodilation observed in this animal model. ${ }^{35}$ The modulation of eNOS activity by estrogens has been confirmed in vitro. Long-term estrogen treatment of cultured human and bovine endothelial cells up-regulates eNOS activity. $^{85}$

\section{III-c-Upregulation of the arginase pathway}

Arginases produce urea and ornithine, using L-Arg as a substrate. By competing with eNOS for the bioavailability of L-Arg, arginases can indirectly contribute the reduction of NO synthesis by eNOS. Accordingly, arginase up-regulation is an important factor that drives endothelial dysfunction. Increased arginase-2 expression was observed in human umbilical endothelium from IUGR fetuses. ${ }^{86}$ Pre-incubation with S-(2-boronoethyl)-L-cysteine (BEC), an arginase inhibitor, improved ex vivo endothelium-dependent relaxation in umbilical and placental vessels from babies born after fetal growth restriction ${ }^{31}$ and in aortic rings from a rat IUGR model induced by maternal LPD (personal unpublished data). These data suggest that arginase activity was increased in these vessels.

\section{III-d- Increased ADMA levels}

Asymmetric dimethylarginine (ADMA), an endogenous NO synthase inhibitor, is also considered an early marker and mediator of endothelial dysfunction. ADMA acts as a competitor of L-Arg, thereby inhibiting NO synthesis by eNOS. However, the observations in human studies are controversial. In pregnancies complicated by IUGR, ADMA levels in maternal serum were found to be either increased ${ }^{87,88}$ or decreased compared with those in 
normal gestations during the first (11-14 weeks), second (20-24 weeks) and third trimesters (28-35 weeks) ${ }^{89}$ Estrogen therapy could improve endothelial function by reducing ADMA levels. Clinical data revealed that estrogen therapy, chiefly the oral form, decreased plasma ADMA concentrations and therefore improved NO production in healthy postmenopausal women. $^{90,91}$

In animal models of atherosclerosis (rabbits and monkeys), endothelial dysfunction was associated with increased ADMA levels. ${ }^{92,93}$ To the best of our knowledge, ADMA levels have not been assessed in animal models of IUGR.

\section{III-e-Oxidative stress}

Oxidative stress plays an important role in endothelial dysfunction. ROS, particularly the superoxide anion $\left(\mathrm{O}_{2}^{-}\right)$, play a central role in vascular physiology, and their overproduction is especially relevant to vascular pathologies. ${ }^{94}$ In IUGR placentae, markers of oxidative stress, such as 8-hydroxy-2'-deoxyguanosine, redox factor-1, ${ }^{95,96}$ malondialdehyde and oxidized LDL, are increased in venous cord blood..$^{97}$ Therefore, it has been suggested that oxidative stress is involved in both the short- and long-term modulation of endothelial function in individuals born after IUGR. ${ }^{98}$ Oxidative stress affects the NO pathway by influencing NO synthesis and bioavailability. NO rapidly reacts with $\mathrm{O}_{2}^{-\cdot}$ to form peroxynitrite, a highly reactive and toxic species, which reduces endothelium-dependent relaxation ${ }^{99}$ and accelerates the development of pre-atherosclerotic lesions. ${ }^{100}$

As mentioned above, L-Arg and $\mathrm{BH}_{4}$ are crucial for $\mathrm{NO}$ production. A deficit in substrate and/or cofactor leads to enzymatic uncoupling, which causes eNOS to produce $\mathrm{O}_{2}^{-}{ }^{-}$rather than $\mathrm{NO},{ }^{101}$ thus contributing to endothelial dysfunction and impaired endothelium-dependent vasodilation. ${ }^{102,103}$ Decreased BH4 bioavailability can contribute to eNOS uncoupling. Regardless of whether the BH4 level is sufficient, the oxidation of L-Arg is coupled with the 
reduction of oxygen molecules to form L-citrulline and NO. However, BH4 bioavailability can be decreased through reduced production, ${ }^{104}$ increased oxidation ${ }^{105}$ or impaired recycling of the oxidized form (BH2) ${ }^{106}$ therefore leading to eNOS uncoupling.

Increased $\mathrm{O}_{2}^{-}$production up-regulates ADMA levels, thus worsening endothelial dysfunction. ${ }^{107}$ In humans, impaired NO-dependent vasodilation in placental vessels from IUGR pregnancies is coupled with a higher sensitivity to oxidative stress. ${ }^{108}$

Increased $\mathrm{O}_{2}^{-}$production mediated by NADPH oxidase and eNOS uncoupling was associated with defective endothelial function in a rat model of HTN induced by deoxycorticosterone and saline treatment ${ }^{109}$ and in a rat model of IUGR induced by maternal diet restriction $(50 \%$ of ad libitum intake throughout gestation) or LPD (9\% casein). ${ }^{32,110}$

\section{III-f-Endothelial progenitor cell dysfunction}

Endothelial dysfunction is characterized by impaired vasculogenesis and decreased repair capacity, functions that are mediated by circulating endothelial progenitor cells (EPCs). These cells are bone marrow-derived stem cells that can differentiate into mature endothelial cells, thus contributing to postnatal vasculogenesis and endothelial repair at damage sites. ${ }^{111}$ EPC subsets are differentiated by their phenotype and functional properties. The myeloid subset represents early EPCs, called colony-forming unit-endothelial cells, that appear early in cultures and display endothelial markers but do not form vessels in vivo. ${ }^{12,113}$ Endothelial colony-forming cells (ECFCs), the true angioblasts, appear later and display properties such as proliferation, auto-renewal, migration, and differentiation; additionally, they can support vascular growth and neovascularization. Both loss and impaired function of EPCs have been identified as markers of endothelial dysfunction, as described by Hill et al. ${ }^{114}$ In adult men with different degrees of cardiovascular risk but without a history of cardiovascular disease, levels of circulating EPCs have been identified as a surrogate biological marker of vascular 
function and cumulative cardiovascular risk. ${ }^{114}$ In pregnancy-related complications, most notably IUGR, aberrant vasculature and abnormal endothelial function were found on both the maternal and fetal sides of the placenta, and it is believed that altered fetal circulating EPCs contribute to these complications. ${ }^{115} \mathrm{We}$ and others have evaluated ECFCs isolated from LBW newborns and observed altered angiogenic properties in vitro, as evidenced by decreased numbers of colonies and sprouts, ${ }^{116}$ and in vivo, as shown by a reduction in the number of perfused vessels. ${ }^{117}$ Moreover, an imbalance between angiogenic and antiangiogenic factors was noted. ${ }^{117,118}$ These data suggest that the impairment of early angiogenic properties (structural and functional) could predispose LBW infants to endothelial dysfunction later in life.

\section{III-g-Vascular senescence}

Vascular senescence can contribute to endothelial dysfunction. ${ }^{119}$ It is characterized by a state of irreversible (replicative senescence) or reversible (stress-induced senescence) growth arrest, the expression of negative cell cycle regulators (such as p53 and p16) and increased senescence-related $\beta$-galactosidase staining. ${ }^{120}$ Senescent endothelial cells have a decreased ability to form new vascular structures; therefore, they contribute to impaired endothelial function. Sirtuins (SIRTs), particularly SIRT1, belong to a family of proteins involved in the regulation of many cellular processes, including senescence. SIRT1 is highly expressed in endothelial cells, wherein it regulates numerous functions, such as NOS expression and cellular senescence. ${ }^{121}$ The depletion of SIRT1 expression in endothelial cells led to endothelial dysfunction and premature senescence in several models of cardiovascular diseases, whereas overexpression of SIRT1 protected endothelial cells from senescenceassociated morphological and molecular changes. ${ }^{122}$ ECFCs from LBW newborns exhibit stress-induced vascular senescence characterized by growth arrest, increased $\beta$-galactosidase 
activity, and $\mathrm{p} 16^{\mathrm{INK} 4 \mathrm{a}}$ expression, all of which are mediated by decreased SIRT1 levels. ${ }^{123}$ Therefore, stress-induced vascular senescence is coincident with impaired angiogenic properties and could participate in the endothelial dysfunction observed later in life in individuals born after IUGR.

\section{IV- Relationship between intrauterine growth restriction and cardiovascular and renal outcomes later in life}

Early endothelial dysfunction observed in individuals born after IUGR could persist for the long term and lead to the onset of cardiovascular-related diseases.

\section{IV-a- Systemic hypertension}

Epidemiological studies have highlighted an inverse correlation between LBW and increased blood pressure in infancy, ${ }^{124}$ adolescence, ${ }^{125,126}$ young adulthood ${ }^{127,128}$ and adulthood. ${ }^{129-132}$ Some authors have questioned these results, suggesting that the data were inappropriately adjusted for confounding factors ${ }^{133}$ that could potentially damage kidneys and/or vascular endothelial cells early in life (e.g., nephrotoxic drugs or umbilical catheter placement). Recent data have indicated that the risk of HTN is not only linked to birth weight but is also amplified by postnatal overfeeding, leading to exaggerated catch-up growth. ${ }^{134}$

Several animal models have shown that IUGR induced by ligation of the bilateral uterine vessels, prenatal exposure to hypoxia $\left(11.5 \%\right.$ vs. $\left.21 \% \mathrm{O}_{2}\right)$ or glucocorticoids, maternal global undernutrition, caloric restriction or LPD during gestation induces HTN in adulthood ${ }^{32,135-141}$ and is often associated with vascular dysfunction. ${ }^{32,142,143}$ However, it is not well established whether HTN precedes endothelial dysfunction. Some clinical investigations have suggested that endothelial dysfunction is a primary defect in essential HTN that appears before the increase in blood pressure, ${ }^{144}$ but other observations have hinted that endothelial dysfunction is a consequence of elevated blood pressure. Different animal models of HTN induced by 
aortic coarctation (rabbits), ${ }^{145}$ a high-salt diet (rats) ${ }^{146}$ or neonatal hyperoxia (rats) ${ }^{67}$ showed selective impairment of endothelium-dependent vasodilation secondary to increased blood pressure. However, in an animal model of IUGR caused by maternal LPD during gestation, impaired endothelium-dependent relaxation preceded the onset of increased blood pressure (personal unpublished data).

\section{IV-b-Coronary heart disease}

Impaired endothelial function plays a major role in the development and progression of atherosclerosis, ${ }^{147,148}$ which ultimately leads to coronary heart disease. Many studies have proposed a relationship between birth weight and coronary heart disease: some showed an inverse relationship between LBW and increased risk of coronary heart disease, ${ }^{149-151}$ while others found no significant correlation $^{152}$ or a positive correlation only in males. ${ }^{153}$ Interestingly, the risk of coronary heart disease decreases with increasing birth weight. In fact, a $1-\mathrm{kg}$ increase in birth weight was associated with a 10-20\% decreased risk of coronary heart disease later in life. ${ }^{151}$

\section{IV-c-Chronic kidney disease}

The role of vascular components in the renal system is of particular significance because the kidneys receive approximately $20-25 \%$ of the total cardiac output. However, the contribution of the endothelial compartment to kidney development has been the subject of many hypotheses. Previous experiments showed that a significant proportion of the renal endothelium is derived from a resident precursor, the metanephric mesenchyme. ${ }^{154}$ Sprouting angiogenesis from the major renal vessels plays a significant role in forming the kidney endothelium, thus giving rise to most of the renal vessels and glomerular capillaries. ${ }^{155}$ Endothelial dysfunction is involved in the development and progression of CKD. ${ }^{156}$ Patients with CKD display microalbuminuria, which is thought to reflect endothelial damage in the 
capillary system of the renal medulla and increased endothelial permeability. ${ }^{156-159}$ Capillary damage is characterized by increased plasma concentrations of endothelium-derived proteins, such as von Willebrand factor, tissue-type plasminogen activator and urokinase-type plasminogen activator, and increased concentrations of markers of endothelial cell injury, such as soluble thrombomodulin. Decreased endothelium-dependent vasodilation occurs in end-stage kidney disease. ${ }^{160}$ Several epidemiological and experimental studies have shown that intrauterine insults are associated with the development of CKD. In humans, birth weight is positively correlated with glomerular number and inversely correlated with glomerular volume. ${ }^{161}$ In a meta-analysis of 18 studies, infants born after fetal growth restriction appeared to have a significantly higher risk of albuminuria (OR, 1.81; 95\% CI, 1.19 to 2.77), end-stage renal disease (OR, 1.58; $95 \% \mathrm{CI}, 1.33$ to 1.88$)$, or a low estimated glomerular filtration rate $(\mathrm{OR}, 1.79 ; 95 \% \mathrm{CI}, 1.31$ to 2.45$) .{ }^{162}$ Similar to HTN, the impairment of glomerular and tubular function secondary to IUGR is further amplified by environmental insults, such as drug exposure during the neonatal period ${ }^{163}$ or overweight in adulthood. ${ }^{164}$

Several animal models have enabled the identification of mechanisms involved in the development of renal dysfunction later in life. Rat models of IUGR induced by exposure to maternal LPD followed by early postnatal overnutrition during the lactation period or not according litter size reduction or increased protein intake to induce accelerated postnatal growth displayed alterations in renal structural development and a risk of chronic renal failure later in life. ${ }^{165-169}$ Decreased glomerular number potentially leads to reduced filtration capacity, reduced salt and water retention and the subsequent development of HTN. Furthermore, early loss of nephron numbers/mass may result in a state of hyperfiltration in the remaining nephrons, which will lead to focal segmental glomerulosclerosis and further loss of glomeruli, thus initiating a vicious circle. ${ }^{170}$ However, it is not clear whether endothelial dysfunction precedes or is a consequence of CKD. Regarding the impact of postnatal nutrition 
on renal maturation, rodent models could likely be more affected than humans because nephrogenesis is completed at approximately 36 weeks of gestation in humans, whereas in rats, this process is completed during postnatal life (between 7 to 10 days of life).

\section{V-Potential preventive approaches}

Several interventions have been identified to potentially prevent IUGR, improve endothelial function and thus antagonize the development of detrimental cardiovascular issues.

\section{V-a-Breastfeeding}

Breast milk could represent a promising approach, and the easiest one, for improving endothelial function in offspring. In fact, breastfeeding, as opposed to feeding with commercial infant formulas, is one of the best approaches for fighting neonatal oxidative stress because of breast milk's ability to "trap" free radicals. Breast milk contains enzymatic and non-enzymatic components such as superoxide dismutase, glutathione peroxidase, vitamins (A, C, and E), alpha-carotene, lactoferrin, and trace amounts of iron. Breastfeeding could improve endothelial function, primarily due to the presence of lactoferrin, an ironbinding glycoprotein with antioxidant, anti-inflammatory, pro-angiogenic and NO-dependent vasodilator properties. Daily treatment with lactoferrin after unilateral hind limb surgeryinduced ischemia in $\mathrm{C} 57 \mathrm{BL} / 6 \mathrm{~J}$ mice promoted angiogenesis, activated endothelial function via an NO-dependent mechanism ${ }^{171}$ and protected HUVECs against hydrogen peroxideinduced oxidative stress. ${ }^{172}$

\section{V-b-Folate supplementation}

Epidemiological studies have shown that folate deficiency is associated with increased 
cardiovascular risk. ${ }^{173,174}$ Because of the homocysteine-lowering and antioxidant effects of folate and its ability to modulate eNOS activity and cofactor availability, folic acid supplementation could improve vascular endothelial structure and function.

In a study including patients with coronary heart disease, the circulating form of folic acid, 5methyltetrahydrofolate, increased NO-dependent vasodilation, reduced vascular superoxide production, and improved enzymatic coupling of eNOS by increasing the availability of tetrahydrobiopterin. ${ }^{175}$ Folate supplementation in patients with acute ischemic stroke ${ }^{176}$ or $\mathrm{HTN}^{177}$ decreased plasma ADMA levels, suggesting that folate intake may also be beneficial in these contexts. Moreover, folic acid supplementation during pregnancy increased the birth weight of newborns. ${ }^{178}$

Folate deficiency in $\mathrm{ApoE}^{-/-}$mice was associated with the development of atherosclerotic lesions, which can be prevented by folate supplementation. ${ }^{179}$ Moreover, folate supplementation of a maternal LPD diet prevented the development of increased blood pressure and restored endothelium-dependent vasodilation and eNOS mRNA expression ${ }^{180}$ and enzyme activity. ${ }^{181}$

\section{V-c-Vitamin supplementation}

Studies of animal models of IUGR and developmental programming of CVD have demonstrated that maternal diet supplementation with vitamins $\mathrm{C}$ and $\mathrm{E}$ can prevent adverse perinatal and long-term outcomes. In an animal model of IUGR induced by high maternal cholesterol levels during the early stages of gestation, maternal dietary supplementation with vitamin $\mathrm{E}$ was found to prevent growth restriction in fetuses. Vitamin $\mathrm{E}$ has been shown to regulate molecular pathways controlling cell proliferation and viability ${ }^{182}$ and to increase the release of vasodilator prostanoids from human aortic endothelial cells ${ }^{183}$ and human umbilical vein endothelial cells, ${ }^{184}$ thus improving placenta-fetal blood flow and thereby increasing 
nutrient delivery to the fetus.

Vitamin C was found to protect chick embryos against the developmental toxicity of ethanol. Indeed, concomitant injection of vitamin $\mathrm{C}$ and ethanol in chick embryos prevented the decreased survival, growth retardation and malformations induced by ethanol alone. ${ }^{185}$

However, in human studies, these treatments have failed to show clear benefits in terms of birth weight and associated long-term diseases. ${ }^{186-189}$ A possible explanation is the potential confounding effects of maternal endogenous antioxidant defenses and redox status and maternal vitamin intake resulting from diversified nutrition. Differences in vitamin metabolism between humans and animals could also be involved in the discrepancy between human and animal studies.

\section{V-d-Antioxidant therapy}

Supplementation with resveratrol, a polyphenolic molecule found at high concentrations in red grapes, berries and peanuts, has been identified as a potential therapeutic strategy for the treatment of cardiovascular diseases, primarily due to its antioxidant properties and ability to modulate the NO signaling pathway. In spontaneously hypertensive rats, maternal dietary supplementation with resveratrol during the perinatal period prevented the onset of HTN in adult offspring. ${ }^{190}$ Resveratrol also modulates SIRT1 expression. Pre-incubation with resveratrol restored angiogenic capacity and reversed the accelerated senescence of ECFCs from LBW newborns. ${ }^{123}$

Lazaroid is a potent inhibitor of free radical formation, notably $\mathrm{O}_{2}^{-}$-mediated lipid peroxidation. Treatment with Lazaroid reversed HTN in several rat models, ${ }^{191,192}$ and the addition of Lazaroid to a maternal LPD diet throughout gestation increased birth weight and reversed later vascular dysfunction in offspring by decreasing oxidative stress. ${ }^{143}$ 
In a guinea pig model of IUGR induced by progressive uterine artery occlusion starting at mid-gestation, maternal $\mathrm{N}$-acetylcysteine treatment during the second half of gestation restored ex vivo eNOS-dependent relaxation in the fetal aorta and umbilical artery and normalized eNOS expression in fetal and umbilical endothelial cells. ${ }^{193}$

Melatonin, a hormone with antioxidant and anti-inflammatory properties, is involved in regulating circadian and circannual rhythms ${ }^{194}$ and could improve endothelial function. Melatonin exhibits direct scavenging activity on $\mathrm{O}_{2}{ }^{-36,195,196}$ up-regulates antioxidant enzymes such as superoxide dismutase and glutathione peroxidase, and down-regulates pro-oxidant enzymes such as lipoxygenase, ${ }^{197}$ thereby increasing NO production and improving its availability to induce vasodilation ${ }^{198}$ in different vascular beds. ${ }^{199-202}$

\section{V-e- L-citrulline supplementation}

L-citrulline is a precursor of L-arginine. L-citrulline is a non-protein amino acid, which is absent from the regular diet, escapes liver metabolism, has high bioavailability, and is quantitatively converted to arginine in vivo. ${ }^{203}$ Data have suggested that L-citrulline supplementation improves fetal growth an in animal model of IUGR induced by in utero exposure to maternal $\mathrm{LPD},{ }^{79}$ probably by improving maternal nutritional status and fetal growth through increased NO synthesis as a result of enhanced L-arginine availability in fetal circulation. L-citrulline can also exert a protective role on vascular endothelium. In fact, it has been proposed that L-citrulline supplementation could represent an alternative to L-arginine supplementation to improve vascular function, ${ }^{204,205}$ and it attenuated blood pressure in young normotensive men. ${ }^{206}$ In animal models, ex vivo pre-incubation with L-citrulline prevented endothelial dysfunction induced by ADMA in porcine coronary artery; indeed, such incubation favors L-citrulline to L-arginine recycling and the restoration of NO production, as a consequence of eNOS expression and activity up-regulation, the inhibition of superoxide 
anion production, and activation of the cGMP pathway. ${ }^{207}$ Such direct beneficial effects of Lcitrulline on endothelium-dependent relaxation suggest that L-citrulline supplementation could be an efficient way to improve endothelial function in individuals born after fetal growth restriction.

\section{V-f-Supplementation with L-arginine and NO mediators}

It was reported that L-Arg could be administered to increase maternal NO levels to enhance birth weight and decrease neonatal morbidity. ${ }^{74}$ More recently, the combined results of ten small trials showed that L-Arg supplementation can increase the body weight and gestational age at birth of IUGR fetuses. ${ }^{208}$ However, this study contrasts with others that reported no benefit of L-Arg therapy. ${ }^{209,210}$ Such differences could be explained by the different route of administration (oral or intravenous). In fact, with oral administration, $40 \%$ of L-Arg is degraded by the small intestine and metabolized by arginase in the liver. Therefore, poor LArg availability in the blood could decrease its efficacy. ${ }^{203,211}$

Among NO modulators, phosphodiesterase inhibitors are promising agents for improving uterine perfusion in pregnancies complicated by IUGR. Type 5 phosphodiesterase (PDE5) is one of the enzymes responsible for the degradation of cGMP to GMP in smooth muscle. Therefore, inhibiting PDE5 delays the breakdown of cGMP and increases vasorelaxation. Sildenafil citrate (Viagra $\left.{ }^{\circledR}\right)$ is probably the most famous PDE5 inhibitor. In women whose pregnancies were complicated by IUGR, sildenafil citrate improved fetoplacental perfusion ${ }^{212}$ and decreased the ex vivo vasoconstriction (in response to the thromboxane analogue U46619)

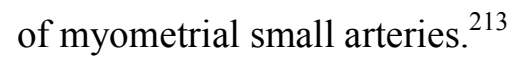

In animal models, parenteral administration of L-Arg (from day 60 of pregnancy to parturition) to underfed ewes prevented fetal growth restriction, ${ }^{214}$ and in a rat model of IUGR induced by maternal LPD, pre-incubating the aortic rings with L-Arg restored impaired 
endothelium-dependent vasodilation (personal unpublished data). Sildenafil citrate supplementation reversed the maternal effects of preeclampsia by improving uteroplacental and fetal perfusion ${ }^{215}$ in a Wistar rat model and increased fetal size in pregnant rats exposed to hypoxia at the end of gestation (18-20 days). ${ }^{216}$

\section{VI- Epigenetic markers of endothelial dysfunction}

Epigenetics plays a major role in the developmental origins of health and diseases. ${ }^{217}$ Epigenetics can be defined as a phenomenon of altered phenotypic expression of heritable genetic information without changes in the DNA sequence. Three main pathways can silence, activate, or regulate the level and time of expression of many genes: DNA methylation, histone modifications (acetylation, methylation, ubiquitination, phosphorylation, or ADPribosylation), and small non-coding RNAs, such as microRNAs (miRNAs). ${ }^{218,219}$ In general, these three epigenetic mechanisms appear to work together to regulate gene expression. DNA methylation or histone modifications can alter the expression of miRNAs, which can in turn regulate the epigenetic processes of DNA methylation and histone modifications.

\section{VI-a-DNA methylation}

DNA methylation has been known to be particularly sensitive to an adverse early environment. DNA methylation occurs through the binding of a methyl group in position 5 of the cytosine ring dinucleotide $\mathrm{CpG}$ sequences present in the DNA by DNA-methyltransferase, which can methylate and demethylate the DNA, thus making the modification reversible. ${ }^{220}$ In general, low levels of DNA methylation (hypomethylation) are associated with increased gene activity, whereas high levels of methylation (hypermethylation) are associated with gene repression. $^{221}$ Moreover, hydroxymethylated cytosine (5-hydroxymethylcytosine $(5 \mathrm{hmeC})$ ) has been identified as another functional DNA modification, representing an intermediate state of active DNA demethylation and also influencing gene expression. ${ }^{222,223}$ 
eNOS expression in human endothelial cells isolated from umbilical arteries (HUAECs) and veins (HUVECs) of IUGR pregnancies can be controlled by DNA methylation levels. eNOS protein and mRNA levels were increased in HUAECs but decreased in HUVECs from IUGR pregnancies ${ }^{86}$ and were associated in the eNOS promoter with decreased DNA methylation at CpG -352 in IUGR-HUAECs and an increased in IUGR-HUVECs. Additionally, in human umbilical artery endothelial cells from patients with placental insufficiency, levels of $5 \mathrm{hmeC}$ at the eNOS transcription start site directly correlated with elevated eNOS levels. ${ }^{224}$ In a guinea pig model of IUGR, increased eNOS expression was associated with decreased DNA methylation levels in eNOS promoter of endothelial cells derived from aorta, femoral and umbilical arteries; such modifications were prevented by maternal administration of $\mathrm{N}$ acetylcysteine. ${ }^{193}$

\section{VI-b-histone modifications}

In the nucleus, DNA is packaged into chromatin as repeating units of nucleosomes, which form a "beads-on-a-string" structure that can compact into higher order structures to affect gene expression. Nucleosomes are composed of 146-bp DNA wrapped in histone octamers (composed of two H2A, H2B, H3, and H4) and are connected by a linker DNA, which can associate with histone $\mathrm{H} 1$ to form heterochromatin. Histone proteins contain a globular domain and an amino-terminal tail, which can be post-translationally modified. The posttranslational modification of lysine (acetylation, methylation, ubiquitination, sumoylation), arginine (methylation) and serine and threonine (phosphorylation) are the most commonly described modifications. ${ }^{218,225}$ In general, the acetylation of histone H3 and H4 is associated with increased gene expression and has been shown to regulate the angiogenic function of endothelial cells.

Levels of $\mathrm{H} 3 \mathrm{~K} 9 \mathrm{ac}$ and $\mathrm{H} 2 \mathrm{~A} . \mathrm{Zac}$ were significantly higher at the eNOS transcription start site 
and were directly correlated with elevated eNOS levels observed in the human umbilical artery endothelial cells from patients with placental insufficiency. ${ }^{224}$ Additionally, increased histone $\mathrm{H} 3$ acetylation in the endothelin-1 promoter of pulmonary vascular endothelial cells and in the peripheral leucocytes in a IUGR rat model induced by maternal undernutrition has been correlated with higher endothelin-1 expression, which could increase the risk of pulmonary disorders (pulmonary hypertension or asthma) later in life. ${ }^{226}$ Recently, we observed that SIRT1 repression in ECFCs from LBW newborns, associated with premature senescence, could be modulated by changes in "active" or "repressive" epigenetic marks. The "active" marks trimethyl-H3K4 (H3K4me3) associated with the SIRT1 promoter were significantly decreased in LBW newborns compared to controls, whereas the "repressive" marks trimethyl- $\mathrm{H} 3 \mathrm{~K} 9$, associated with heterochromatin formation, were increased. ${ }^{123}$

\section{VI-c-Non-coding RNAs}

MiRNAs are small single-strand RNAs that do not encode proteins. Each miRNA binds to specific messenger RNAs (mRNAs), resulting in the degradation of target mRNA or the inhibition of its translation into protein. miRNAs regulate the post-transcriptional expression level of many genes and processes such as apoptosis, cell growth, and differentiation in a large range of tissues, ${ }^{227,228}$ and notably in the regulation of endothelial functions. MiR-21 expression is increased in cases of shear stress, which helps to protect endothelial cells by decreasing apoptosis and increasing eNOS expression and NO production. ${ }^{229}$ However, in atherosclerotic plaques, an up-regulation of miR-21 decreases the function of superoxide dismutase, which leads to increased ROS production and decreased migration of the progenitor cells. ${ }^{230}$ MiR-221 and miR-222 are highly expressed in endothelial cells ${ }^{231}$ and exert antiangiogenic, antiproliferative, antimigration and proapoptotic effects on endothelial cells, ${ }^{231}$ which can be partly caused by reduced eNOS expression. ${ }^{232}$ Additionally, miRNAs can modulate SIRT1 expression. Increased expression of miR-217 and miR-34a have been 
observed in endothelial senescence, which leads to loss of SIRT1 function, notably by reducing eNOS expression. $^{233}$

\section{VI-Conclusions}

In individuals born after fetal growth restriction, early endothelial dysfunction plays an important role in the subsequent development of HTN, coronary heart disease and CKD. Decreased NO synthesis and bioavailability caused by defective eNOS function and oxidative stress, decreased EPC number and function, and vascular senescence have all been shown to be involved in endothelial dysfunction (Figure 1). Preventive approaches, including breastfeeding and supplementation with folate, vitamins, antioxidants, L-citrulline, L-Arg and NO modulators, represent promising and simple ways to prevent fetal growth restriction, improve endothelial function and vasodilation responses early in life and delay/prevent detrimental cardiovascular issues.

Epigenetic modulation of gene expression appears to be one of the main contributors to the long-term effects of an adverse perinatal environment. The identification of early biomarkers of endothelial dysfunction, especially epigenetic biomarkers, could allow early screening and follow-up of individuals at risk of developing CVD, thus contributing to the development of preventive and therapeutic strategies to avert the long-term effects of endothelial dysfunction in infants born after IUGR. 


\section{VII-Acknowledgements}

The authors thank Dolorès Mosig, Katya Nardou and Dr. Fabienne Maurer for their invaluable contributions. 


\section{VIII-Financial Support}

This research received no specific grant from any funding agency in the commercial or notfor-profit sectors. 


\section{IX-Conflicts of interest}

None. 


\section{X-References}

1. Brodsky D, Christou H. Current concepts in intrauterine growth restriction. J Intensive Care Med. 2004; 19, 307-319.

2. Jang DG, Jo YS, Lee SJ, Kim N, Lee GS. Perinatal outcomes and maternal clinical characteristics in IUGR with absent or reversed end-diastolic flow velocity in the umbilical artery. Arch Gynecol Obstet. 2011; 284, 73-78.

3. Saleem T, Sajjad N, Fatima S, et al. Intrauterine growth retardation--small events, big consequences. Ital J Pediatr. 2011; 37, 41.

4. Mongelli M, Gardosi J. Symphysis-fundus height and pregnancy characteristics in ultrasound-dated pregnancies. Obstet Gynecol. 1999; 94, 591-594.

5. Committee on Practice Bulletins--Gynecology ACoO, Gynecologists WDCUSA. Intrauterine growth restriction. Clinical management guidelines for obstetriciangynecologists. American College of Obstetricians and Gynecologists. Int J Gynaecol Obstet. 2001; 72, 85-96.

6. Alberry M, Soothill P. Management of fetal growth restriction. Arch Dis Child Fetal Neonatal Ed. 2007; 92, F62-67.

7. Figueras F, Gardosi J. Intrauterine growth restriction: new concepts in antenatal surveillance, diagnosis, and management. Am J Obstet Gynecol. 2011; 204, 288-300.

8. Barker ED, McAuliffe FM, Alderdice F, et al. The role of growth trajectories in classifying fetal growth restriction. Obstet Gynecol. 2013; 122, 248-254.

9. Villar J, Cheikh Ismail L, Victora CG, et al. International standards for newborn weight, length, and head circumference by gestational age and sex: the Newborn Cross-Sectional Study of the INTERGROWTH-21st Project. Lancet. 2014; 384, 857 868. 
10. Villar J, Giuliani F, Fenton TR, et al. INTERGROWTH-21st very preterm size at birth reference charts. Lancet. 2016; 387, 844-845.

11. Rosario FJ, Jansson N, Kanai Y, et al. Maternal protein restriction in the rat inhibits placental insulin, mTOR, and STAT3 signaling and down-regulates placental amino acid transporters. Endocrinology. 2011; 152, 1119-1129.

12. Johansson M, Karlsson L, Wennergren M, Jansson T, Powell TL. Activity and protein expression of $\mathrm{Na}+/ \mathrm{K}+$ ATPase are reduced in microvillous syncytiotrophoblast plasma membranes isolated from pregnancies complicated by intrauterine growth restriction. $J$ Clin Endocrinol Metab. 2003; 88, 2831-2837.

13. Settle P, Sibley CP, Doughty IM, et al. Placental lactate transporter activity and expression in intrauterine growth restriction. J Soc Gynecol Investig. 2006; 13, 357363.

14. Chaiworapongsa T, Chaemsaithong P, Yeo L, Romero R. Pre-eclampsia part 1: current understanding of its pathophysiology. Nat Rev Nephrol. 2014; 10, 466-480.

15. Adams Waldorf KM, McAdams RM. Influence of infection during pregnancy on fetal development. Reproduction. 2013; 146, R151-162.

16. Derricott H, Jones RL, Heazell AE. Investigating the association of villitis of unknown etiology with stillbirth and fetal growth restriction - a systematic review. Placenta. 2013; 34, 856-862.

17. Baba S, Wikstrom AK, Stephansson O, Cnattingius S. Changes in snuff and smoking habits in Swedish pregnant women and risk for small for gestational age births. BJOG. $2013 ; 120,456-462$.

18. Maruyama H, Shinozuka M, Kondoh Y, et al. Thrombocytopenia in preterm infants with intrauterine growth restriction. Acta Med Okayama. 2008; 62, 313-317. 
19. Hall JG. Review and hypothesis: syndromes with severe intrauterine growth restriction and very short stature--are they related to the epigenetic mechanism(s) of fetal survival involved in the developmental origins of adult health and disease? Am J Med Genet A. 2010; 152A, 512-527.

20. Malik S, Cleves MA, Zhao W, et al. Association between congenital heart defects and small for gestational age. Pediatrics. 2007; 119, e976-982.

21. Hillman S, Peebles DM, Williams DJ. Paternal metabolic and cardiovascular risk factors for fetal growth restriction: a case-control study. Diabetes Care. 2013; 36, 1675-1680.

22. Li J, Tsuprykov O, Yang X, Hocher B. Paternal programming of offspring cardiometabolic diseases in later life. J Hypertens. 2016; 34, 2111-2126.

23. Minshall RD, Tiruppathi C, Vogel SM, Malik AB. Vesicle formation and trafficking in endothelial cells and regulation of endothelial barrier function. Histochem Cell Biol. $2002 ; 117,105-112$.

24. Purnomowati A, Kariadi SH, Achmad TH, Mose JC, Setianto B. Endothelial dysfunction in the young adult: a retrospective cohort study on the effect of low birth weight. Acta Med Indones. 2014; 46, 111-116.

25. Bassareo PP, Fanos V, Puddu M, et al. Reduced brachial flow-mediated vasodilation in young adult ex extremely low birth weight preterm: a condition predictive of increased cardiovascular risk? J Matern Fetal Neonatal Med. 2010; 23 Suppl 3, 121 124.

26. Martin H, Lindblad B, Norman M. Endothelial function in newborn infants is related to folate levels and birth weight. Pediatrics. 2007; 119, 1152-1158. 
27. Leeson P, Thorne S, Donald A, et al. Non-invasive measurement of endothelial function: effect on brachial artery dilatation of graded endothelial dependent and independent stimuli. Heart. 1997; 78, 22-27.

28. Leeson C, Whincup P, Cook D, et al. Flow-mediated dilation in 9- to 11-year-old children: the influence of intrauterine and childhood factors. Circulation. 1997; 96, $2233-2238$.

29. Goodfellow J, Bellamy MF, Gorman ST, et al. Endothelial function is impaired in fit young adults of low birth weight. Cardiovasc Res. 1998; 40, 600-606.

30. Leeson C, Kattenhorn M, Morley R, Lucas A, Deanfield J. Impact of low birth weight and cardiovascular risk factors on endothelial function in early adult life. Circulation. $2001 ; 103,1264-1268$.

31. Krause BJ, Carrasco-Wong I, Caniuguir A, et al. Endothelial eNOS/arginase imbalance contributes to vascular dysfunction in IUGR umbilical and placental vessels. Placenta. 2013; 34, 20-28.

32. Yzydorczyk C, Gobeil F, Jr., Cambonie G, et al. Exaggerated vasomotor response to ANG II in rats with fetal programming of hypertension associated with exposure to a low-protein diet during gestation. Am J Physiol Regul Integr Comp Physiol. 2006; 291, R1060-1068.

33. Pladys P, Sennlaub F, Brault S, et al. Microvascular rarefaction and decreased angiogenesis in rats with fetal programming of hypertension associated with exposure to a low-protein diet in utero. Am J Physiol Regul Integr Comp Physiol. 2005; 289, R1580-1588.

34. Brawley L, Itoh S, Torrens $\mathrm{C}$, et al. Dietary protein restriction in pregnancy induces hypertension and vascular defects in rat male offspring. Pediatr Res. 2003; 54, 83-90. 
35. Franco MC, Arruda R, Dantas A, et al. Intrauterine undernutrition: expression and activity of the endothelial nitric oxide synthase in male and female adult offspring. Cardiovasc Res. 2002; 56, 145-153.

36. Tare M, Parkington HC, Wallace EM, et al. Maternal melatonin administration mitigates coronary stiffness and endothelial dysfunction, and improves heart resilience to insult in growth restricted lambs. $J$ Physiol. 2014; 592, 2695-2709.

37. Borwick SC, Rhind SM, McMillen SR, Racey PA. Effect of undernutrition of ewes from the time of mating on fetal ovarian development in mid gestation. Reprod Fertil Dev. 1997; 9, 711-715.

38. Hurtado R, Celani M, Geber S. Effect of short-term estrogen therapy on endothelial function: a double-blinded, randomized, controlled trial. Climacteric. 2016; 19, 448451.

39. Gleeson M, Bishop NC, Stensel DJ, et al. The anti-inflammatory effects of exercise: mechanisms and implications for the prevention and treatment of disease. Nat Rev Immunol. 2011; 11, 607-615.

40. Leinonen E, Hurt-Camejo E, Wiklund O, et al. Insulin resistance and adiposity correlate with acute-phase reaction and soluble cell adhesion molecules in type 2 diabetes. Atherosclerosis. 2003; 166, 387-394.

41. Pellanda LC, Duncan BB, Vigo A, et al. Low birth weight and markers of inflammation and endothelial activation in adulthood: the ARIC study. Int J Cardiol. $2009 ; 134,371-377$.

42. Teeninga N, Schreuder MF, Bokenkamp A, Delemarre-van de Waal HA, van Wijk JA. Influence of low birth weight on minimal change nephrotic syndrome in children, including a meta-analysis. Nephrol Dial Transplant. 2008; 23, 1615-1620. 
43. Skilton MR, Evans N, Griffiths KA, Harmer JA, Celermajer DS. Aortic wall thickness in newborns with intrauterine growth restriction. Lancet. 2005; 365, 1484-1486.

44. Koklu E, Ozturk MA, Gunes T, Akcakus M, Kurtoglu S. Is increased intima-media thickness associated with preatherosclerotic changes in intrauterine growth restricted newborns? Acta Paediatr. 2007; 96, 1858; author reply 1859.

45. Litwin M, Niemirska A. Intima-media thickness measurements in children with cardiovascular risk factors. Pediatr Nephrol. 2009; 24, 707-719.

46. Cosmi E, Visentin S, Fanelli T, Mautone AJ, Zanardo V. Aortic intima media thickness in fetuses and children with intrauterine growth restriction. Obstet Gynecol. $2009 ; 114,1109-1114$.

47. Crispi F, Figueras F, Cruz-Lemini M, et al. Cardiovascular programming in children born small for gestational age and relationship with prenatal signs of severity. Am J Obstet Gynecol. 2012; 207, 121 e121-129.

48. Crispi F, Bijnens B, Figueras F, et al. Fetal growth restriction results in remodeled and less efficient hearts in children. Circulation. 2010; 121, 2427-2436.

49. Oren A, Vos LE, Uiterwaal CS, et al. Birth weight and carotid intima-media thickness: new perspectives from the atherosclerosis risk in young adults (ARYA) study. Ann Epidemiol. 2004; 14, 8-16.

50. Jensen GM, Moore LG. The effect of high altitude and other risk factors on birthweight: independent or interactive effects? Am J Public Health. 1997; 87, $1003-$ 1007.

51. Lueder FL, Kim SB, Buroker CA, Bangalore SA, Ogata ES. Chronic maternal hypoxia retards fetal growth and increases glucose utilization of select fetal tissues in the rat. Metabolism. 1995; 44, 532-537. 
52. Barker DJ. The fetal origins of coronary heart disease. Acta Paediatr Suppl. 1997; $422,78-82$.

53. Barker DJ, Osmond C, Golding J, Kuh D, Wadsworth ME. Growth in utero, blood pressure in childhood and adult life, and mortality from cardiovascular disease. BMJ. $1989 ; 298,564-567$.

54. Giaccia AJ, Simon MC, Johnson R. The biology of hypoxia: the role of oxygen sensing in development, normal function, and disease. Genes Dev. 2004; 18, 2183 2194.

55. Malamitsi-Puchner A, Boutsikou T, Economou E, et al. Angiopoietin-2 in the perinatal period and the role of intrauterine growth restriction. Acta Obstet Gynecol Scand. 2006; 85, 45-48.

56. Griendling KK, Harrison DG. Dual role of reactive oxygen species in vascular growth. Circ Res. 1999; 85, 562-563.

57. Irani K. Oxidant signaling in vascular cell growth, death, and survival : a review of the roles of reactive oxygen species in smooth muscle and endothelial cell mitogenic and apoptotic signaling. Circ Res. 2000; 87, 179-183.

58. Touyz RM, Schiffrin EL. Reactive oxygen species in vascular biology: implications in hypertension. Histochem Cell Biol. 2004; 122, 339-352.

59. Ushio-Fukai M, Zafari AM, Fukui T, Ishizaka N, Griendling KK. p22phox is a critical component of the superoxide-generating NADH/NADPH oxidase system and regulates angiotensin II-induced hypertrophy in vascular smooth muscle cells. J Biol Chem. 1996; 271, 23317-23321.

60. Griendling KK, Minieri CA, Ollerenshaw JD, Alexander RW. Angiotensin II stimulates NADH and NADPH oxidase activity in cultured vascular smooth muscle cells. Circ Res. 1994; 74, 1141-1148. 
61. Zafari AM, Ushio-Fukai M, Akers M, et al. Role of NADH/NADPH oxidase-derived H2O2 in angiotensin II-induced vascular hypertrophy. Hypertension. 1998; 32, 488495.

62. Tyagi SC, Simon SR. Regulation of neutrophil elastase activity by elastin-derived peptide. J Biol Chem. 1993; 268, 16513-16518.

63. Chow AK, Cena J, Schulz R. Acute actions and novel targets of matrix metalloproteinases in the heart and vasculature. Br J Pharmacol. 2007; 152, 189-205.

64. Rajagopalan S, Meng XP, Ramasamy S, Harrison DG, Galis ZS. Reactive oxygen species produced by macrophage-derived foam cells regulate the activity of vascular matrix metalloproteinases in vitro. Implications for atherosclerotic plaque stability. $J$ Clin Invest. 1996; 98, 2572-2579.

65. Sesso R, Franco MC. Abnormalities in metalloproteinase pathways and IGF-I axis: a link between birth weight, hypertension, and vascular damage in childhood. Am J Hypertens. 2010; 23, 6-11.

66. Huyard F, Yzydorczyk C, Castro MM, et al. Remodeling of aorta extracellular matrix as a result of transient high oxygen exposure in newborn rats: implication for arterial rigidity and hypertension risk. PLoS One. 2014; 9, e92287.

67. Yzydorczyk C, Comte B, Cambonie G, et al. Neonatal oxygen exposure in rats leads to cardiovascular and renal alterations in adulthood. Hypertension. 2008; 52, 889-895.

68. Mivelaz Y YC, Barbier A, Cloutier A, Fouron JC, Nuyt AM. Neonatal oxygen exposure leads to increased aortic wall stiffness in adult rats: a doppler ultrasound study. J Dev Orig Health Dis. 2011; 2, 6.

69. Chatterjee A, Black SM, Catravas JD. Endothelial nitric oxide (NO) and its pathophysiologic regulation. Vascul Pharmacol. 2008; 49, 134-140. 
70. Förstermann U, Münzel T. Endothelial nitric oxide synthase in vascular disease: from marvel to menace. Circulation. 2006; 113, 1708-1714.

71. Searles CD. Transcriptional and posttranscriptional regulation of endothelial nitric oxide synthase expression. Am J Physiol Cell Physiol. 2006; 291, C803-816.

72. De Caterina R, Libby P, Peng HB, et al. Nitric oxide decreases cytokine-induced endothelial activation. Nitric oxide selectively reduces endothelial expression of adhesion molecules and proinflammatory cytokines. J Clin Invest. 1995; 96, 60-68.

73. Hata T, Hashimoto M, Manabe A, et al. Maternal and fetal nitric oxide synthesis is decreased in pregnancies with small for gestational age infants. Hum Reprod. 1998; 13, 1070-1073.

74. Singh S, Singh A, Sharma D, et al. Effect of 1-Arginine on Nitric Oxide Levels in Intrauterine Growth Restriction and its Correlation with Fetal Outcome. Indian J Clin Biochem. 2015; 30, 298-304.

75. Lyall F, Greer IA, Young A, Myatt L. Nitric oxide concentrations are increased in the feto-placental circulation in intrauterine growth restriction. Placenta. 1996; 17, 165 168.

76. Myatt L, Eis AL, Brockman DE, Greer IA, Lyall F. Endothelial nitric oxide synthase in placental villous tissue from normal, pre-eclamptic and intrauterine growth restricted pregnancies. Hum Reprod. 1997; 12, 167-172.

77. Payne JA, Alexander BT, Khalil RA. Reduced endothelial vascular relaxation in growth-restricted offspring of pregnant rats with reduced uterine perfusion. Hypertension. 2003; 42, 768-774.

78. Sathishkumar K, Elkins R, Yallampalli U, Yallampalli C. Protein restriction during pregnancy induces hypertension and impairs endothelium-dependent vascular function in adult female offspring. J Vasc Res. 2009; 46, 229-239. 
79. Bourdon A, Parnet P, Nowak C, et al. 1-Citrulline Supplementation Enhances Fetal Growth and Protein Synthesis in Rats with Intrauterine Growth Restriction. J Nutr. $2016 ; 146,532-541$.

80. Sathishkumar K, Elkins R, Yallampalli U, Balakrishnan M, Yallampalli C. Fetal programming of adult hypertension in female rat offspring exposed to androgens in utero. Early Hum Dev. 2011; 87, 407-414.

81. Hracsko Z, Hermesz E, Ferencz A, et al. Endothelial nitric oxide synthase is upregulated in the umbilical cord in pregnancies complicated with intrauterine growth retardation. In Vivo. 2009; 23, 727-732.

82. Dellee U, Tobias S, Li H, Mildenberger E. Expression of NO synthases and redox enzymes in umbilical arteries from newborns born small, appropriate, and large for gestational age. Pediatr Res. 2013; 73, 142-146.

83. Takushima S, Nishi Y, Nonoshita A, et al. Changes in the nitric oxide-soluble guanylate cyclase system and natriuretic peptide receptor system in placentas of pregnant Dahl salt-sensitive rats. J Obstet Gynaecol Res. 2015; 41, 540-550.

84. Arroyo JA, Anthony RV, Parker TA, Galan HL. eNOS, NO, and the activation of ERK and AKT signaling at mid-gestation and near-term in an ovine model of intrauterine growth restriction. Syst Biol Reprod Med. 2010; 56, 62-73.

85. Tolbert T, Thompson JA, Bouchard P, Oparil S. Estrogen-induced vasoprotection is independent of inducible nitric oxide synthase expression: evidence from the mouse carotid artery ligation model. Circulation. 2001; 104, 2740-2745.

86. Krause BJ, Costello PM, Munoz-Urrutia E, et al. Role of DNA methyltransferase 1 on the altered eNOS expression in human umbilical endothelium from intrauterine growth restricted fetuses. Epigenetics. 2013; 8, 944-952. 
87. Laskowska M, Laskowska K, Oleszczuk J. Differences in the association between maternal serum homocysteine and ADMA levels in women with pregnancies complicated by preeclampsia and/or intrauterine growth restriction. Hypertens Pregnancy. 2013; 32, 83-93.

88. Gumus E, Atalay MA, Cetinkaya Demir B, Sahin Gunes E. Possible role of asymmetric dimethylarginine (ADMA) in prediction of perinatal outcome in preeclampsia and fetal growth retardation related to preeclampsia. J Matern Fetal Neonatal Med. 2016; 29, 3806-3811.

89. Rizos D, Eleftheriades M, Batakis E, et al. Levels of asymmetric dimethylarginine throughout normal pregnancy and in pregnancies complicated with preeclampsia or had a small for gestational age baby. J Matern Fetal Neonatal Med. 2012; 25, 1311 1315.

90. Post MS, Verhoeven MO, van der Mooren MJ, et al. Effect of hormone replacement therapy on plasma levels of the cardiovascular risk factor asymmetric dimethylarginine: a randomized, placebo-controlled 12-week study in healthy early postmenopausal women. J Clin Endocrinol Metab. 2003; 88, 4221-4226.

91. Karkanaki A, Vavilis D, Traianos A, Kalogiannidis I, Panidis D. Hormone therapy and asymmetrical dimethylarginine in postmenopausal women. Hormones (Athens). $2010 ; 9,127-135$.

92. Yu XJ, Li YJ, Xiong Y. Increase of an endogenous inhibitor of nitric oxide synthesis in serum of high cholesterol fed rabbits. Life Sci. 1994; 54, 753-758.

93. Boger RH, Bode-Boger SM, Sydow K, Heistad DD, Lentz SR. Plasma concentration of asymmetric dimethylarginine, an endogenous inhibitor of nitric oxide synthase, is elevated in monkeys with hyperhomocyst(e)inemia or hypercholesterolemia. Arterioscler Thromb Vasc Biol. 2000; 20, 1557-1564. 
94. Griendling KK, FitzGerald GA. Oxidative stress and cardiovascular injury: Part I: basic mechanisms and in vivo monitoring of ROS. Circulation. 2003; 108, 1912-1916.

95. Burton GJ, Jauniaux E. Oxidative stress. Best Pract Res Clin Obstet Gynaecol. 2011; $25,287-299$.

96. Takagi Y, Nikaido T, Toki T, et al. Levels of oxidative stress and redox-related molecules in the placenta in preeclampsia and fetal growth restriction. Virchows Arch. 2004; 444, 49-55.

97. Maisonneuve E, Delvin E, Edgard A, et al. Oxidative conditions prevail in severe IUGR with vascular disease and Doppler anomalies. J Matern Fetal Neonatal Med. $2015 ; 28,1471-1475$.

98. Webster RP, Roberts VH, Myatt L. Protein nitration in placenta - functional significance. Placenta. 2008; 29, 985-994.

99. Kossenjans W, Eis A, Sahay R, Brockman D, Myatt L. Role of peroxynitrite in altered fetal-placental vascular reactivity in diabetes or preeclampsia. Am J Physiol Heart Circ Physiol. 2000; 278, H1311-1319.

100. Santilli F, D'Ardes D, Davi G. Oxidative stress in chronic vascular disease: From prediction to prevention. Vascul Pharmacol. 2015; 74, 23-37.

101. Yzydorczyk C, Comte B, Huyard F, et al. Developmental programming of eNOS uncoupling and enhanced vascular oxidative stress in adult rats after transient neonatal oxygen exposure J Cardiovasc Pharmacol. 2013; 61, 8-16.

102. Vasquez-Vivar J, Kalyanaraman B, Martasek P, et al. Superoxide generation by endothelial nitric oxide synthase: the influence of cofactors. Proc Natl Acad Sci USA. $1998 ; 95,9220-9225$. 
103. d'Uscio LV, Santhanam AV, Katusic ZS. Erythropoietin prevents endothelial dysfunction in GTP-cyclohydrolase I-deficient hph1 mice. J Cardiovasc Pharmacol. 2014; 64, 514-521.

104. Yang YM, Huang A, Kaley G, Sun D. eNOS uncoupling and endothelial dysfunction in aged vessels. Am J Physiol Heart Circ Physiol. 2009; 297, H1829-1836.

105. Landmesser U, Dikalov S, Price SR, et al. Oxidation of tetrahydrobiopterin leads to uncoupling of endothelial cell nitric oxide synthase in hypertension. J Clin Invest. $2003 ; 111,1201-1209$.

106. Chalupsky K, Cai H. Endothelial dihydrofolate reductase: critical for nitric oxide bioavailability and role in angiotensin II uncoupling of endothelial nitric oxide synthase. Proc Natl Acad Sci USA. 2005; 102, 9056-9061.

107. Sydow K, Munzel T. ADMA and oxidative stress. Atheroscler Suppl. 2003; 4, 41-51.

108. Schneider D, Hernandez C, Farias M, et al. Oxidative stress as common trait of endothelial dysfunction in chorionic arteries from fetuses with IUGR and LGA. Placenta. 2015; 36, 552-558.

109. Mitchell BM, Cook LG, Danchuk S, Puschett JB. Uncoupled endothelial nitric oxide synthase and oxidative stress in a rat model of pregnancy-induced hypertension. Am J Hypertens. 2007; 20, 1297-1304.

110. Oliveira V, Akamine EH, Carvalho $\mathrm{MH}$, et al. Influence of aerobic training on the reduced vasoconstriction to angiotensin II in rats exposed to intrauterine growth restriction: possible role of oxidative stress and AT2 receptor of angiotensin II. PLoS One. 2014; 9, e113035.

111. Asahara T, Murohara T, Sullivan A, et al. Isolation of putative progenitor endothelial cells for angiogenesis. Science. 1997; 275, 964-967. 
112. Yoder MC, Mead LE, Prater D, et al. Redefining endothelial progenitor cells via clonal analysis and hematopoietic stem/progenitor cell principals. Blood. 2007; 109, 1801-1809.

113. Purhonen S, Palm J, Rossi D, et al. Bone marrow-derived circulating endothelial precursors do not contribute to vascular endothelium and are not needed for tumor growth. Proc Natl Acad Sci USA. 2008; 105, 6620-6625.

114. Hill JM, Zalos G, Halcox JP, et al. Circulating endothelial progenitor cells, vascular function, and cardiovascular risk. N Engl J Med. 2003; 348, 593-600.

115. Sipos PI, Crocker IP, Hubel CA, Baker PN. Endothelial progenitor cells: their potential in the placental vasculature and related complications. Placenta. 2010; 31, 110.

116. Hwang HS, Kwon YG, Kwon JY, et al. Senescence of fetal endothelial progenitor cell in pregnancy with idiopathic fetal growth restriction. J Matern Fetal Neonatal Med. $2012 ; 25,1769-1773$.

117. Ligi I, Simoncini S, Tellier E, et al. A switch toward angiostatic gene expression impairs the angiogenic properties of endothelial progenitor cells in low birth weight preterm infants. Blood. 2011; 118, 1699-1709.

118. Ligi I, Simoncini S, Tellier E, et al. Altered angiogenesis in low birth weight individuals: a role for anti-angiogenic circulating factors. J Matern Fetal Neonatal Med. 2014; 27, 233-238.

119. Minamino T, Komuro I. Vascular cell senescence: contribution to atherosclerosis. Circ Res. 2007; 100, 15-26.

120. Erusalimsky JD, Fenton M. Further in vivo evidence that cellular senescence is implicated in vascular pathophysiology. Circulation. 2002; 106, e144; author reply e144. 
121. Borradaile NM, Pickering JG. NAD $(+)$, sirtuins, and cardiovascular disease. Curr Pharm Des. 2009; 15, 110-117.

122. Ota H, Akishita M, Eto M, et al. Sirt1 modulates premature senescence-like phenotype in human endothelial cells. J Mol Cell Cardiol. 2007; 43, 571-579.

123. Vassallo PF, Simoncini S, Ligi I, et al. Accelerated senescence of cord blood endothelial progenitor cells in premature neonates is driven by SIRT1 decreased expression. Blood. 2014; 123, 2116-2126.

124. Fattal-Valevski A, Bernheim J, Leitner Y, et al. Blood pressure values in children with intrauterine growth retardation. Isr Med Assoc J. 2001; 3, 805-808.

125. Rossi P, Tauzin L, Marchand E, et al. Respective roles of preterm birth and fetal growth restriction in blood pressure and arterial stiffness in adolescence. $J$ Adolesc Health. 2011; 48, 520-522.

126. Chiolero A, Cachat F, Burnier M, Paccaud F, Bovet P. Prevalence of hypertension in schoolchildren based on repeated measurements and association with overweight. $J$ Hypertens. 2007; 25, 2209-2217.

127. Leon DA, Johansson M, and Rasmussen F. Gestational age and growth rate of fetal mass are inversely associated with systolic blood pressure in young adults: an epidemiologic study of 165,136 Swedish men aged 18 years. Am J Epidemiol. $2000 ; 152,8$.

128. Nilsson PM, Ostergren PO, Nyberg P, Soderstrom M, Allebeck P. Low birth weight is associated with elevated systolic blood pressure in adolescence: a prospective study of a birth cohort of 149378 Swedish boys. J Hypertens. 1997; 15, 1627-1631.

129. Gennser G, Rymark P, Isberg PE. Low birth weight and risk of high blood pressure in adulthood. Br Med J (Clin Res Ed). 1988; 296, 1498-1500. 
130. Martyn CN, Barker DJ, Jespersen S, Greenwald S, Osmond C, Berry C. Growth in utero, adult blood pressure, and arterial compliance. Br Heart J 1995; 73, 6.

131. Curhan GC, Willett WC, Rimm EB, et al. Birth weight and adult hypertension, diabetes mellitus, and obesity in US men. Circulation. 1996; 94, 3246-3250.

132. Law CM, Shiell AW. Is blood pressure inversely related to birth weight? The strength of evidence from a systematic review of the literature. J Hypertens. 1996; 14, 935941.

133. Huxley R, Neil A, Collins R. Unravelling the fetal origins hypothesis: is there really an inverse association between birthweight and subsequent blood pressure? Lancet. $2002 ; 360,659-665$.

134. Tauzin L, Rossi P, Grosse C, et al. Increased systemic blood pressure and arterial stiffness in young adults born prematurely. J Dev Orig Health Dis. 2014; 5, 448-452.

135. Wlodek ME, Westcott K, Siebel AL, Owens JA, Moritz KM. Growth restriction before or after birth reduces nephron number and increases blood pressure in male rats. Kidney Int. 2008; 74, 187-195.

136. Alexander BT. Placental insufficiency leads to development of hypertension in growth-restricted offspring. Hypertension. 2003; 41, 457-462.

137. Bourque SL, Gragasin FS, Quon AL, et al. Prenatal hypoxia causes long-term alterations in vascular endothelin-1 function in aged male, but not female, offspring. Hypertension. 2013; 62, 753-758.

138. Ortiz LA, Quan A, Zarzar F, Weinberg A, Baum M. Prenatal dexamethasone programs hypertension and renal injury in the rat. Hypertension. 2003; 41, 328-334.

139. Mossa F, Carter F, Walsh SW, et al. Maternal undernutrition in cows impairs ovarian and cardiovascular systems in their offspring. Biol Reprod. 2013; 88, 92. 
140. Goyal R, Van-Wickle J, Goyal D, Longo LD. Antenatal maternal low protein diet: ACE-2 in the mouse lung and sexually dimorphic programming of hypertension. $B M C$ Physiol. 2015; 15, 2.

141. Gilbert JS, Lang AL, Grant AR, Nijland MJ. Maternal nutrient restriction in sheep: hypertension and decreased nephron number in offspring at 9 months of age. $J$ Physiol. 2005; 565, 137-147.

142. Ozaki T, Nishina H, Hanson M, Poston L. Dietary restriction in pregnant rats causes gender-related hypertension and vascular dysfunction in offspring. J Physiol. 2001; $530,141-152$

143. Cambonie G, Comte B, Yzydorczyk C, et al. Antenatal antioxidant prevents adult hypertension, vascular dysfunction, and microvascular rarefaction associated with in utero exposure to a low-protein diet. Am J Physiol Regul Integr Comp Physiol. 2007; 292, R1236-1245.

144. Taddei S, Virdis A, Mattei P, Arzilli F, Salvetti A. Endothelium-dependent forearm vasodilation is reduced in normotensive subjects with familial history of hypertension. J Cardiovasc Pharmacol. 1992; 20 Suppl 12, S193-195.

145. Miller MJ, Pinto A, Mullane KM. Impaired endothelium-dependent relaxations in rabbits subjected to aortic coarctation hypertension. Hypertension. 1987; 10, 164-170.

146. d'Uscio LV, Barton M, Shaw S, Moreau P, Luscher TF. Structure and function of small arteries in salt-induced hypertension: effects of chronic endothelin-subtype-Areceptor blockade. Hypertension. 1997; 30, 905-911.

147. Verma S, Anderson TJ. Fundamentals of endothelial function for the clinical cardiologist. Circulation. 2002; 105, 546-549. 
148. Ludmer PL, Selwyn AP, Shook TL, et al. Paradoxical vasoconstriction induced by acetylcholine in atherosclerotic coronary arteries. N Engl J Med. 1986; 315, 10461051.

149. Barker DJ, Gluckman PD, Godfrey KM, et al. Fetal nutrition and cardiovascular disease in adult life. Lancet. 1993; 341, 938-941.

150. Leon DA, Lithell HO, Vagero D, et al. Reduced fetal growth rate and increased risk of death from ischaemic heart disease: cohort study of 15000 Swedish men and women born 1915-29. BMJ. 1998; 317, 241-245.

151. Wang SF, Shu L, Sheng J, et al. Birth weight and risk of coronary heart disease in adults: a meta-analysis of prospective cohort studies. J Dev Orig Health Dis. 2014; 5, 408-419.

152. Eriksson M, Tibblin G, Cnattingius S. Low birthweight and ischaemic heart disease. Lancet. 1994; 343, 731.

153. Banci M, Saccucci P, Dofcaci A, et al. Birth weight and coronary artery disease. The effect of gender and diabetes. Int J Biol Sci. 2009; 5, 244-248.

154. Abrahamson DR, Robert B, Hyink DP, St John PL, Daniel TO. Origins and formation of microvasculature in the developing kidney. Kidney Int Suppl. 1998; 67, S7-11.

155. Hyink DP, Tucker DC, St John PL, et al. Endogenous origin of glomerular endothelial and mesangial cells in grafts of embryonic kidneys. Am J Physiol. 1996; 270, F886899.

156. Stehouwer CD, Henry RM, Dekker JM, et al. Microalbuminuria is associated with impaired brachial artery, flow-mediated vasodilation in elderly individuals without and with diabetes: further evidence for a link between microalbuminuria and endothelial dysfunction--the Hoorn Study. Kidney Int Suppl. 2004; 66, S42-44. 
157. Pedrinelli R, Giampietro O, Carmassi F, et al. Microalbuminuria and endothelial dysfunction in essential hypertension. Lancet. 1994; 344, 14-18.

158. Mancuso P, Antoniotti P, Quarna J, et al. Validation of a standardized method for enumerating circulating endothelial cells and progenitors: flow cytometry and molecular and ultrastructural analyses. Clin Cancer Res. 2009; 15, 267-273.

159. Perticone F, Maio R, Perticone M, et al. Endothelial dysfunction and subsequent decline in glomerular filtration rate in hypertensive patients. Circulation. 2010; 122, $379-384$.

160. Gris JC, Branger B, Vecina F, et al. Increased cardiovascular risk factors and features of endothelial activation and dysfunction in dialyzed uremic patients. Kidney Int. $1994 ; 46,807-813$.

161. Manalich R, Reyes L, Herrera M, Melendi C, Fundora I. Relationship between weight at birth and the number and size of renal glomeruli in humans: a histomorphometric study. Kidney Int. 2000; 58, 770-773.

162. White SL, Perkovic V, Cass A, et al. Is low birth weight an antecedent of CKD in later life? A systematic review of observational studies. Am J Kidney Dis. 2009; 54, 248261.

163. Giapros V, Papadimitriou P, Challa A, Andronikou S. The effect of intrauterine growth retardation on renal function in the first two months of life. Nephrol Dial Transplant. 2007; 22, 96-103.

164. Silverwood RJ, Pierce M, Hardy R, et al. Low birth weight, later renal function, and the roles of adulthood blood pressure, diabetes, and obesity in a British birth cohort. Kidney Int. 2013; 84, 1262-1270.

165. Vehaskari VM, Aviles DH, Manning J. Prenatal programming of adult hypertension in the rat. Kidney Int. 2001; 59, 238-245. 
166. Woods LL, Ingelfinger JR, Nyengaard JR, Rasch R. Maternal protein restriction suppresses the newborn renin-angiotensin system and programs adult hypertension in rats. Pediatr Res. 2001; 49, 460-467.

167. Boubred F, Delamaire E, Buffat C, et al. High protein intake in neonatal period induces glomerular hypertrophy and sclerosis in adulthood in rats born with IUGR. Pediatr Res. 2016; 79, 22-26.

168. Boubred F, Buffat C, Feuerstein JM, et al. Effects of early postnatal hypernutrition on nephron number and long-term renal function and structure in rats. Am J Physiol Renal Physiol. 2007; 293, F1944-1949.

169. Boubred F, Daniel L, Buffat C, et al. Early postnatal overfeeding induces early chronic renal dysfunction in adult male rats. Am J Physiol Renal Physiol. 2009; 297, F943-951.

170. Anderson S, King AJ, Brenner BM. Hyperlipidemia and glomerular sclerosis: an alternative viewpoint. Am J Med. 1989; 87, 34N-38N.

171. Ikeda Y, Tajima S, Izawa-Ishizawa Y, et al. Bovine milk-derived lactoferrin exerts proangiogenic effects in an Src-Akt-eNOS-dependent manner in response to ischemia. J Cardiovasc Pharmacol. 2013; 61, 423-429.

172. Safaeian L, Javanmard SH, Mollanoori Y, Dana N. Cytoprotective and antioxidant effects of human lactoferrin against $\mathrm{H} 2 \mathrm{O} 2$-induced oxidative stress in human umbilical vein endothelial cells. Adv Biomed Res. 2015; 4, 188.

173. Verhaar MC, Stroes E, Rabelink TJ. Folates and cardiovascular disease. Arterioscler Thromb Vasc Biol. 2002; 22, 6-13.

174. Robinson K, Arheart K, Refsum H, et al. Low circulating folate and vitamin B6 concentrations: risk factors for stroke, peripheral vascular disease, and coronary artery disease. European COMAC Group. Circulation. 1998; 97, 437-443. 
175. Antoniades C, Shirodaria C, Warrick N, et al. 5-methyltetrahydrofolate rapidly improves endothelial function and decreases superoxide production in human vessels: effects on vascular tetrahydrobiopterin availability and endothelial nitric oxide synthase coupling. Circulation. 2006; 114, 1193-1201.

176. Xia XS, Li X, Wang L, et al. Supplementation of folic acid and vitamin $B(1)(2)$ reduces plasma levels of asymmetric dimethylarginine in patients with acute ischemic stroke. J Clin Neurosci. 2014; 21, 1586-1590.

177. Wu CJ, Wang L, Li X, et al. [Impact of adding folic acid, vitamin B(12) and probucol to standard antihypertensive medication on plasma homocysteine and asymmetric dimethylarginine levels of essential hypertension patients]. Zhonghua Xin Xue Guan Bing Za Zhi. 2012; 40, 1003-1008.

178. Li JM, Qu PF, Dang SN, et al. [Effect of folic acid supplementation in childbearing aged women during pregnancy on neonate birth weight in Shaanxi province]. Zhonghua Liu Xing Bing Xue Za Zhi. 2016; 37, 1017-1020.

179. Alessio AC, Santos CX, Debbas V, et al. Evaluation of mild hyperhomocysteinemia during the development of atherosclerosis in apolipoprotein E-deficient and normal mice. Exp Mol Pathol. 2011; 90, 45-50.

180. Torrens C, Brawley L, Anthony FW, et al. Folate supplementation during pregnancy improves offspring cardiovascular dysfunction induced by protein restriction. Hypertension. 2006; 47, 982-987.

181. Stroes ES, van Faassen EE, Yo M, et al. Folic acid reverts dysfunction of endothelial nitric oxide synthase. Circ Res. 2000; 86, 1129-1134.

182. Zingg JM, Azzi A. Non-antioxidant activities of vitamin E. Curr Med Chem. 2004; 11, 1113-1133. 
183. Wu D, Liu L, Meydani M, Meydani SN. Vitamin E increases production of vasodilator prostanoids in human aortic endothelial cells through opposing effects on cyclooxygenase-2 and phospholipase A2. J Nutr. 2005; 135, 1847-1853.

184. Tran K, Chan AC. R,R,R-alpha-tocopherol potentiates prostacyclin release in human endothelial cells. Evidence for structural specificity of the tocopherol molecule. Biochim Biophys Acta. 1990; 1043, 189-197.

185. Memon S, Pratten MK. Developmental toxicity of ethanol in chick heart in ovo and in micromass culture can be prevented by addition of vitamin $\mathrm{C}$ and folic acid. Reprod Toxicol. 2009; 28, 262-269.

186. Hovdenak N, Haram K. Influence of mineral and vitamin supplements on pregnancy outcome. Eur J Obstet Gynecol Reprod Biol. 2012; 164, 127-132.

187. Sesso HD, Buring JE, Christen WG, et al. Vitamins E and C in the prevention of cardiovascular disease in men: the Physicians' Health Study II randomized controlled trial. JAMA. 2008; 300, 2123-2133.

188. Rumbold A, Ota E, Nagata C, Shahrook S, Crowther CA. Vitamin C supplementation in pregnancy. Cochrane Database Syst Rev. 2015, CD004072.

189. Rumbold AR, Crowther CA, Haslam RR, et al. Vitamins C and E and the risks of preeclampsia and perinatal complications. N Engl J Med. 2006; 354, 1796-1806.

190. Care AS, Sung MM, Panahi S, et al. Perinatal resveratrol supplementation to spontaneously hypertensive rat dams mitigates the development of hypertension in adult offspring. Hypertension. 2016; 67, 1038-1044.

191. Vaziri ND, Ding Y, Ni Z, Gonick HC. Altered nitric oxide metabolism and increased oxygen free radical activity in lead-induced hypertension: effect of lazaroid therapy. Kidney Int. 1997; 52, 1042-1046. 
192. Vaziri ND, Ni Z, Oveisi F, Trnavsky-Hobbs DL. Effect of antioxidant therapy on blood pressure and NO synthase expression in hypertensive rats. Hypertension. 2000; $36,957-964$.

193. Herrera EA, Cifuentes-Zuniga F, Figueroa E, et al. N-Acetylcysteine, a glutathione precursor, reverts vascular dysfunction and endothelial epigenetic programming in intrauterine growth restricted guinea pigs. J Physiol. 2016.

194. Hardeland R, Cardinali DP, Srinivasan V, et al. Melatonin--a pleiotropic, orchestrating regulator molecule. Prog Neurobiol. 2011; 93, 350-384.

195. Reiter RJ, Tan DX, Terron MP, Flores LJ, Czarnocki Z. Melatonin and its metabolites: new findings regarding their production and their radical scavenging actions. Acta Biochim Pol. 2007; 54, 1-9.

196. Franco Mdo C, Akamine EH, Aparecida de Oliveira M, et al. Vitamins C and E improve endothelial dysfunction in intrauterine-undernourished rats by decreasing vascular superoxide anion concentration. J Cardiovasc Pharmacol. 2003; 42, 211-217.

197. Galano A, Tan DX, Reiter RJ. On the free radical scavenging activities of melatonin's metabolites, AFMK and AMK. J Pineal Res. 2013; 54, 245-257.

198. Lopez A, Garcia JA, Escames G, et al. Melatonin protects the mitochondria from oxidative damage reducing oxygen consumption, membrane potential, and superoxide anion production. J Pineal Res. 2009; 46, 188-198.

199. Herrera EA, Macchiavello R, Montt C, et al. Melatonin improves cerebrovascular function and decreases oxidative stress in chronically hypoxic lambs. J Pineal Res. $2014 ; 57,33-42$.

200. Weekley LB. Effects of melatonin on isolated pulmonary artery and vein: role of the vascular endothelium. Pulm Pharmacol. 1993; 6, 149-154. 
201. Girouard H, Chulak C, Lejossec M, Lamontagne D, de Champlain J. Vasorelaxant effects of the chronic treatment with melatonin on mesenteric artery and aorta of spontaneously hypertensive rats. J Hypertens. 2001; 19, 1369-1377.

202. Das R, Balonan L, Ballard HJ, Ho S. Chronic hypoxia inhibits the antihypertensive effect of melatonin on pulmonary artery. Int J Cardiol. 2008; 126, 340-345.

203. Curis E, Nicolis I, Moinard C, et al. Almost all about citrulline in mammals. Amino Acids. 2005; 29, 177-205.

204. Romero MJ, Platt DH, Caldwell RB, Caldwell RW. Therapeutic use of citrulline in cardiovascular disease. Cardiovasc Drug Rev. 2006; 24, 275-290.

205. Chien SJ, Lin KM, Kuo HC, et al. Two different approaches to restore renal nitric oxide and prevent hypertension in young spontaneously hypertensive rats: 1-citrulline and nitrate. Transl Res. 2014; 163, 43-52.

206. Figueroa A, Trivino JA, Sanchez-Gonzalez MA, Vicil F. Oral L-citrulline supplementation attenuates blood pressure response to cold pressor test in young men. Am J Hypertens. 2010; 23, 12-16.

207. Xuan C, Lun LM, Zhao JX, et al. L-citrulline for protection of endothelial function from ADMA-induced injury in porcine coronary artery. Sci Rep. 2015; 5, 10987.

208. Chen J, Gong X, Chen P, Luo K, Zhang X. Effect of L-arginine and sildenafil citrate on intrauterine growth restriction fetuses: a meta-analysis. BMC Pregnancy Childbirth. 2016; 16, 225.

209. Gui S, Jia J, Niu X, et al. Arginine supplementation for improving maternal and neonatal outcomes in hypertensive disorder of pregnancy: a systematic review. $J$ Renin Angiotensin Aldosterone Syst. 2014; 15, 88-96.

210. Vadillo-Ortega F, Perichart-Perera O, Espino S, et al. Effect of supplementation during pregnancy with L-arginine and antioxidant vitamins in medical food on pre- 
eclampsia in high risk population: randomised controlled trial. BMJ. 2011; 342, d2901.

211. Wu G, Bazer FW, Cudd TA, et al. Pharmacokinetics and safety of arginine supplementation in animals. $J$ Nutr. 2007; 137, 1673S-1680S.

212. Dastjerdi MV, Hosseini S, Bayani L. Sildenafil citrate and uteroplacental perfusion in fetal growth restriction. J Res Med Sci. 2012; 17, 632-636.

213. Wareing M, Myers JE, O'Hara M, Baker PN. Sildenafil citrate (Viagra) enhances vasodilatation in fetal growth restriction. J Clin Endocrinol Metab. 2005; 90, 25502555.

214. Lassala A, Bazer FW, Cudd TA, et al. Parenteral administration of L-arginine prevents fetal growth restriction in undernourished ewes. $J$ Nutr. 2010; 140, 1242-1248.

215. Herraiz S, Pellicer B, Serra V, et al. Sildenafil citrate improves perinatal outcome in fetuses from pre-eclamptic rats. BJOG. 2012; 119, 1394-1402.

216. Refuerzo JS, Sokol RJ, Aranda JV, et al. Sildenafil citrate and fetal outcome in pregnant rats. Fetal Diagn Ther. 2006; 21, 259-263.

217. Cutfield WS, Hofman PL, Mitchell M, Morison IM. Could epigenetics play a role in the developmental origins of health and disease? Pediatr Res. 2007; 61, 68R-75R.

218. Chen M, Zhang L. Epigenetic mechanisms in developmental programming of adult disease. Drug Discov Today. 2011; 16, 1007-1018.

219. McKay JA, Mathers JC. Diet induced epigenetic changes and their implications for health. Acta Physiol (Oxf). 2011; 202, 103-118.

220. Kangaspeska S, Stride B, Metivier R, et al. Transient cyclical methylation of promoter DNA. Nature. 2008; 452, 112-115.

221. Lorenzen JM, Martino F, Thum T. Epigenetic modifications in cardiovascular disease. Basic Res Cardiol. 2012; 107, 245. 
222. Ito S, D'Alessio AC, Taranova OV, et al. Role of Tet proteins in $5 \mathrm{mC}$ to $5 \mathrm{hmC}$ conversion, ES-cell self-renewal and inner cell mass specification. Nature. 2010; 466, 1129-1133.

223. Kriaucionis S, Heintz N. The nuclear DNA base 5-hydroxymethylcytosine is present in Purkinje neurons and the brain. Science. 2009; 324, 929-930.

224. Postberg J, Kanders M, Forcob S, et al. CpG signalling, H2A.Z/H3 acetylation and microRNA-mediated deferred self-attenuation orchestrate foetal NOS3 expression. Clin Epigenetics. 2015; 7, 9.

225. Canani RB, Costanzo MD, Leone L, et al. Epigenetic mechanisms elicited by nutrition in early life. Nutr Res Rev. 2011; 24, 198-205.

226. Xu XF, Xu SS, Fu LC, et al. Epigenetic changes in peripheral leucocytes as biomarkers in intrauterine growth retardation rat. Biomed Rep. 2016; 5, 548-552.

227. Shruti K, Shrey K, Vibha R. Micro RNAs: tiny sequences with enormous potential. Biochem Biophys Res Commun. 2011; 407, 445-449.

228. Sayed D, Abdellatif M. MicroRNAs in development and disease. Physiol Rev. 2011; $91,827-887$.

229. Weber M, Baker MB, Moore JP, Searles CD. MiR-21 is induced in endothelial cells by shear stress and modulates apoptosis and eNOS activity. Biochem Biophys Res Commun. 2010; 393, 643-648.

230. Fleissner F, Jazbutyte V, Fiedler J, et al. Short communication: asymmetric dimethylarginine impairs angiogenic progenitor cell function in patients with coronary artery disease through a microRNA-21-dependent mechanism. Circ Res. 2010; 107, 138-143. 
231. Liu X, Cheng Y, Yang J, Xu L, Zhang C. Cell-specific effects of miR-221/222 in vessels: molecular mechanism and therapeutic application. J Mol Cell Cardiol. 2012;

$52,245-255$.

232. Suarez Y, Fernandez-Hernando C, Pober JS, Sessa WC. Dicer dependent microRNAs regulate gene expression and functions in human endothelial cells. Circ Res. 2007; $100,1164-1173$.

233. Xu Q, Seeger FH, Castillo J, et al. Micro-RNA-34a contributes to the impaired function of bone marrow-derived mononuclear cells from patients with cardiovascular disease. J Am Coll Cardiol. 2012; 59, 2107-2117. 